NASA-CR-169924 NAS

\title{
$1.26: 169924$
}

19830010954

DOE/JPL-1060-56

(DE83005140)

\section{A SURVEY OF MANUFACTURERS OF SOLAR THERMAL ENERGY SYSTEMS}

By

Ned Levine

Marie Slonski

August 1982

Work Performed Under Contract No. Al01-76ET20307

Jet Propulsion Laboratory

California Institute of Technology

Pasadena, California

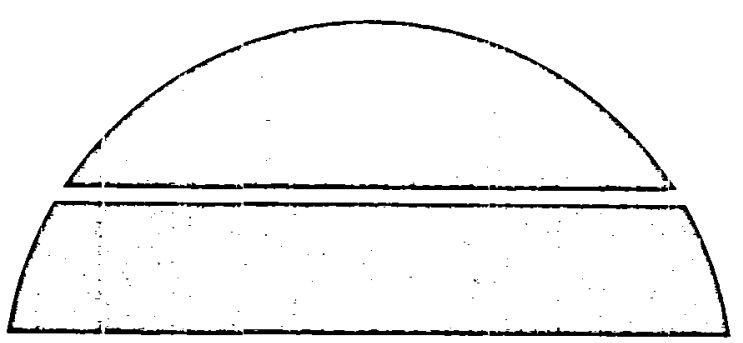

\section{LERAR GOPY}

TEB 24 ค 183

LANGGLEY RESEARCH CENTER LIERARY, NASA

HAMIPTON VIRGINIA

\section{$\because$}
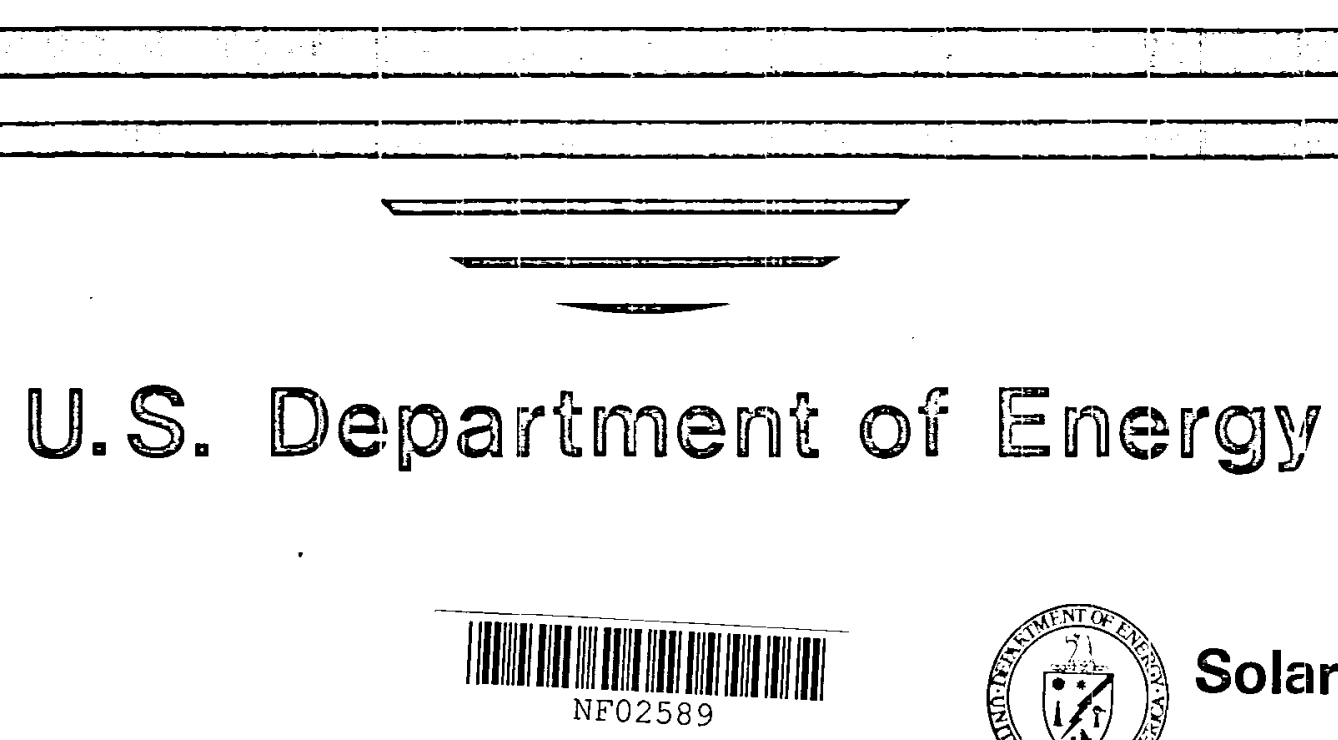


\title{
DISCLAIMER
}

\begin{abstract}
"This report was prepared as an account of work sponsored by an agency of the United States Government. Neither the United States Government nor any agency thereof, nor any of their employees, makes any warranty, express or implied, or assumes any legal liability or responsibility for the accuracy, completeness, or usefulness of any information, apparatus, product, or proces: disclosed, or represents that its use would not infringe private."y owned rights. Reference herein to any specific commercial product, process, or service by trade name, trademark, manufacturer, or otherwise, does not necessarily constitute or imply its endorsement, recommendation, or favoring by the United States Government or any agency thereof. The views and opinions of authors expressed herein do not necessarily state or reflect those of the United States Government or any agency thereof."
\end{abstract}

This report has been reproduced directly from the best available copy.

Available from the National 'Technical Information Service, U. S. Department of Commerce, Springfield, Virginia 22161.

Price: Printed Copy A06

Microfiche A01

Codes are used for pricing all publications. The code is determined by the number of pages in the publication. Information pertaining to the pricing codes can be found in the current is sues of the following publications, which are gerierally available in most libraries: Energy Research Abstracts. (ERA); Government Reports Announcements and Index (GRA and I); Scientific and Technical Abstract Reports (STAR); and publication, NTIS.PR-360 available from (NTIS) at the above address. 

DISPLAY $19 / 2 / 1$

8W19223\% ISSUE 9 PAGE 1384 CATEGOE 44 RPT: WASA-CR-169924 JPL-PUE-82-94 JPL-5106-25, DOE/JFL-1060-56 HAS 1.26:169924 82/08/00 100 PAGES DUCLASSIFIED DOOUHENT

UTIL: A survey of manufacturers of solar thermal energy systems

AUTH: ALEVINE, M. B GLUSK, M.

CORP: Jet Propulsion Lab. califomia Inst, of Tech. Pasadena. AVIL, WIIS SAP: HC A05/MF AOI Sponsored by MASA and DOE

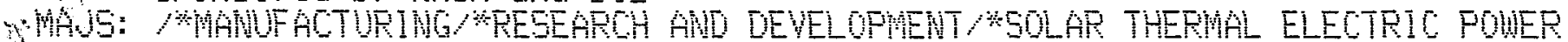
n. ?

ABA:

$\mathrm{ABS}:$ PLAITS GOEEWENTS MARETING RISK

S.L.

Gixty-seven firms that had recelved funding for development of solar thermal energy systens (STES) mere surveved. The effect of the solar thermal technology systems program in acolerating (STES) were assessed. The 54 firms still developing STES were grouped into a production typology comparing the three maior techologies with three besic functions. It ubs discovered thet large and smali firms were developing primarily central recelver systems, but also typlcally morked on more than one technology, host medum-sized firms morked only on distributed systems. Federal support of STES was percelved as necessary to allom producers to take ENTER: otheruise unacceptabie risks. Approximately half of the respondents would 


\section{A Survey of Manufacturers of Solar Thermal Energy Systems}

Ned Levine

Marie Slonski

August 1982

\section{Prepared for}

U.S. Department of Energy

through an Agreement with

National Aeronautics and Space Administration

by

Jet Propulsion Laboratory

California Institute of Technology

Pasadena, California

(JPL PUBLICATION 82.94) 
Intentionally Left Blank 
Sixty-seven firms that had received Department of Energy (DOE) funding for development of solar thermal energy systems (STES) were surveyed by telephone in 1981. The primary goal of the survey was to assess the effect of the DOE Solar Thermal Technology Systems program in accelerating STES development.

The 54 firms still developing STES were grouped into a production typology comparing the three major technologies with three basic functions. It was discovered that large and small firms were developing primarily central receiver systems, but also typically worked on more than one technology. Most medium-sized firms worked only on distributed systems.

Federal support of STES was perceived as necessary to allow producers to take otherwise unacceptable risks. Approximately half of the respondents would drop out of STES if DOE support were terminated, including a disproportionate number of medium-sized firms. A differentiated view of the technology - taking into account differing firm sizes and the various stages of technology development - was suggested for policy and planning purposes. 


\section{ACKNOWLEDGEMENTS}

The authors would like to acknowledge the support of many individuals who helped with this project: Mr. E. S. (Ab) Davis, the director of the Solar Thermal Planning and Information Project; Robert Easter and Reed Wilcox who provided support and encouragement throughout; and the staff of interviewers, in particular Valerie Gray, Ellen Holden, Merrilee Fellows, David Lamm, Tim Tutt, Rose Marie Dishman, and Cal Davis. 
CONTENTS

PAGE

EXECUTIVE SUMMARY $\ldots \ldots \ldots \ldots \ldots \ldots \ldots \ldots \ldots \ldots \ldots \ldots \ldots \ldots \ldots$

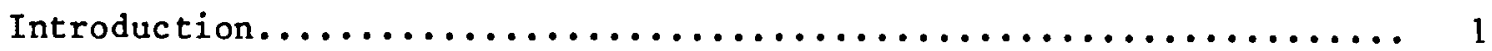

Distribution.....................................

Technologies .......................................

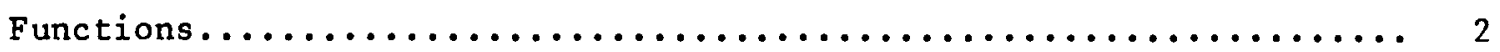

Production Types...................................

Marketing Time Horizon...............................

Size of the firm................................... 4

Current Marketing...................................

Uncertainties in Making STES Competitive.................... 5

Future Marketing Plans...............................

Commitment to STES if STTS Program Discontinued...............6

Types of Federal support Needed..........................6

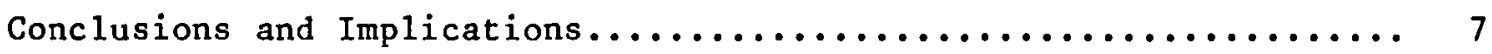

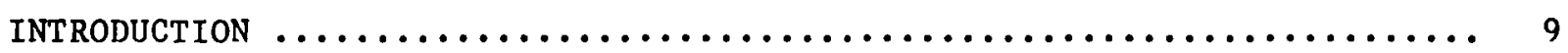

Department of Energy Solar Thermal Technology

systems Program .....................................99

Goals of the survey.................................. 10

METHODOLOGY ........................................... 13

Sampling Frame..................................... 13

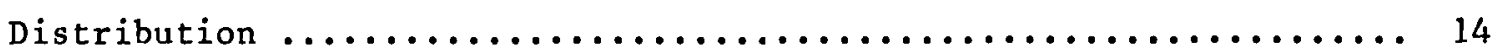

Questionnaire Development ............................... 14

Data Collection, Processing and Analysis .................. 16

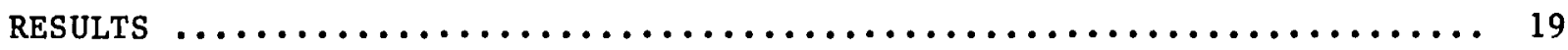

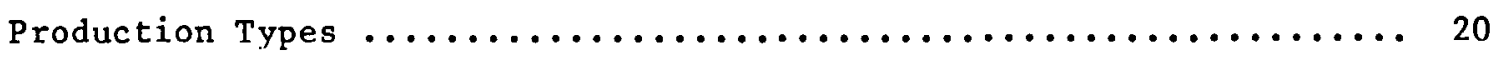


Technologies.................................... 20

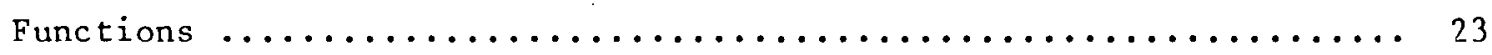

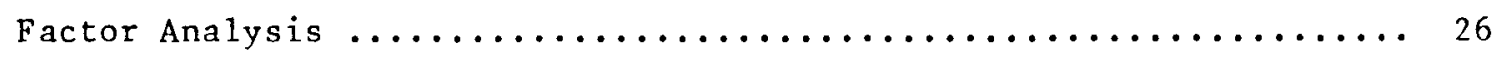

Independence of Techniques and Functions $\ldots \ldots \ldots \ldots \ldots \ldots \ldots \ldots$

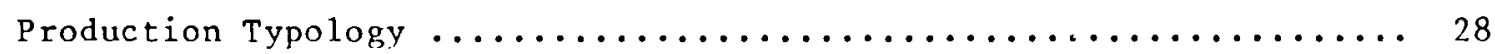

Time Horizon for the Different Technologies $\ldots \ldots \ldots \ldots \ldots \ldots \ldots \ldots$

Characteristics of Organizations $\ldots \ldots \ldots \ldots \ldots \ldots \ldots \ldots \ldots \ldots \ldots \ldots$

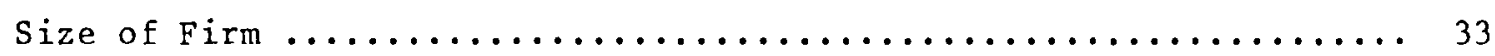

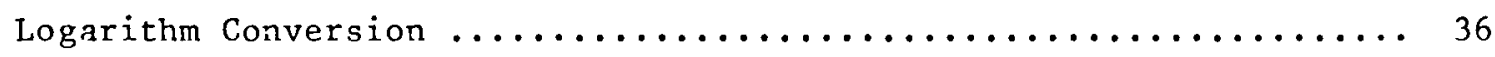

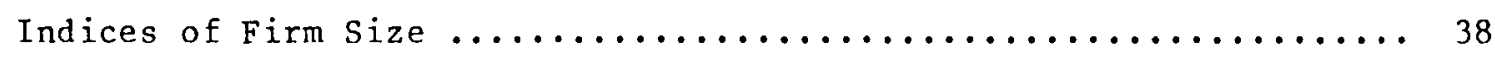

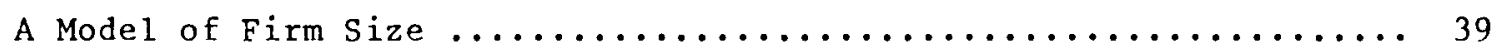

Firm Size and Production Type........................ 41

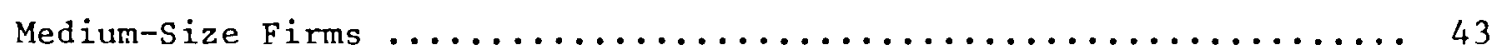

Organizational Predictors of Production Types $\ldots \ldots \ldots \ldots \ldots \ldots \ldots .44$

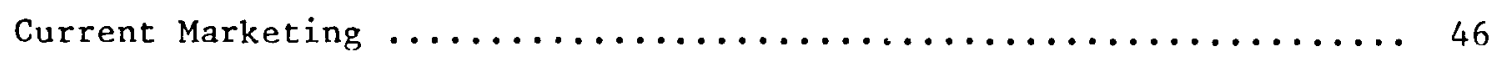

Uncertainties in Making STES Competitive $\ldots \ldots \ldots \ldots \ldots \ldots \ldots \ldots$

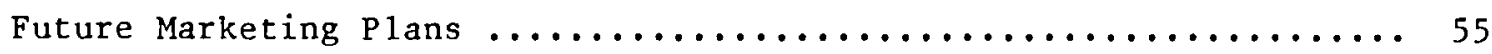

Commitment to STES if STTS Program Discontinued $\ldots \ldots \ldots \ldots \ldots \ldots . \ldots 7$

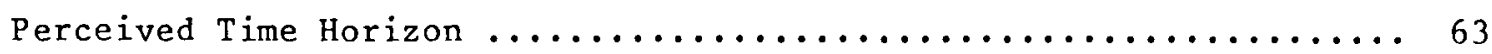

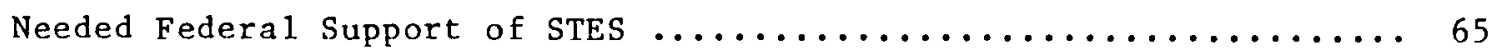

Perceptions of the Department of Energy $\ldots \ldots \ldots \ldots \ldots \ldots \ldots \ldots \ldots .68$

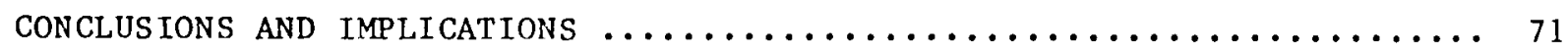

Differentiated Policy Approach....................... 71

Federal support Need............................ 72

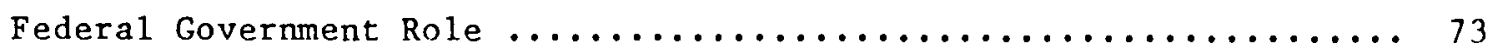

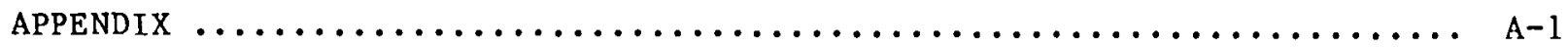


A. Production Typology................................. 3

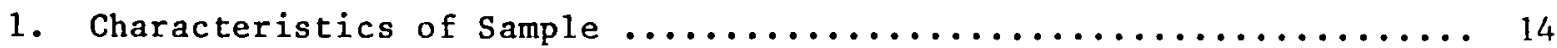

2. Geographical Distribution of Firms That Received DOE Funding for

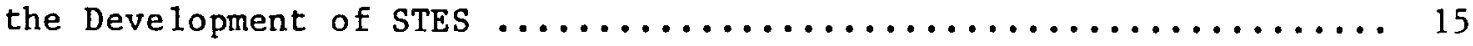

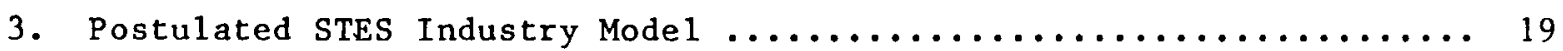

4. Distribution of Internal Funds as a Percent of Total STES Funds .... 35

5. Rank-Size Distribution of All Firms by DOE and Internal Funds .... 37

6. Schematic Model of Firm Size - $\log _{10}$ Transformation ........... 40

7. Organizational Predictors of Production Typologies ........... 45

8. Predictors of Current Marketing $\ldots \ldots \ldots \ldots \ldots \ldots \ldots \ldots \ldots \ldots \ldots$

9. Multiple Regression Predictors of Two Uncertainties ........... 54

10. Determinants of Future Marketing Plans $\ldots \ldots \ldots \ldots \ldots \ldots \ldots \ldots \ldots$

11. Rank-Size Distribution of Al1 Firms by STES R\&D Budget for Those That Will Continue If STTS Program is Discontinued ........ 59

12. Rank-Size Distribution of Central Receiver Firms by Total STES R\&D Budget for Those That Will Continue if STTS Program

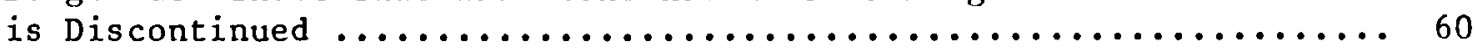

13. Rank-Size Distribution of Trough Firms by Total STES R\&D Budget for Those That Will Continue if STTS Program is Discontinued ........ 61

14. Rank-Size Distribution of Dish Firms by Total STES Budget for Those That Will Continue If STTS Program is Discontinued............ 62

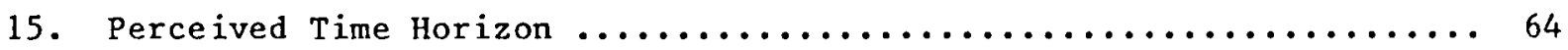

16. Predictors of Overall Federal Support Need................. 67 
1. Distribution of STES Technologies $\ldots \ldots \ldots \ldots \ldots \ldots \ldots \ldots \ldots \ldots \ldots \ldots$. 21

2. Number of Different Solar Thermal Technologies

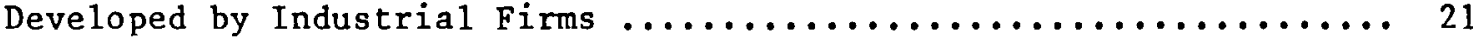

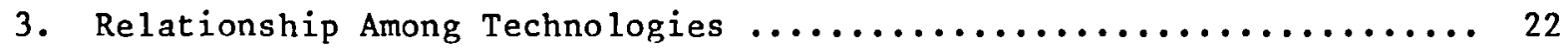

4. Distribution of Production Functions $\ldots \ldots \ldots \ldots \ldots \ldots \ldots \ldots \ldots \ldots \ldots$

5. Number of Production Functions Firms Are Providing ............ 25

6. Relationship Among Functions ........................ 25

7. Factor Analysis of Technologies and Functions $\ldots \ldots \ldots \ldots \ldots \ldots \ldots$.

8. Production Typology .................................. 29

9. Distribution of Firms in Production Typology ................ 30

10. Time Horizon for Different Production Typologies ............. 32

11. Measures of Firm Size: "Gravity" Effects .................. 34

12. "Corrected" Indices of Firm Size in $\log _{10}$ Form ............. 38

13. Relationship of Specific Variables and General Indices of Firm Size - "Corrected" $\log _{10}$ Form...................... 39

14. Size of Firm by Production Typology $\ldots \ldots \ldots \ldots \ldots \ldots \ldots \ldots \ldots \ldots \ldots \ldots$

15. Average Percentage of Firms' Internal Funding for Different Size Firms ............................... 43

16. Marketing Time Horizon by Size of Firm .................. 44

17. Distribution of Firms That Are Currently Marketing ............ 46

18. Percent of Firms Currently Marketing by Typology ............ 47

19. Consequences of Current Marketing ..................... 50

20. Perceived STES Uncertainties and Their Correlations ........... 51

21. Percent of Firms That Perceived R\&D Solutions as Uncertainty ...... 53

22. Percent of Firms That Perceived Competing Energy as Uncertainty .... 53

23. Distribution of Firms That Are Planning to Market in the Future ... 55

24. Correlations Among Future Marketing Functions Firms Will Provide ... 56

25. Distribution of Firms That Would Continue Same Technology If STES Program Discontinued .......................... 57

26. Percent of Firms That Will Continue STES Development If DOE STES Program Discontinued ........................... 58

27. Types of Federal R\&D Support Needed $\ldots \ldots \ldots \ldots \ldots \ldots \ldots \ldots \ldots \ldots \ldots$

28. Types of "Other" Federal Support Needed $\ldots \ldots \ldots \ldots \ldots \ldots \ldots \ldots \ldots \ldots 66$

29. Policy Priorities for Different Production Typologies .......... 67

30. Perceptions of DOE STTS Program $\ldots \ldots \ldots \ldots \ldots \ldots \ldots \ldots \ldots \ldots \ldots \ldots . \ldots 68$ 
EXECUTIVE SUMMARY

\section{$\underline{\text { Introduction }}$}

A survey of 67 firms that had received U.S. Department of Energy funding for the development of solar thermal energy systems (STES) was conducted in the summer of 1981. Solar thermal technologies concentrate sunlight to produce either electricity or medium-temperature heat for industrial or agricultural processes. The purpose of the survey was to assess the effect of the Department of Energy (DOE) Solar Thermal Technology Systems (STTS) program in accelerating development of solar thermal energy systems. Because of requirements of the "Sunset Review" conducted by The Department of Energy in 1981, the survey was expanded to assess the response of the industry to possible discontinuation of the program.

\section{Distribution}

of the 67 firms contacted, 54 were still involved in the development of solar thermal energy systems, while 13 were no longer developing these technologies. The geographical distribution of the manufacturers tended to concentrate in California, Colorado, the northeast corridor, and around the Washington, D.C. area, with pockets in Texas and the midwest. The firms represented a number of advanced technology sectors, with aerospace and electronics predominating.

\section{Technologies}

Most firms were developing more than one technology, with more firms working on central receivers and parabolic dishes than on the other technologies. There was also a significant overlap between parabolic trough and parabolic dish manufacturers, with $80 \%$ of the trough manufacturers working on dishes and $60 \%$ of the dish manufacturers working on troughs. Unfortunately, that overlap caused the responses regarding the two technologies to be virtually indistinguishable in the analysis. Consequently, the responses were grouped together under the heading "distributed systems" throughout most of this report. A significant number of central receiver manufacturers were also developing the dish technology, which suggests that manufacturers were expanding their efforts into new technologies (e.g., the parabolic dish) because central receivers and troughs were the earliest 
technologies to start development. This seems especially apparent because neither the central receiver manufacturers nor trough manufacturers tended to be working on the other technology.

\section{Functions}

Most firms were providing research and development (R\&D) to the government. Also, most firms were providing architectural and engineering (A\&E) services. About half of the firms were manufacturing subsystems or components, while only about one-quarter were producing entire "turnkey" systems. The heavy concentration of $R \& D$ to the government is a result of government sponsorship of STES research, of course. The extent of A\&E services suggests that most projects require extensive design and construction. As one would expect, there were also more component and subsystems manufacturers than "turnkey" system suppliers.

\section{Production Types}

In general, there was little relationship between the technologies that manufacturers were developing and the type of function they adopted. Thus, a specific technology cannot be treated as a single "entity" in the analysis. Rather, each technology is at a different stage of development. To illustrate this, firms are grouped into a production typology (see Figure A) that compares the technologies with the functions. For each of the three major technologies--distributed systems (dishes, troughs), bowls, and central receivers--there are three functions: "turnkey" systems, engineering, subsystems and compcnents, and "pure" R\&D, yielding nine different possibilities (Type 1 through Type 9).

Because some firms were working on more than one technology or function, they are grouped into more than one category; however, the amount of double categorization is small. When the firms were classified according to the production typologies, it was found that three types were most predominant. The most common type is engineering, subsystems and components for central receivers (Type 8 ), where 24 firms were included in this production type; second is engineering, subsystems and components for distributed systems (Type 2), with 19 firms; and third is "turnkey" systems for distributed systems (Type 1), with 11 firms. A small number of firms are "pure" R\&D firms, either for distributed systems or central receivers (Types 3 and 9 , respectively), 
T E C H N O L O

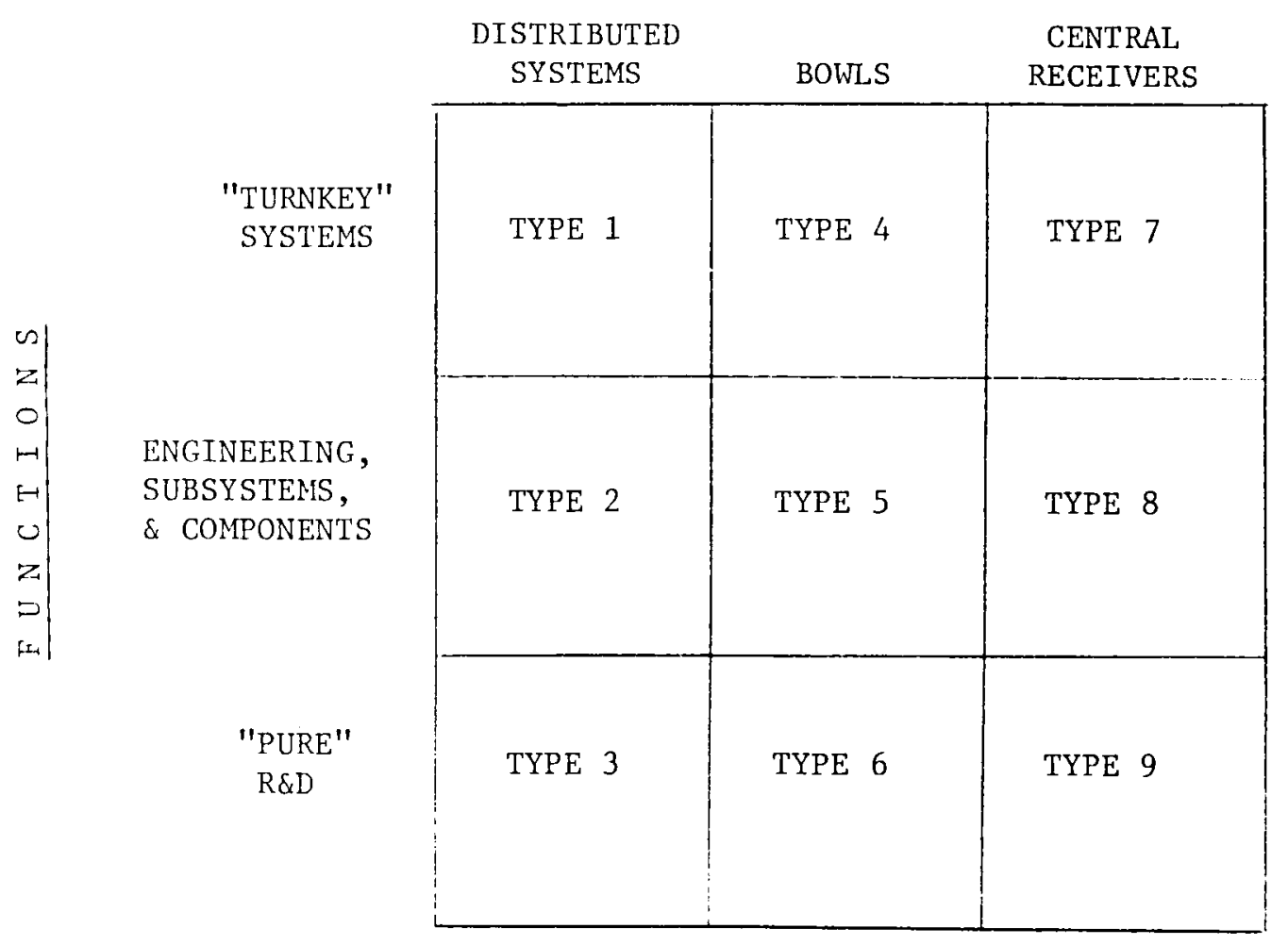

while only a few are spread among the other four categories (Types 4, 5, 6, and 7).

\section{Marketing Time Horizon}

There are differences in the marketing time horizon associated with each of the production types. Firms were asked to estimate how many years it would be until they could market their first STES product without government subsidy. Type 1 firms--"turnkey" distributed systems--were nearest to marketing, with most firms already marketing. On the other hand, Type 3 firms--"pure" R\&D on distributed systems--were farthest from marketing. Thus, within distributed systems, there are products that were being marketed or 
were very close to being marketed, and products that were farthest from marketing. The difference seems to be that the near-term technologies comprise the trough and the low-temperature dish, whereas the long-term technology is the high-temperature dish, which is in the R\&D stage. Across all the technologies, companies offering "turnkey" systems were closest to marketing. Engineering, subsystems and components manufacturers were closer to marketing than those firms that were only performing research and development.

\section{Size of the Firm}

The size of the firm is an important factor for production decisions. The size of the firms in the sample included several very large firms, some mediumsize firms, and some small and very small firms. Generally, the larger firms had more research assets, hired more staff, developed more projects, approached larger-scale projects, attracted more Department of Energy funding, put more capital into STES, and planned to sell more than small firms. Production decisions are also related to the size of the firm. The survey sample was roughly divided into three groups based on the total amount of STES funding (both DOE funding and internal funding). The large firms tended to work on central receiver technologies (Types 7-9) and distributed system technologies (Types 1-3) to an equal degree. The small firms tended to work primarily on central receiver technologies (Types 7-9) and, to a lesser extent, on distributed system technologies (Types 1-3). The medium-size firms, on the other hand, worked almost exclusively on distributed systems (Types 1-3). This dichotomy suggests that there is a manufacturers' "division of labor" operating for STES development that could be described as follows: The large-scale nature of central receiver projects attracts large firms that have the resources required for the technology; these firms, in turn, sub-contract with small firms. Medium-size firms, on the other hand, have sufficient resources to develop distributed systems, since the capital outlay is not as extensive. "Pure" R\&D appears to be the purview of small firms, suggesting that the longest-term research is carried out by small firms, rather than by medium or large firms. 
Overal1, $52 \%$ of the firms were currently marketing STES products. However, there are large differences among the different production types. Almost three-fourths of the Type 1 firms--"turnkey" distributed systems, were currently marketing, whereas none of the "pure" R\&D firms (for all three technologies) were currently marketing. For distributed systems and central receivers, the "turnkey" producers were more likely to be currently marketing than those producing engineering, subsystems and components; the latter, however, were more likely to be currently marketing than "pure" research types. In addition, firms that were developing STES prior to their first contract with the Department of Energy were more likely to be currently marketing; because these firms were in the field earlier, they were generally closer to marketing.

\section{Uncertainties in Making STES Competitive}

Each firm contacted was asked to specify the major uncertainties affecting the development of STES. The "general economy" was perceived to be more of an uncertainty, followed closely by the "cost of competing energy sources." On the other hand, less than half of the firms perceived "solutions to R\&D problems" to be an uncertainty. For many of the manufacturers, especially those producing "turnkey" systems or engineering, subsystems and components, the research problems have been solved. For firms working on long-term developments, on the other hand, research solutions were still a problem. However, there are only slight differences among the different production types.

\section{Future Marketing Plans}

The majority of firms surveyed had future marketing plans. When asked what types of products would be produced, the most frequent responses were items related to distributed system products: troughs, dishes, industrial process heat systems, and collectors. A few firms mentioned central receivers, but most of the responses indicated a variety of components and subsystems that could be used for all the technologies: control systems, gas turbines, Rankine engines, positioning systems, Brayton power systems, power conditioners, and thermal storage. The best near-term markets from the firms' point of view were industrial process heat and electric utilities, followed by 
government and remote applications. The best long-term markets were very similar to these.

\section{Commitment to STES if STTS Program Discontinued}

When asked whether the firms would continue STES development if the Department of Energy STTS program was discontinued next year, 53\% said yes. "Pure" K\&D firms were more likely to drop out than "turnkey" systems and engineering, subsystems and components firms. But even for the most committed of the production types, "turnkey" distributed systems (Type 1), $45 \%$ of the firms indicated they would drop out. The development of STES technology is still very dependent on Department of Energy funding, both for component and research development, as we 11 as for demonstration prototypes and testing facilities. Without government support, the STES technologies appear to be very vulnerable. In terms of which firms would continue or discontinue STES development if the government program was discontinued, a higher proportion of the medium-size firms would drop out than either the large or small firms. It appears that one of the unplanned consequences of discontinuing the STTS program would be a more skewed production distribution comprising a handful of large firms and many small firms, with only a few medium-size firms remaining.

\section{Types of Federal Support Needed}

When asked what type and priority of federal $R \& D$ support is needed, the highest priorities indicated were the testing of prototypes and the development of subsystems and components. Nearly as important were full-scale system tests, followed by conceptual designs; less than half the firms thought basic research on fundamental phenomena was required. In addition to R\&D support, a majority of firms indicated that investment tax credits and demonstration projects are needed. Only about half the firms favored deregulation, the most frequently mentioned form being the deregulation of natural gas. There did not seem to be a major difference of opinion among the different production types regarding the type of federal support needed. Almost all were agreed on the need for tax credits, prototypes, systems tests, and component developments. Even the firms closest to marketing--"turnkey" distributed systems, Type 1--were strong in their desire for federal support. It is apparent that these firms had actually taken greater risks in terms of 
investment commitment because of federal support. Thus, the federal government, rather than preventing them from risking their own resources, had actually provided a base upon which they could build.

\section{Conclusions and Implications}

Two conclusions have been reached as a result of the analysis. First, a more differentiated view of the technology is required for planning purposes. Because the size of the firm is important to the type of production planning decisions made, the Department of Energy should take the size differences into consideration when developing its plans. In particular, the Department of Energy has previously distinguished between large and small firms within the STTS program, but it appears that medium-size firms should have separate recognition as well. This is especially important because the medium-size firms appear to be wiliing to take on a greater proportion of investment risk. In addition, particular concern should be directed toward ascertaining the effect of a more skewed distribution if the STTS program is discontinued, because medium-size firms are more likely to drop out. Whether such a distribution will be harmful, beneficial, or neutral needs to be examined in detail. Further, each technology, as defined by the Department of Energy, is actually associated with several different stages of development, and planning and discussion should be cognizant of these differences. The typology developed represents one basis for developing a planning strategy.

Second, there is still a strong need for federal support of STES technology. Virtually all the firms perceived a need for continuing federal support, primarily because the technology is still in a vulnerable state. Even those firms closest tn marketing expressed a very strong desire for continued federal suppport, in particular for component development, system tests and demonstrations. It seems apparent that rather than provide a "cushion" designed to prevent producers from facing the economic realities of the market, federal support allows firms to take risks they would not otherwise take. Few of the firms interviewed made sharp distinctions between federal support and the marketplace; rather, the federal government was perceived as helping in the development of technology still vulnerable in the marketplace. 
Intentionally Left Blank 


\section{INTRODUCTION}

A survey of manufacturers of solar thermal energy systems (STES) and components was conducted in the summer of 1981. This report presents the results of that survey. Sixty-seven firms that have received Department of Energy (DOE) funding for the development of solar thermal energy systems were contacted in order to document the current status of technology development and future marketing plans, diagnose solar thermal manufacturers' needs for developing the technology further, evaluate the role of the federal government in accelerating the development of the technology, and assess the response to possible discontinuation of the program.

\section{Department of Energy Solar Thermal Technology Systems Program}

The Solar Thermal Technology Systems (STTS) Program is a major solar energy program established as a result of the Solar Energy Research, Development and Demonstration Act of 1974 (P.L. 93-473). The goal of the program is to accelerate the introduction and widespread use of solar energy to provide fuels, petrochemical substitutes, thermal and mechanical power, and electrical energy. ${ }^{1}$

Solar thermal conversion technologies comprise four concentrating technologies and solar ponds. The four concentrating technologies are central receivers, parabolic troughs, parabolic dishes, and hemispherical bowls. The concentrating systems all use reflective surfaces to focus or concentrate the sun's rays on a small area where the radiant energy is converted into either latent or sensible heat. The solar pond is a body of water capable of converting solar energy into sensible heat and then storing it for extended periods.

While each of the technologies has a variety of applications in different markets, there are unique major applications associated with each. Central receiver systems incorporate a central tower surrounded by hundreds of mirrors that track the sun (heliostats). The mirrors focus light on the tower where it heats a liquid or gas. Liquid or gas temperatures as high as $3000^{\circ} \mathrm{F}$ can

1 Multi-Year Program Plan; Solar Thermal Energy Systems Division, Office of Solar Applications for Industry, U.S. Department of Energy, Washington, DC, April 1, 1981. 
be generated, making this energy source ideal for large-scale electric utility applications. The parabolic trough, sometimes called a line-focus distributed receiver system, is a long "u"-shaped trough that reflects the sun's energy onto a long tube running parallel to the trough. Troughs are designed to stand alone or in small clusters and are ideal for producing medium temperature heat for such uses as industrial process heat. Parabolic dishes are large parabolic mirror systems that track the sun and then focus the energy onto a receiver located at the focal point of the mirror. Dishes are designed to stand alone and are appropriate for small load and for on-site electric applications. Hemispherical bowl systems are stationary bowls that are large enough for sunlight to continually reflect off the mirrored walls onto a receiver that tracks the changing focal point of the mirror. These systems are appropriate for small utility steam and electric applications. The fifth solar thermal technology, the solar pond, is not a concentrating system but a body of water that captures the sun's energy and stores it for later use. Heavy concentrations of salt are maintained at the bottom of the pond to prevent upward convection of heat. Solar ponds are appropriate for large and medium load electricity generation and for low-temperature applications.

The solar thermal program at the Department of Energy has grown considerably in recent years. In 1975, the entire program had a budget of $\$ 15.5$ million, while by 1980 this had grown to $\$ 143$ million. The program has made significant progress in the development of solar thermal technologies, has constructed a variety of facilities, and has succeeded in involving the private sector in the development of the technology. In 1982, however, the program underwent a major retrenchment, with the government requesting only $\$ 44$ million; $\$ 53$ million, including $\$ 16$ million deferred from 1981 , was subsequently appropriated. Program activities include completing construction of a 10-MWe central receiver facility at Barstow, California, field testing of industrial designs of parabolic dish systems, and developing design principles for large-scale solar pond applications. Both the parabolic trough and the hemispherical bowl programs are in the process of being phased out.

\section{Goals of the Survey}

The survey had three general goals. The first was to document the current status of solar thermal energy systems (STES) technology development. 
Factors of interest were which private-sector firms were involved with the technology, which of the five technologies were being developed, which firms were currently marketing, and which nearest-term and best far-term markets were perceived.

Second, the survey attempted to diagnose the perceived need for further technology development and the perceived importance of federal funding and support to private firms. Prior federal support cushioned many of the risks involved in technology development; now it was necessary to assess how much support was still needed and what particular form it should take.

A third goal, broader and more theoretical, was to achieve further insight into the effect of the federal government in the development of a new technology. The recent attention toward reducing the growth of the federal budget has raised a number of broad questions concerning the appropriate role for the federal government in both economic and social affairs. One purpose of this survey was to assess manufacturers' perceptions of that role, especially in relationship to the development of this new technology. The assumption was that manufacturers are balancing three different criteria in perceiving a role for the federal government: 1) the risk in developing a new technology, i.e. the cost and time required to bring the technology to fruition; 2) uncertainty concerning the future market for their products, especially in relationship to future costs of other energy sources; and 3 ) the fear of excessive federal regulation over the production process. The survey results provide insights into how private-sector manufacturers felt about federal government involvement. 
Intentionally Left Blank 


\section{METHODOLOGY}

Both a sampling frame and a fairly extensive questionnaire were developed. The survey was then conducted by telephone interview.

\section{Sampling Frame}

The population studied was private-sector firms that had received Department of Energy funding for STES development. The firms surveyed were involved on several levels: producing entire solar thermal systems ("turnkey" systems), producing subsystems or components, providing design and engineering services, or performing pure research and development.

It was intended to survey all firms that had received funds from the Department of Energy for the development of solar thermal energy systems (STES). Because there was no single list of all the firms, this population was synthesized and approximated from a variety of sources. The STTS Program Summary documents for 1978, 1979, and 1980 were reviewed; all firms that had received funding from the Department of Energy either directly, or indirectly through the national laboratories, were included in the sample. A list of firms that were currently under contract with the Department of Energy and a list of firms that possibly had been under contract were included also. These lists were combined to produce the initial sampling frame, a list of 93 firms.

A11 93 firms were contacted, and it was found that 67 had been under Department of Energy contract for the development of STES. The remaining 26 firms were eliminated for a variety of reasons: they were involved in STES but had not been under DOE contract at any time; they were 1 isted more than once, such as multiple divisions of a large company; they had been under DOE contract for STES development but were not manufacturers (e.g. utility companies); or they were not involved in STES and had not been under DOE contract. The $67 \mathrm{firms,}$ therefore, represents the best estimate of the population of private sector companies that had received DOE funding for the development of STES.

Further screening of the 67 firms revealed that 54 were currently involved in STES development, while 13 had discontinued their development efforts. Of the $67 \mathrm{firms,}$ only one refused to be interviewed. Figure 1 presents the breakdown of the sample. 
Figure 1. Characteristics of Sample.

FIRMS CONTACTED:

FIRMS IN SAMPLE:
93

67
$54(81 \%)$

Firms currently developing STES
$13(19 \%)$

Firms no longer

involved in STES

REFUSALS :

1

\section{Distribution}

The geographical distribution of the firms, presented in Figure 2, shows a concentration in several areas associated with other high-technology industries. Of the 67 firms contacled, 22 were in California, 15 of which were in southern California. A second cluster was around the Washington, D.C. area, and a sizeable number were distributed along the northeastern seaboard. The only other sizeable concentrations were in Colorado and Texas. There were few firms in the Midwest and in the South and the Southwest, where one would expect many firms to exist because of high solar insolation. The distribution suggests that an important factor affecting the distribution of firms involved in STES is the association with an advanced technology industrial infrastructure. Many of the firms, especially the larger ones, were involved in other high technologies, with aerospace and electronics firms being in the forefront. Solar thermal energy systems are not a "backyard" technology; they require a great deal of sophistication in terms of optical materials, heat exchange and electronic tracking of the sun. Consequently, the existence of firms with experience in these materials and processes is not surprising. The concentration of firms around the Washington, D.C. area also suggests that political factors may play a part in the location of firms, especially having close access to the Department of Energy.

\section{Questionnaire Development}

The questionnaire was developed over a 2-month period. The content was formulated and reviewed by a project team involved in STES at JPL. After four iterations by the JPL team, a pre-test was conducted with nine firms. Pre-test interviewers were instructed to write detailed notes on the content 
Figure 2. Geographical Distribution of Firms That Received DOE Funding for the Development of STES.

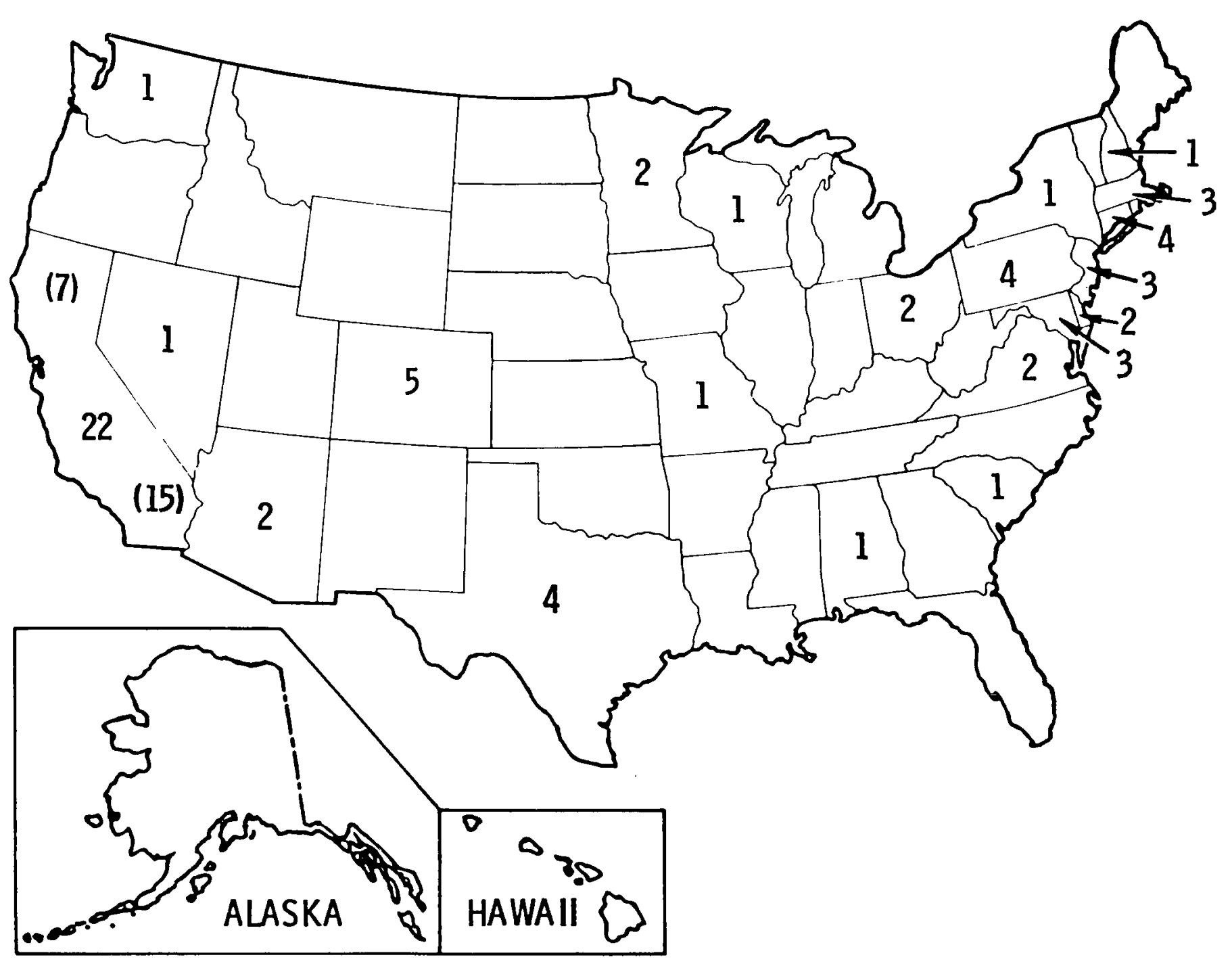


and format of the questionnaire, noting difficulties encountered. An extensive debriefing was held after the interviews were conducted. On the basis of this information, the questionnaire was revised two more times before the final version was completed.

The final questionnaire, which is presented in the Appendix, is divided into five main sections. First is a Call Record Sheet (p. 1) to record the history of the telephone calls. Second is a screening question ( .2 ) used to locate the highest ranking technical or marketing person responsible for solar thermal energy systems in the firm. Third, there is an Informed Consent statement ( $p .3$ ) that was read to the selected respondent stating the rights of the respondent and the firm and indicating the conditions upon which the data would be collected. Respondents were repeatedly assured that their responses were confidential and that the rights of both the respondent and the firm would be protected. In some instances, permission was obtained from the respondent to quote selected responses anonymously. Fourth, there is a screening question ( $p .4$ ) to determine whether firms were still involved with STES development. Fifth is the body of the questionnaire (p. 5-18), as used for the 54 firms that were currently involved in STES development.

The body of the questionnaire is further divided into five parts:

1. Technology orientation: Q2 - Q5.

2. Current marketing: Q6 - Q11.

3. Research and development on STES: Q12 - Q15.

4. Future marketing plans: Q16 - Q17.

5. Evaluation of federal role in STES: Q18 - Q24.

Specific content of questions within each section will be discussed in the context of the results.

\section{Data Collection, Processing and Analysis}

The interviews were conducted over a six-week period during July and August 1981. The interviewers were al1 JPL personnel who had been involved in the solar thermal program and were, therefore, familiar with the technology. Upon completion of each interview, the interviewer was required to review the responses on the questionnaire for completeness. Questionnaires were then logged, coded, and keypunched for computer processing. Analysis was conducted 
utilizing the SPSS computer program (Statistical Package for the Social Sciences) $^{2}$. The analysis and results presented below concern the 54 firms that were still involved in STES development at the time of the survey.

2 Nie, N.H., et al, Statistical Package for the Social Sciences (SPSS), 2nd Edition, McGraw-Hi11 Book Co., New York, 1975. 
Intentionally Left Blank 
The results of the survey are discussed within the framework of a conceptual model (Figure 3) which is an interlinked set of working assumptions used for analyzing the data. An important aspect of the model is that "causality" is defined $\underline{\text { a priori }}$ as a means to organize and analyze the data systematically. The seven basic elements that were assumed provide the framework of the model. The first element comprises the characteristics of the organizations (geographical distribution, size, number of years they have been involved in STES, and number of personnel working on STES). This element is the starting point for the analysis. The second element comprises the different technologies the firms were developing, identified in Figure 3 as "Production Types". The model assumes that the decision to develop the various types of technology is a function of a number of variables, only some of which can be measured in this study. However, some of the most important variables are expected to be those that comprise the characteristics of the organization, especially its size and experience with STES. Thus it was assumed that, in terms of the analysis model, the characteristics of the organization, (Box 1--Organizational Characteristics) "predict" the choice of technology (Box 2--Production Types); the reverse, however, is not true. It is conceivable that developing a particular production type could affect the characteristics of the organization, expecially if the production type is maintained over a long period. However, it was assumed that it is more likely for the organizational characteristics to affect the production types.

\section{F1gure 3. Postulated STES Industry Model.}

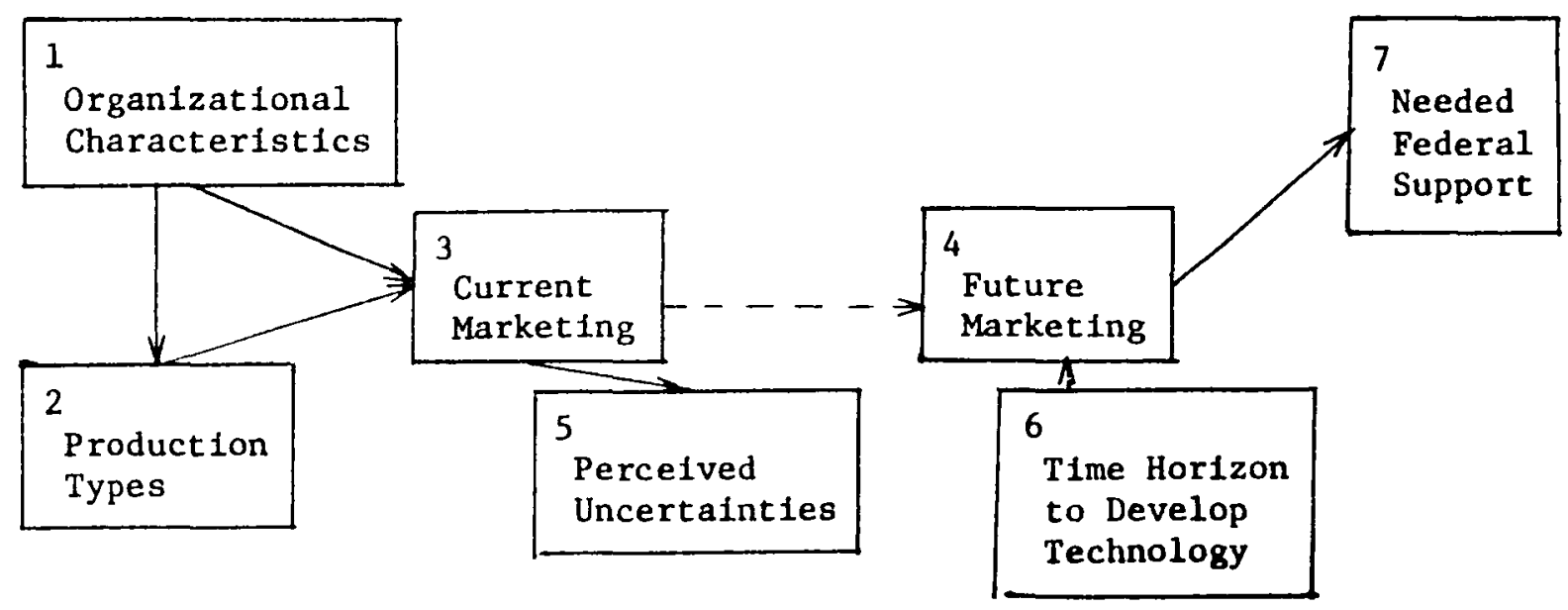


The third element concerns whether or not the firm is currently marketing. In the model, the decision to market an STES product is a function of both the technology the firm is developing and the type of organization. Thus, the first two elements were assumed to predict the third. Whether or not the firm is currently marketing affects its decision with respect to future marketing (Box 4), but this relationship is indirect. It is mediated by the firm's assessment of the uncertainties involved in developing the technology (Box 5), which in turn affects the time horizon needed to develop the technology to the point where it can be competitive without government subsidy (Box 6). Finally, all of these factors were assumed to affect the extent and type of federal support that was perceived as being needed to continue developing the technology (Box 7). Again, causality in the model was defined, rather than empirically demonstrated. It is conceivable that any one of these elements could feed back and in turn determine one of the antecedents. Thus, causality could presumably be reversed from the way in which a model is formulated. "Causality" is a theoretical problem, not an empirical one, and the model is but one possible "storyline" for this survey. Nonetheless, the model makes sense, both logically and in terms of the actual data. The discussion starts with the Production Types (Box 2).

\section{Production Types}

The Production Types of the firms (Box 2 in Figure 3 ) comprise a particular constellation of activities that characterize a firm's product: the type of technology they were developing; the amount of personnel and resources that were directed towards the development of the technology; the type of product or service to be produced; the relationship to other firms in the industry; and the type of market to be targeted. All of these characteristics involve decisions by a firm to "carve out a niche" in the industry, and it is the unique collection of these decisions, combined with location and resources, that defines each firm.

\section{Technologies}

Firms were asked to indicate which specific technologies they were developing. Table 1 presents the distribution of technologies over all firms. The two most common technologies that firms indicated they were 
Table 1. Distribution of STES Technologies.

\begin{tabular}{lc}
\hline Technology & No. \\
\hline Central Receivers \\
Dishes & 33 \\
Troughs & 32 \\
Bowls & 24 \\
Other & 8 \\
\hline
\end{tabular}

developing were central receivers ( $33 \mathrm{firms}$ ) and parabolic dishes (32 firms). The predominance of firms working on central receivers parallels Department of Energy policy in emphasizing this technology. The large number working on dishes, however, is surprising considering that a smaller proportion of the Department of Energy STES budget has been focused on dishes. Possibly since troughs and central receivers were the earliest technologies to be developed, manufacturers are now expanding into new technologies, such as the dish, as the opportunities develop.

Many firms were working on more than one technology, since the sum of technologies (111) is more than double the number of firms interviewed (54). Table 2 presents the distribution of the number of different technologies that firms were developing. A majority of firms (34) were working on more than one technology, with two technologies being the most common. There are at least

Table 2. Number of Different Solar Thermal Technologies Developed by Industrial Firms.

\begin{tabular}{cc}
$\begin{array}{c}\text { Number of } \\
\text { Technologies }\end{array}$ & $\begin{array}{c}\text { Number } \\
\text { of Firms }\end{array}$ \\
\hline No information & 2 \\
0 & 1 \\
1 & 17 \\
2 & 18 \\
3 & 12 \\
4 & 3 \\
5 & 1 \\
\hline
\end{tabular}


two possible reasons for this. First, because STES is a new technology with five different concepts of operation, it is not clear which concept, if any, will be successful in the marketplace. Thus, many firms may "hedge" their commitments by developing more than one product-line. Second, many of the designs, subsystems, and components of the various concepts may be similar from one technology to another, thereby allowing firms to adapt their product to more than one technology concept.

This second factor is supported from correlation coefficients among the different technologies (Table 3$)^{3}$. The strongest relationship is between troughs and dishes. Nineteen of the 24 trough firms were working on dishes,

Table 3. Relationship Among Technologies.

\section{Pearson " $r$ " Correlations}

\begin{tabular}{|c|c|c|c|c|c|}
\hline & $\begin{array}{l}\text { Central } \\
\text { Receivers }\end{array}$ & Bowls & Dishes & Troughs & Other \\
\hline Central Receivers & 1.00 & 0.23 & 0.03 & -0.20 & -0.21 \\
\hline Bowls & & 1.00 & 0.24 & 0.15 & 0.01 \\
\hline Dishes & & & 1.00 & $0.36 * x$ & $-0.30 *$ \\
\hline Troughs & & & & 1.00 & -0.10 \\
\hline Other & & & & & 1.00 \\
\hline $\begin{array}{l}* \text { Significant at } \\
* * \text { Significant at } p\end{array}$ & & & & & \\
\hline
\end{tabular}

3 Correlation coefficients are indices of linear association, varying from -1.00 to +1.01 . Thus, if a correlation coefficient is positive, firms tend to work on both technologies or on neither. A negative coefficient indicates that firms tend to work on one or the other, but not on both. A zero correlation indicates that there is no relationship. The significance tests indicate the likelihood that a correlation could be due to chance. It is based on a theoretical sampling distribution. Generally, if the likelihood that the particular correlation is due to chance is less than $5 \%$ $(\mathrm{p} \leq .05)$ or $1 \%(\mathrm{p} \leq .01)$, then the correlation is treated as a "real" effect. Otherwise, it is considered not to be different from a zero correlation. Strictly speaking, correlations wich discreet binomial 
while 19 of the 32 dish firms were developing troughs. There is also a negative relationship between central receivers and troughs; central receiver firms tended not to develop troughs, and vice versa. Only 12 of the 33 central receiver firms were developing troughs, and only 12 of the 24 trough firms were developing central receivers. A number of dish manufacturers were also developing central receivers (20 out of 32 ), so that the overwhelming majority of dish manufacturers also were developing troughs or central receivers. The bowl manufacturers overwhelmingly were developing central receivers also ( 7 out of 8 ). Thus, it appears that there are two distinct types of firms: 1) trough firms, most of which also developed dishes, and 2) central receiver firms, that also may have developed either bowls or dishes.

\section{Functions}

This overlap among technologies means that firms cannot be typed solely by the technology they were developing. The function, that is, the type of product or service that was being provided, should also be considered. Table 4 presents the distribution of functions that firms were providing. The two

Table 4. Distribution of Production Functions.

\begin{tabular}{lc}
$\begin{array}{l}\text { Production } \\
\text { Function }\end{array}$ & $\begin{array}{c}\text { No. } \\
\text { Firms }\end{array}$ \\
\hline R\&D to Government & 43 \\
A\&E Services & 40 \\
Subsystems. or Components & $2 \dot{4}$ \\
"Turnkey" Systems & 14 \\
Using STES Energy & 8 \\
Other & 7 \\
\hline
\end{tabular}

variables (i.e., "yes-no" answers) may produce biased estimators of the "true" parameters, especially with regression coefficients. The directions of the relationship, however, are not biased (i.e., whether they are positive, negative, or zero) and a significance test is equivalent to a phi-coefficient, based on the chi-square significance test (see S. Wiseman, Correlation Methods, Manchester, England: Manchester University Press, 1966). Since correlations and regressions are being used to assess the direction of relationships only, and not regression coefficients, their use with discreet binomial variables is appropriate. 
most common functions were providing research and development to the government ( 43 firms) and providing architectural and engineering services (40 firms). These were followed by the manufacturing functions, subsystems or components ( 24 firms), and "turnkey" systems ( 14 firms). In addition, when asked whether they were using energy produced by STES, 8 firms responded in the affirmative.

As with specific technologies, most firms (41) were providing more than one function (Table 5), most typically three. Thus, most firms were providing $R \& D$ to the government and architectural and engineering (A\&E) services. A smaller number were also producing products. From the analyses, an interesting pattern has emerged (Table 6). First, there is a positive relationship between providing R\&D to the government and producing subsystems or components: 22 of the 24 firms that were manufacturing subsystems or components were also providing R\&D to the government. The reverse is not true, however, as on $1 y 22$ of the 43 firms that were providing R\&D to the government were manufacturing subsystems or components. There is also a negative relationship between firms providing R\&D to the government and providing A\&E services which is spurious due to the pattern of responses. That is, 30 out of 43 firms that were providing R\&D to the government were also supplying A\&E services, while 30 out of 40 firms that were supplying A\&E services were providing $R \& D$ to the government. $R \& D$ to the government and A\&E services appear to be general functions that were adopted by most firms. The federal government appears to be central to the development of STES technology. Finally, the use of energy from STES is more idiosyncratic, and involved only eight firms, seven of which were also providing R\&D to the government and six of which were producing subsystems and components. 
Table 5. Number of Production Functions Firms are Providing.

\begin{tabular}{cc}
$\begin{array}{l}\text { No. } \\
\text { Functions }\end{array}$ & $\begin{array}{c}\text { No. } \\
\text { Firms }\end{array}$ \\
\hline 1 & 13 \\
2 & 12 \\
3 & 18 \\
4 & 10 \\
5 & 1 \\
\hline
\end{tabular}

Table 6. Relationship Among Functions.

\begin{tabular}{|c|c|c|c|c|c|c|}
\hline & \multicolumn{6}{|c|}{ Pearson "r" Correlations } \\
\hline & $\begin{array}{l}\text { R\&D to } \\
\text { Gov't. }\end{array}$ & $\begin{array}{l}\text { "Turnkey" } \\
\text { Systems }\end{array}$ & $\begin{array}{l}\text { Subsystems } \\
\text { or } \\
\text { Components }\end{array}$ & $\begin{array}{l}\text { A\&E } \\
\text { Services }\end{array}$ & $\begin{array}{l}\text { Using } \\
\text { STES } \\
\text { Energy }\end{array}$ & Other \\
\hline R\&D to Gov't. & 1.00 & 0.19 & $0.27 *$ & -0.19 & 0.08 & 0.06 \\
\hline $\begin{array}{l}\text { "Turnkey" } \\
\text { Systems }\end{array}$ & & 1.00 & 0.15 & $0.25 *$ & -0.13 & $-0.23 *$ \\
\hline $\begin{array}{l}\text { Subsystems or } \\
\text { Components }\end{array}$ & & & 1.00 & 0.19 & $0.26 *$ & $-0.23 *$ \\
\hline A\&E Services & & & & 1.00 & 0.01 & $-0.27 *$ \\
\hline $\begin{array}{l}\text { Using STES } \\
\text { Energy }\end{array}$ & & & & & 1.00 & -0.16 \\
\hline Other & & & & & & 1.00 \\
\hline
\end{tabular}


Factor Analysis

The relationship between the different technologies and the different

functions was examined by performing a factor analysis on the four technology variables and the five function variables. 4

Five relatively independent factors were extracted from the analysis and are presented in Table 7 (only significant loadings are presented). The first factor has a high positive loading (correlation) on R\&D to the government, a moderate positive loading on producing subsystems or components, and a moderate negative loading on providing A\&E services. Since it was determined that the negative correlation between providing $R \& D$ to the government and supplying A\&E services was slightly spurious, this factor should be considered a uni-directional factor and is called providing R\&D to the government, with minor weighting for producing subsystems and components. Most firms provided R\&D to the government, especially the subsystem and component manufacturers; only a minority did not. The second factor has a high positive loading on supplying "turnkey" systems, a slight positive loading on developing parabolic troughs, and a strong negative loading for developing central receivers. Since it was determined that there was a simple negative correlation between central receivers and troughs, this factor has been named "turnkey" vs. central receiver. Some firms were exclusively developing "turnkey" systems, especially the parabolic trough firms, and some were exclusively developing central receivers; the remaining firms were combinations of the two.

The third factor is uni-directional with moderate positive loadings on subsystems or components and A\&E services, and a slight positive loading on "turnkey" systems. This factor has been named engineering, subsystems and components. Some firms were producing subsystems or components and conducting

4 A factor analysis creates independent dimensions (factors) and then relates each variable to each factor through a factor loading, which is a correlation of the variable with the factor. The factor represents the common overlap between the variables and can be considered an underlying dimension. The theoretical factor axes can be rotated to achieve cleaner distinctions between variables. The independence of the dimensions can be broken in order to allow even sharper distinctions (i.e., a variable will have either a high positive or negative loading or a zero loading). Such a solution is called oblique. The factor analysis performed was a principal factor solution that extracted all factors with latent roots greater than 1.00 . An oblique rotation was then carried out on the extracted factors using the oblimin criteria (see H. Hanman, Modern Factor Analysis, Chicago: University of Chicago Press, 1967). 
Table 7. Factor Analysis of Technologies and Functions.

\begin{tabular}{|c|c|c|c|c|c|}
\hline & \multicolumn{5}{|c|}{$\begin{array}{c}\text { Significant Factor Loadings* } \\
(> \pm 0.30)\end{array}$} \\
\hline & $\mathrm{I}$ & II & II I & IV & $\mathrm{V}$ \\
\hline Central Receivers & - & -0.73 & - & - & - \\
\hline \multirow[t]{2}{*}{ Bowls } & - & - & - & - & - \\
\hline & - & - & 0.68 & - & - \\
\hline Troughs & - & 0.33 & - & 0.47 & - \\
\hline$R \& D$ to Gov't. & 0.72 & - & - & - & - \\
\hline $\begin{array}{l}\text { "Turnkey" } \\
\text { Systems }\end{array}$ & - & 0.80 & 0.32 & - & - \\
\hline $\begin{array}{l}\text { Subsystems or } \\
\text { Components }\end{array}$ & 0.39 & - & 0.67 & - & - \\
\hline A\&E Services & -.50 & - & 0.62 & - & - \\
\hline \multirow{2}{*}{$\begin{array}{l}\text { Using STES } \\
\text { Energy }\end{array}$} & - & - & - & - & 0.79 \\
\hline & $\begin{array}{l}R \& D \text { to } \\
\text { Gov't. }\end{array}$ & $\begin{array}{l}\text { "Turnkey" } \\
\text { vs } \\
\text { Central } \\
\text { Receiver }\end{array}$ & $\begin{array}{l}\text { Engineering, } \\
\text { Subsystems, } \\
\& \text { Components }\end{array}$ & $\begin{array}{l}\text { Distributed } \\
\text { Systems }\end{array}$ & $\begin{array}{l}\text { STES } \\
\text { Energy }\end{array}$ \\
\hline
\end{tabular}

* Only those loadings greater than \pm 0.30 are presented. This is approximately the $5 \%$ significance level. 
A\&E services, and possibly supplying "turnkey" systems. This category identifies those firms that were producers. The fourth factor has moderate positive loadings for dishes and troughs; this factor is called distributed systems. Finally, the fifth factor is a single-variable dimension of using STES energy. Since only a handful of firms were using energy from STES, this factor is considered a special subgroup of current users. For the rest of the analysis, this dimension will be ignored.

Independence of Techniques and Functions

The four main groupings of technologies and functions has a number of interesting implications. First, it indicates that technologies and functions are somewhat unrelated. A firm developing one or more technologies has several functional options. It can provide R\&D to the government, manufacture subsystems or components, or provide "turnkey" systems. The only empirical relationship observed is that "turnkey" manufacturers tended not to be developing central receivers. Second, the factor analysis indicates that dishes and troughs are being developed by the same firms, as the correlation analysis suggested. Thus, the same companies tend to develop both dishes and troughs, either "turnkey" systems or components. Even though the trough is considered to be more near-term than the dish, especially the high-temperature dish, many components and subsystems can be used in both technologies. Third, bowls do not show any significant pattern. As a technology, it does not have a pattern distinct enough to become isolated as a variable. As has been shown, almost all bowl manufacturers also developed central receivers (but not the reverse). Thus, the bowl manufacturers can be conceptualized as a subset of the central receiver firms.

\section{Production Typology}

The results of the factor analysis suggest a production typology that classifies firms into fairly distinct groups. A useful typology classifies three different technologies and three different functions, with the interaction characterized by a three-by-three matrix (Table 8). The technologies, comprising the vertical columns of the matrix, are distributed systems, bowls, and central receivers. The functions, comprising the horizontal rows of the matrix, are "turnkey" systems; engineering, subsystems, and components; and "pure" R\&D. The three-by-three matrix defines nine logical "types", which are referred to as Type 1 through Type 9. 
Table 8. Production Typology.

T E C H N O L O G I E S

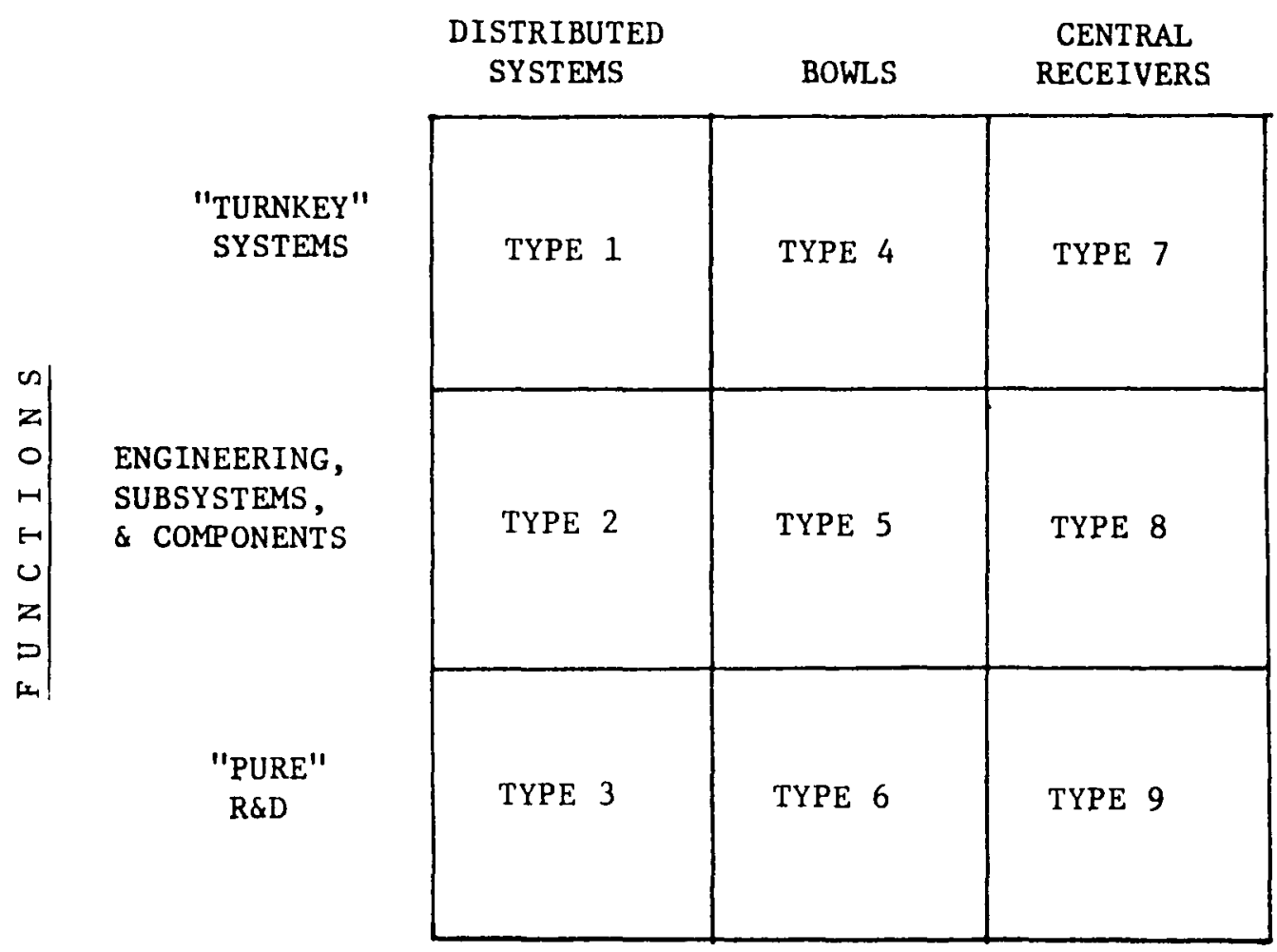

Al1 firms were empirically grouped into one or more of the nine types (Table 9). Because most firms were developing more than one technology and providing more than one function, the matrix has some duplicate groupings; that is, a firm can be included in more than one technology (i.e. more than one column) and also in more than one function (i.e. in more than one row). Even though there is not independence between the categories, each type represents the entire collection of firms having those characteristics. 5 Since most firms were providing R\&D to the government, "pure" R\&D firms were defined as those providing only $R \& D$ to the government; thus they could not be developing either "turnkey" systems or engineering, subsystems and

5 The matrix can be conceived of as nine independent populations; Type 1 firms are all those which are producing distributed "turnkey" systems; Type 2 firms are all those which are producing engineering, subsystems and components for distributed systems, and so forth. In making comparisons, however, there is only one response for a firm. Thus, the statistics within each type are not independent (i.e., mean or percentage); they should be conceived as slightly biased estimates of the "true" value within each type. 
Table 9. Distribution of Firms in Production Typology.

\begin{tabular}{|c|c|c|c|}
\hline & $\begin{array}{c}\text { DISTRIBUTED } \\
\text { SYSTEMS }\end{array}$ & BOWLS & $\begin{array}{l}\text { CENTRAL } \\
\text { RECEIVERS }\end{array}$ \\
\hline $\begin{array}{l}\text { "TURNKEY" } \\
\text { SYSTEMS }\end{array}$ & $\begin{array}{c}\quad \text { TYPE 1 } \\
11 \\
{\left[\begin{array}{ll}8 & \text { Both } \\
2 & \text { Trough } \\
1 & \text { Dish }\end{array}\right]}\end{array}$ & $\begin{array}{l}\text { TYPE } 4 \\
2\end{array}$ & TYPE 7 \\
\hline $\begin{array}{l}\text { ENGINEERING, } \\
\text { SUBSYSTEMS, } \\
\& \text { COMPONENTS }\end{array}$ & $\begin{array}{c}\quad \text { TYYE 2 } \\
19 \\
{\left[\begin{array}{ll}8 & \text { Both } \\
3 & \text { Trough } \\
8 & \text { Dish }\end{array}\right]}\end{array}$ & $\begin{array}{l}\text { TYPE } 3 \\
4\end{array}$ & TYPE 8 \\
\hline $\begin{array}{l}\text { "PURE" } \\
\text { R\&D }\end{array}$ & $\begin{array}{c}\text { TYFE ' } \\
7 \\
{\left[\begin{array}{ll}3 & \text { Both } \\
4 & \text { Dish }\end{array}\right]}\end{array}$ & TYPE 0 & TYPE 9 \\
\hline
\end{tabular}

components. There were five firms that were not developing one of the nine types and could not be grouped into this typology, forming an "Other" category. The most common technologies were distributed systems and central receivers, and the most common functions were engineering, subsystems and components and, to a lesser extent, "turnkey" systems. Type 8 (engineering, subsystems, and components for central receivers) is the most common production type followed by Type 2 (engineering, subsystems, and components for distributed systems). Thus, the most common type of production orientation was towards producing subsystems or components and A\&E services for either central receivers or distributed systems. The third most common type was Type 1 ("turnkey" distributed systems), followed by Type 3 ("pure" R\&D on distributed systems), and Type 9 ("pure" R\&D on central receivers). There were only a handful of bowl firms for any of the functions, and only three "turnkey" central receiver firms. In summary, firms are distributed throughout in all nine types, but more than two-thirds of the firms fall into three main groupings. 
Time Horizon for the Different Technologies

The production typology does more than group firms into different types; it can be shown that the different types have quite different decision patterns for production. Each respondent was asked in which year the firm would be able to market its first solar thermal product or services without government subsidy. Some firms were already marketing products or services, but the majority were not. Each estimate was converted into the number of years until marketing, or a negative number if the firm was already marketing. For the overall sample, the average response was 2.3 years, with a standard deviation of 4.5 years. The earliest firm to market STES products started 6 years ago, while the longest estimate before a product would be marketed was 11 years. Although there may be a certain amount of optimism in these estimates, with a certain amount of uncertainty associated with the estimates in the future, they can nevertheless be treated on a relative basis.

Table 10 presents the mean ratings for each of the nine production types. The standard deviation is included within the parenthesis. The production type closest to marketing without DOE support is Type 1 - "turnkey" distributed systems (in particular, the trough), where the average is -0.3 years with a standard deviation of 4.0 years. At the other extreme, the production type with the longest time horizon is Type 3 - "pure" R\&D on distributed systems (the high-temperature dish), where the average estimate is 4.8 years with a standard deviation of 2.8 years. Aside from Type 6 - "pure" R\&D on bowls, where no firms gave estimates, the time horizon for each technology increases from "turnkey" systems through engineering, subsystems, and components, to "pure" R\&D. Thus Type 9 - "pure" R\&D on central receivers, has almost as long a time horizon as Type 3 - "pure" R\&D on distributed systems. Firms providing engineering, subsystems, and components (Types 2, 5, and 8 ) have intermediate time horizons and the three "turnkey" systems types have the shortest time horizons of all.

The production typology provides a means for distinguishing the time horizons for different types of firms. The production types can be considered as different constellations of production decisions that firms have adopted, indicating the trade-off between a technology choice and a production function mode. It also will be shown that the typology distinguishes other characteristics of firms, thereby lending credence to the validity of the typology as a model of STES production. Production must be considered as an interaction between technology and function; this unique interaction defines 
Table 10. Time Horizon for Different Production Typologies.

\begin{tabular}{|c|c|c|c|}
\hline & $\begin{array}{l}\text { DISTRIBUTED } \\
\text { SYSTEMS }\end{array}$ & BOWLS & $\begin{array}{l}\text { CENTRAL } \\
\text { RECEIVERS }\end{array}$ \\
\hline $\begin{array}{l}\text { "TURNKEY" } \\
\text { SYSTEMS }\end{array}$ & $\begin{array}{l}\text { TYPE } 1 \\
-0.3 \\
(4.0)\end{array}$ & $\begin{array}{l}\text { TYPE } 4 \\
2.0 \\
(7.1)\end{array}$ & $\begin{array}{l}\text { TYPE } \\
1.3 \\
(5.1)\end{array}$ \\
\hline $\begin{array}{l}\text { ENGINEERING, } \\
\text { SUBSYSTEMS, } \\
\& \text { COMPONENTS }\end{array}$ & $\begin{array}{c}\text { TYPE } 2 \\
\\
3.8 \\
(4.6)\end{array}$ & $\begin{array}{c}\text { TYPE } 5 \\
\\
4.5 \\
(3.1)\end{array}$ & $\begin{array}{c}\text { TYPE } 8 \\
\\
3.9 \\
(4.1)\end{array}$ \\
\hline $\begin{array}{l}\text { "PURE" } \\
\text { R\&D }\end{array}$ & TYPE 3 & TYPE 6 & $\begin{array}{c}4.5 \\
(2.1)\end{array}$ \\
\hline
\end{tabular}

Note: The mean number of years until a firm will market a STES product without government subsidy. The standard deviation is in parentheses.

how a firm will operate in developing the new technology. The important point is that each technology must be treated in relation to the type of production function to which the firm is committed. From a policy point of view, the model also suggests that a number of distinct policies (perhaps as many as nine) need to be defined to reflect the distinct differences in how firms operate with regard to STES. To have a uniform policy for all firms or to have a policy based on specific technologies alone would ignore the subtle differences among firms in the way they approach the impending market of STES. 


\section{Characteristics of Organizations}

Another essential point is that firms operate differently in terms of their own organizational characteristics, in particular their size. The size of a firm provides an index of the amount of resources that $c$ an be directed toward the development of solar thermal systems, which, in turn, affects the type of production decision a firm will make.

\section{Size of Firm}

The firms differed considerably in size. While the size of the firm was not measured directly (e.g. in terms of total sales or assets), there were six indirect measures:

1. Total funding from the Department of Energy for the development of STES;

2. Funding for STES provided by a firm's internal sources;

3. The average number of employees working on STES during 1980;

4. The 1980 total STES sales, for those firms that were currently marketing;

5. A perceived estimate of how much had been saved through Department of Energy funding for those firms that were currently marketing; and, 6. An estimate of the additional capital needed to bring STES up to the point where it will be competitive without federal subsidy.

Each of these factors produced a highly skewed distribution. For example, the total funding from the Department of Energy varied from a high of $\$ 90,000,000$ to a low of $\$ 60,000$; the mean is $\$ 5,805,000$ but the median is only $\$ 1,415,000$. Such a skewed distribution is typical of measures of size and income. The six measures produced highly skewed distributions of this nature and indicate that there are a small number of very large firms, a slightly larger number of medium-size firms, and many small firms. However, such measures can produce distortions in conclusions when evaluated individually and without adequate statistical correction. To illustrate this point, Table 11 presents the Pearson correlation coefficients for the intercorrelations for the six measures. With the exception of the sixth measure, which was subsequently dropped from the analysis, the correlations were extremely high. Among the first five measures, the lowest correlation is 0.77 while the highest is 0.97. Taken alone, these results would suggest an almost one-to-one ranking of firms for all the measures. For example, the simple correlation between DOE funding and internal funding is 0.88 , a result that suggests a matching 
Table 11. Measures of Firm Size: "Gravity" Effects.

\begin{tabular}{|c|c|c|c|c|c|c|}
\hline & \multicolumn{6}{|c|}{ Pearson " $r$ " Correlations } \\
\hline & $\begin{array}{l}\text { Average } \\
\text { Number of } \\
\text { Employees } \\
(1980)\end{array}$ & $\begin{array}{l}1980 \\
\text { Sales } \\
(\$ K)\end{array}$ & $\begin{array}{l}\text { DOE } \\
\text { STES } \\
\text { Fund } s \\
(\$ K)\end{array}$ & $\begin{array}{l}\text { Interna } 1 \\
\text { STES } \\
\text { Fund s } \\
(\$ K)\end{array}$ & $\begin{array}{l}\text { Fund s } \\
\text { Saved } \\
(\$ K)\end{array}$ & $\begin{array}{l}\text { Addn'1. } \\
\text { Capital } \\
\text { Required } \\
(\$ K)\end{array}$ \\
\hline $\begin{array}{l}\text { Avg. Number } \\
\text { of Employees }\end{array}$ & 1.00 & 0.86 & 0.93 & 0.93 & 0.93 & -0.01 \\
\hline 1980 Sales & & 1.00 & 0.97 & 0.77 & 0.94 & 0.94 \\
\hline $\begin{array}{l}\text { DOE STES } \\
\text { Funds }\end{array}$ & & & 1.00 & 0.88 & 0.89 & -0.05 \\
\hline $\begin{array}{l}\text { Internal STES } \\
\text { Funds }\end{array}$ & & & & 1.00 & 0.90 & -0.01 \\
\hline Funds Saved & & & & & 1.00 & -0.05 \\
\hline $\begin{array}{l}\text { Addn'1. Capita } 1 \\
\text { Req. }\end{array}$ & & & & & & 1.00 \\
\hline
\end{tabular}

proportional to size (i.e. big firms put in more because they are big, while small firms put in less because they are smal1). While this is undoubtedly correct, it tends to minimize differential choice on the part of the firm, irrespective of the size. Additional analysis, using the Spearman rank-order correlation for this association ${ }^{6}$, results in a correlation of only 0.58 , which suggests that some firms are matching proportionately more than what their size would indicate while others are matching proportionately less than what their size would indicate. Further, the relative weights given to DOE funding versus internal funding is considerable across firms. Figure 4 presents the distribution of internal funding as a percentage of total STES funding, (i.e., a new measure computed as follows: STES internal funding divided by the sum of DOE funding and STES internal funding, and multiplied by $100 \%$ ) There results a skewed distribution that varies from a low of $0 \%$

6 This correlation relates the rank-order of the firms on each of the two variables rather than their level of magnitudes. 
Figure 4. Distribution of Internal Funds as a Percent of Total STES Funds.

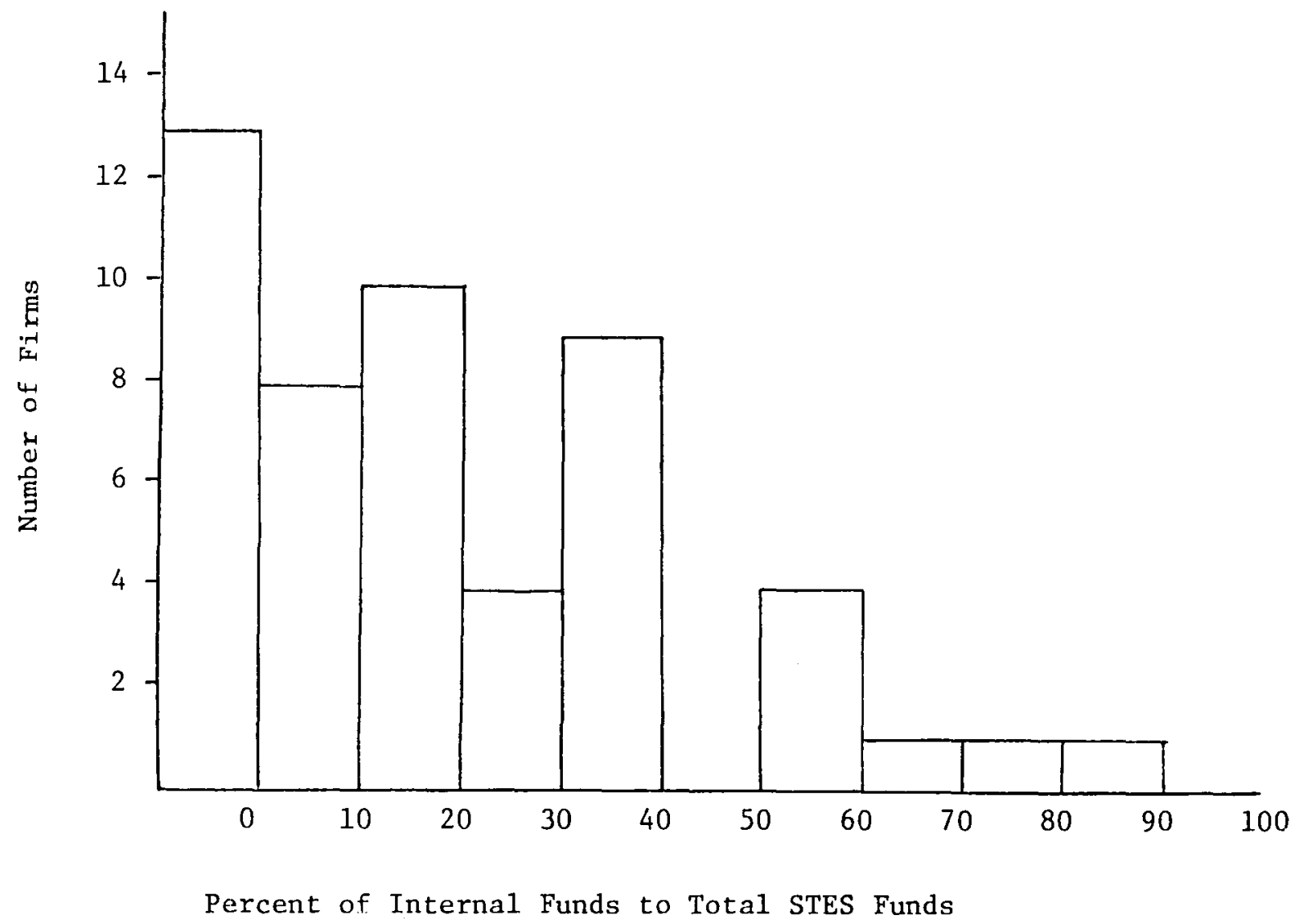

to a high of $85 \%$. While most firms matched DOE funds with only a small proportion (the mean is $24 \%$ but the median is only $17 \%$ ), there were seven firms that put in more than what DOE had given them (i.e. those firms that have scores greater than $50 \%$ ). In other words, hidden behind the extremely high simple correlations between DOE funding and internal funding is a wide range of differential choice among the firms.

The largest firms are extremely large relative to the other firms. For example, it has been estimated that the Department of Energy has given approximately $\$ 313,000,000$ to these 54 firms over the last few years (the time reference of the survey question does not permit an exact temporal delineation). Of this amount, the largest firms received a very high proportion. The top five firms together received $65 \%$ of the total STES funding given by the Department of Energy that was accounted for in the 
survey. Thus, the high correlations among the different size variables are partly exaggerated by the largest firms that have tended to match DOE funding with funds in direct proportion to their size. Figure 5 presents the rank-size distribution of DOE STES funding and internal STES funding for the firms for which there was complete information. For the measure of DOE funding there was information for $50 \mathrm{firms,}$ while for internal funding there was information for $48 \mathrm{firms.} \mathrm{Although} \mathrm{there} \mathrm{are} \mathrm{slight} \mathrm{differences} \mathrm{in} \mathrm{the}$ available information, the rankings can nevertheless be compared. In Figure 5 the rank-order of firms is indicated along the $X$-axis and the amount of funds along the Y-axis; both axes are logarithmic scales. As can be seen, both distributions are highly skewed and rapidly fall off as the rank increases. Firms tend to match DOE funding roughly in proportion to what they receive. However, from about rank $\# 6$ to about rank 121 , the distribution for DOE funding has a "bulge", suggesting that DOE has provided these firms with proportionately more funding than firms in the rest of the distribution. The largest firms were receiving the most, as would be expected, and the smallest firms were receiving the least, but the medium-size firms (medium relative to all the firms in this sample) appear to have been receiving slightly more than what would be expected if the distribution were to fall off smoothly.

\section{Logarithm Conversion}

Because of the skewed nature of the data, all firm size indices have been converted into logarithms (to the base 10) in order to minimize the effects of the largest firms on the correlations. Table 12 presents the intercorrelations among five logarithms of the firm size variables. As can be seen, the correlations are more moderate though still high. The correlation between the logs of DOE STES funding and internal STES funding is now 0.51 (instead of $0.88)$, a correlation more in keeping with the rank-order correlation ( 0.58$)$. The logarithms have reduced the differences among the different size firms, so that the index more accurately compares the largest firms with the smallest firms. Throughout the rest of the analysis, all size variables will be used in logarithmic form. 
Figure 5. Rank-Size Distribution of Ali Firms by DOE and Internal Funds.

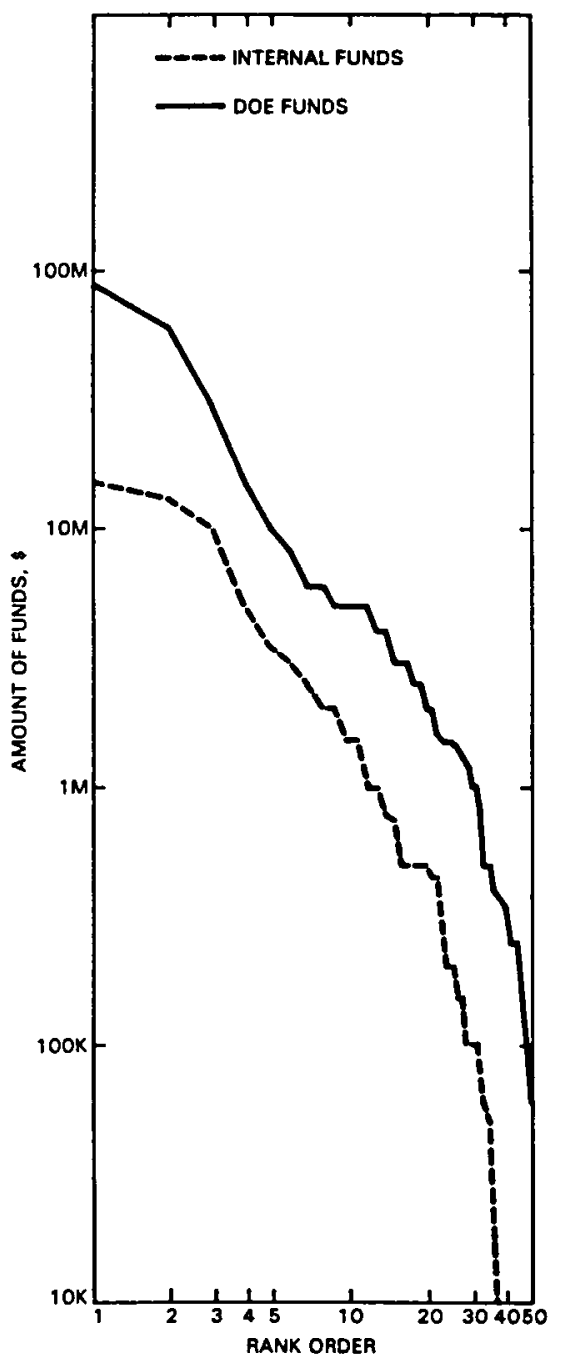


Table 12. "Corrected" Indices of Firm Size in Log10 Form.

$$
\text { Pearson " } r \text { " Correlations }{ }^{a}
$$

\begin{tabular}{|c|c|c|c|c|c|}
\hline & $\begin{array}{l}\text { Avg. } \\
\text { Number of } \\
\text { Employees } \\
(1980)\end{array}$ & $\begin{array}{l}1980 \\
\text { Sales } \\
\text { (\$K) }\end{array}$ & $\begin{array}{l}\text { DOE } \\
\text { STES } \\
\text { Fund s } \\
(\$ \mathrm{~K})\end{array}$ & $\begin{array}{l}\text { Internal } \\
\text { STES } \\
\text { Funds } \\
(\$ K)\end{array}$ & $\begin{array}{l}\text { Funds } \\
\text { Saved } \\
\text { (\$K) }\end{array}$ \\
\hline $\begin{array}{l}\text { Avg. Number } \\
\text { of Employees }\end{array}$ & 1.00 & 0.61 & 0.70 & 0.58 & 0.57 \\
\hline 1980 Sales & & 1.00 & 0.40 & 0.33 & 0.37 \\
\hline $\begin{array}{l}\text { DOE STES } \\
\text { Funds }\end{array}$ & & & 1.00 & 0.51 & 0.74 \\
\hline $\begin{array}{l}\text { Internal STES } \\
\text { Funds }\end{array}$ & & & & 1.00 & 0.63 \\
\hline Funds Saved & & & & & 1.00 \\
\hline
\end{tabular}

a. Each variable is in $\log _{10}$ form.

Indices of Firm Size

Though there are moderate correlations among the five measures, there is a need for an overall index of firm size; two overall indices were created and used. First, an index of the total STES research and development budget was created by adding the amount of DOE funding to the amount of interna 1 funding. Second, a rough index of the total research budget of the firm (for all technologies, not just STES) was created by dividing the amount of internal STES funds by the firm's estimate of the proportion of their total research budget that amount represented. Both indices were converted into log scales. Table 13 presents the correlations of the five size variables with these two new indices. As can be seen, the correlations are all moderately high and relatively consistent. The two new indices capture a substantial proportion of the variability of each of the individual size indices, and they correlate substantially with each other. Thus, it is apparent that larger tirms tend to have higher rankings for all the indices, but not to the degree that the non-logarithmic analysis suggested. 
Table 13. Relationship of Specific Variables and General Indices of Firm Size - "Corrected" Log10 Form.

\begin{tabular}{|c|c|c|}
\hline \multirow[b]{3}{*}{$\begin{array}{l}\text { Firm Size } \\
\text { Variables }\end{array}$} & \multicolumn{2}{|c|}{ Pearson "r" Correlations } \\
\hline & \multicolumn{2}{|c|}{ General Index of Firm Size } \\
\hline & $\begin{array}{l}\text { Tota1 STES } \\
\text { R\&D Budget }\end{array}$ & $\begin{array}{c}\text { Total R\&D } \\
\text { Budget }\end{array}$ \\
\hline \multicolumn{3}{|l|}{ Average 非 } \\
\hline Employees & 0.73 & 0.60 \\
\hline \multicolumn{3}{|l|}{1980 Sales } \\
\hline & 0.43 & 0.30 \\
\hline \multicolumn{3}{|l|}{ DOE STES } \\
\hline Funds & 0.97 & 0.72 \\
\hline \multicolumn{3}{|l|}{ Internal STES } \\
\hline Funds & 0.65 & 0.87 \\
\hline Funds Saved & 0.84 & 0.86 \\
\hline \multicolumn{3}{|l|}{ Total STES. } \\
\hline R\&D Budget & -- & 0.79 \\
\hline \multicolumn{3}{|l|}{ Total R\&D } \\
\hline Budget & 0.79 & -- \\
\hline
\end{tabular}

a. Each variable is in $\log _{10}$ form.

\section{A Model of Firm Size}

From these correlations, a model of firm size was constructed (Figure 6); the lines indicate predicted relationships and the path coefficients are zero-order correlations. The total research budget of the firm is an index of the resources the firm has available for the development of any technology, including sTES. These resources determine how much internal funding the firm can contribute to STES as well as how much funding can be extracted from the Department of Energy. Thus, large firms contribute more and receive more than small firms; the firm size relationship is slightly higher for internal funds than for DOE funds. There are undoubtedly many reasons why large firms 
Figure 6. Schematic Model of Firm Size - $\log _{10}$ Transformation.

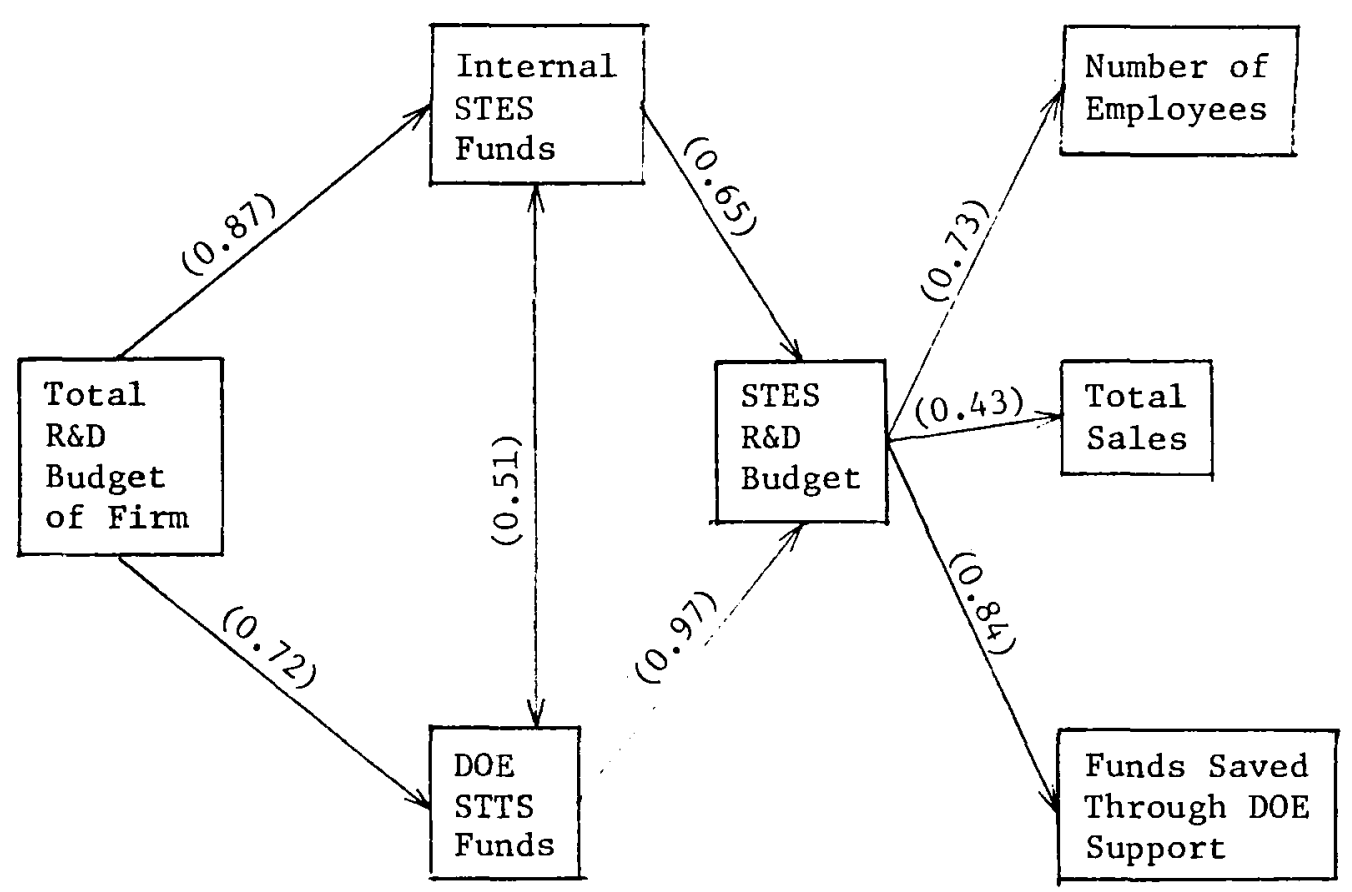

Note: The numbers on the paths (path coefficients) are zero-order correlations rather than multiple regression coefficients. Because of the high correlations, multicolinearity would result if multiple regression were used.

receive more from the government than small firms: they can handle larger projects; they have more resources that they can bring to bear on a problem; they have better proposal-writing teams. But the fact remains that firms receive government funding somewhat in proportion to their size. The STES budget to the firm, in turn, comes from two sources, DOE and internal. The model indzcates that government funding determines the firm's STES research budget to a much larger extent than do internal funds. Nevertheless, the eftects of size are still evident: large firms contribute more of their own funds than do small firms. Finally, the size of the firm's STES budget correlates with a number of factors: 1) the number of employees that can work on the development of STES; 2) total sales if the firm is currently marketing a product; and 3 ) the amount of development funds perceived to have been saved as a result of DOE support, if the firm is currently marketing a product. 


\section{Firm Size and Production Type}

Firm size also affects which technologies are chosen by the firms for development. Table 14 presents the distribution of the production types by firm size. Firms have been divided into small, medium and large firms on the basis of the firm's total STES budget. Firms with total STES funds in excess of $\$ 5$ million have been categorized as large firms, those having STES funding between $\$ 1.5$ million and $\$ 5$ million have been categorized as medium-size firms, and those with funds less than $\$ 1.5 \mathrm{mil1ion}$ have been categorized as small firms. The table shows a differentiation among different size firms in terms of the technology choices. Earlier, it was suggested that central receivers and troughs represented two opposites with respect to technology choice, with bowls being developed by central receiver firms and dishes by both trough and central receiver firms. Here the distribution suggests that the largest and smallest firms were developing central receivers, while the medium-size firms were developing the distributed systems. Since it has been argued that DOE has provided the medium-size firms with proportionately more funding than might be expected, it is suggested that distributed systems have been supported through the funding to medium-size firms. This point will be discussed further as part of the examination of firms that will remain in the field if government funding of STES is discontinued.

Another essential factor is that different size firms appear to have different research and development strategies. The large firms, having more resources, were working on all three technologies to an extent unmatched by either of the other size groups. The small firms seem to parallel the large firms, suggesting that they survive through subcontracting from the larger firms. The medium-size firms, on the other hand, have generally chosen one technology path to develop. Because of their size, they may lack sufficient internal resources to commit themselves to more than one technology. Thus, they tend to bring a higher proportion of their resources to bear on the development of one technology. Table 15 presents the average percentage of the total STES budget funded by internal sources for each of three size groups, broken down by the total R\&D budget and by the STES R\&D budget. In terms of the firm's total R\&D budget, which is the potential research resources of the firm, the medium-size firms funded a higher proportion of their STES budget from internal sources than either the large firms or the small firms. The medium-size firms also had a much higher standard deviation, 
Table 14. Size of Firm by Production Typology

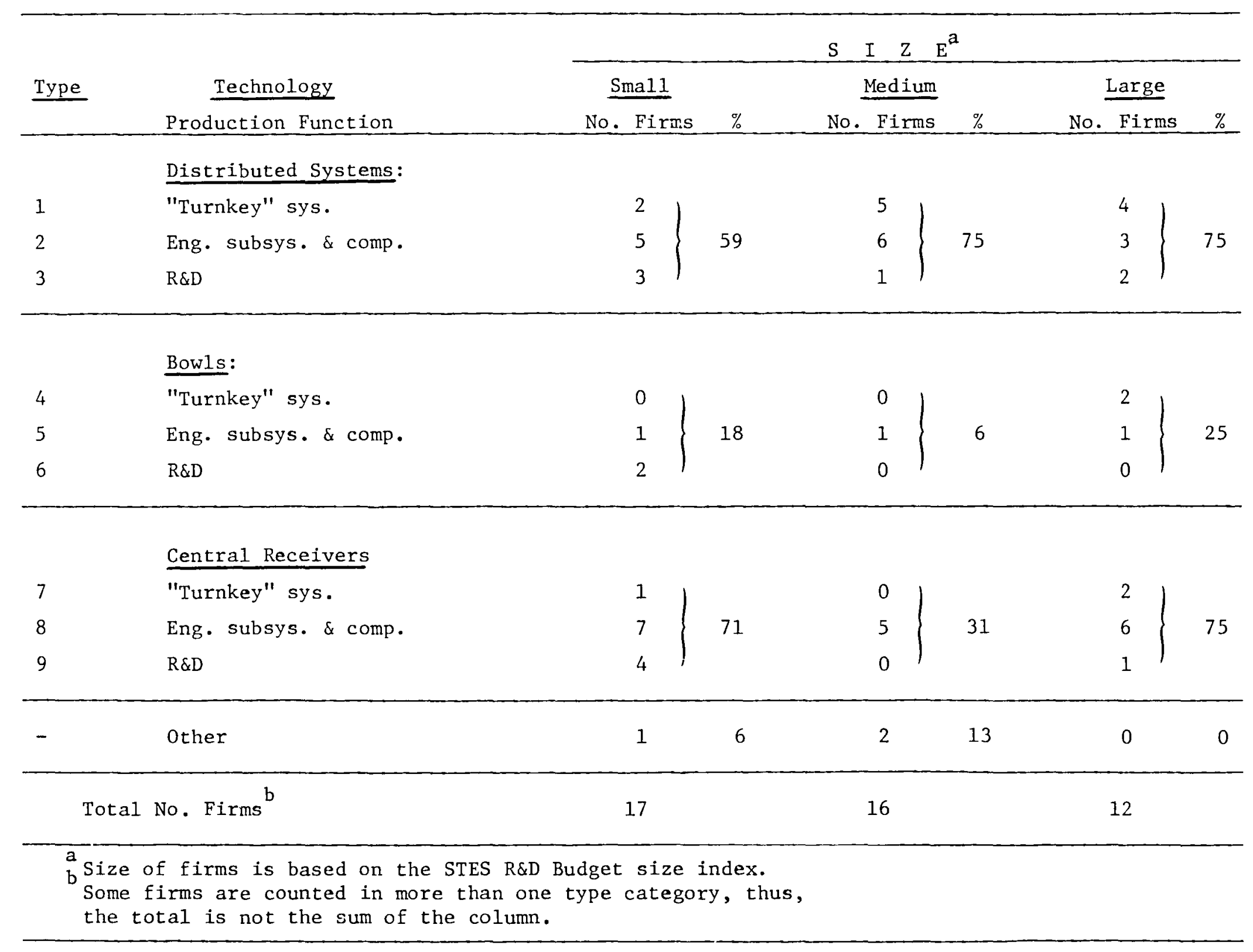


Table 15. Average Percentage of Firms' Internal Funding for Different Size Firms.

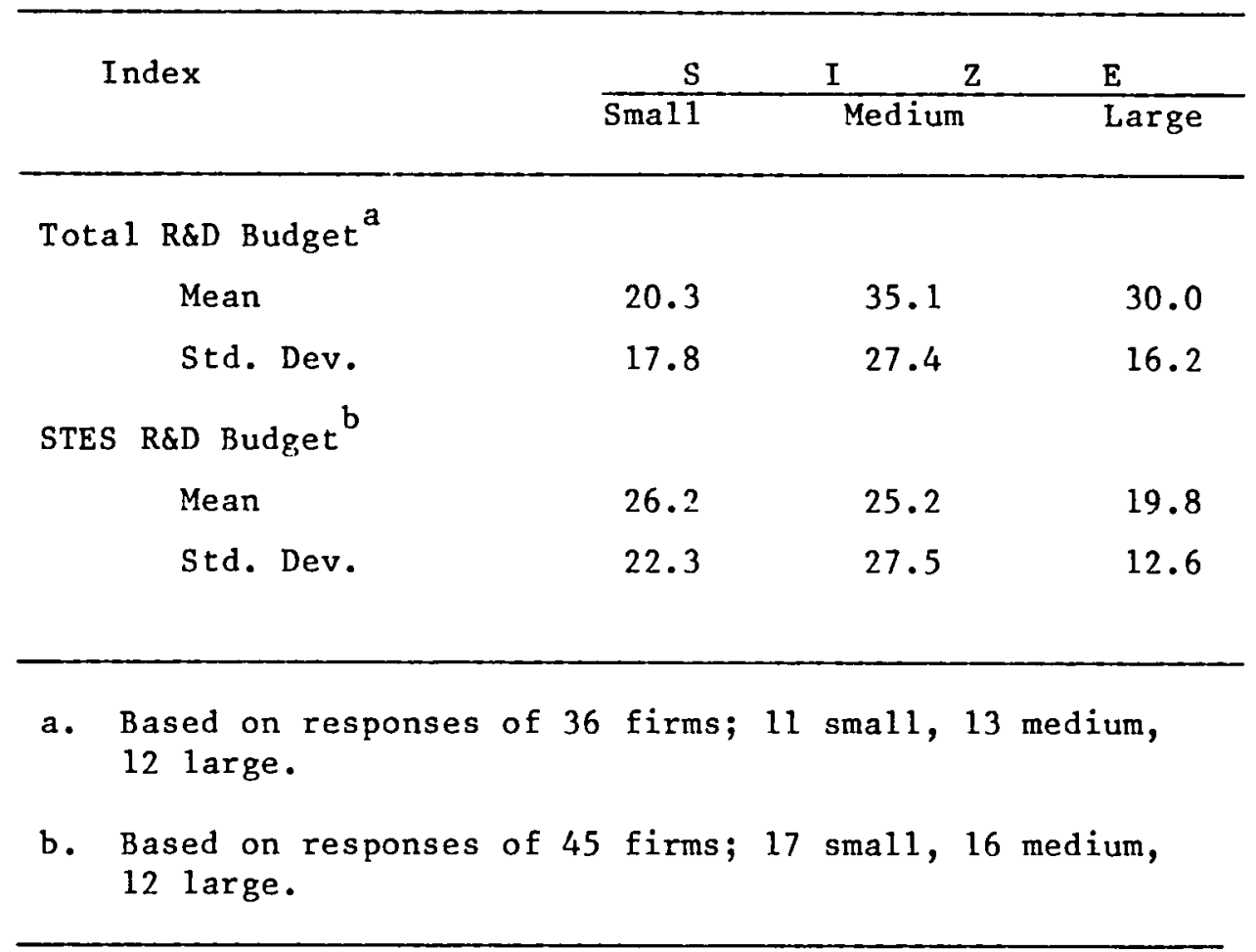

indicating that some medium-size firms funded a very high proportion of their STES budget from internal sources and others funded a very low proportion internally. Thus, when the breakdown by STES R\&D budget is examined, some of the medium-size firms are more in line with small firms in terms of total STES R\&D budget, and some of the large firms are in line with medium-size firms in this area. But the overall pattern remains. A number of the medium-size firms have given a very large commitment to STES in terms of putting in a high proportion of their own internal funds.

\section{Medium-Size Firms}

The marketing strategy of the medium-size firms was different than that of large firms, and more similar to that of the small firms. Table 16 presents the average estimates, for each size class, of the number of years until the firms can market their first product without goverument subsidy. As can be seen, medium-size firms tend to have shorter time estimates than either the large or small firms. The distributed systems are more near-term, especially the trough and the low-temperature dish, and the medium-size firms have committed themselves to this technology. 
Table 16. Marketing Time Horizon by Size of Firm.

\begin{tabular}{lcc} 
Size & $\begin{array}{c}\text { Number of Years } \\
\text { (Mean) }\end{array}$ & $\begin{array}{c}\text { Standard } \\
\text { Deviation }\end{array}$ \\
\hline Small & 2.7 & 3.1 \\
Medium & 1.9 & 5.5 \\
Large & 3.0 & 4.0 \\
\hline
\end{tabular}

a. Number of years until an STES product can be marketed without government subsidy.

\section{Organizational Predictors of Production Types}

These results have been incorporated into a schematic diagram indicating the relationship between organizational characteristics of the firms and the production types (Figure 7 ); other organizational variables have been included along with firm size. Multiple regression models were constructed based on the relationships between each of the dependent variables and the independent variables preceding them in the model. The solid lines indicate significant relationships while dotted lines indicate weaker relationships. As was mentioned in footnote 3 on page 20, only the direction of the relationships and the significance tests are being used; the regression coefficients are biased and are presented only to indicate the approximate strength of the relationship.

Three production types can be distinctly predicted by the organizational variables (the rest are undifferentiated). Type 1 - "turnkey" distributed systems, is related positively to the number of STES employees in the firm, but negatively to the total research budget of the firm. Thus, medium-size firms that have committed a large proportion of their research resources to STES would fit this pattern; they employ more personnel, but they have relatively fewer resources than large firms. Type 9 firms - "pure" R\&D on central receivers, tend to be firms with small STES budgets. Type 8 firms engineering, subsystems, and components on central receivers, tend to be firms with large total research budgets that have been involved in STES only recently and are not currently under contract with DOE. Thus, there are production 
Figure 7. Organizational Predictors of Production Typologies.

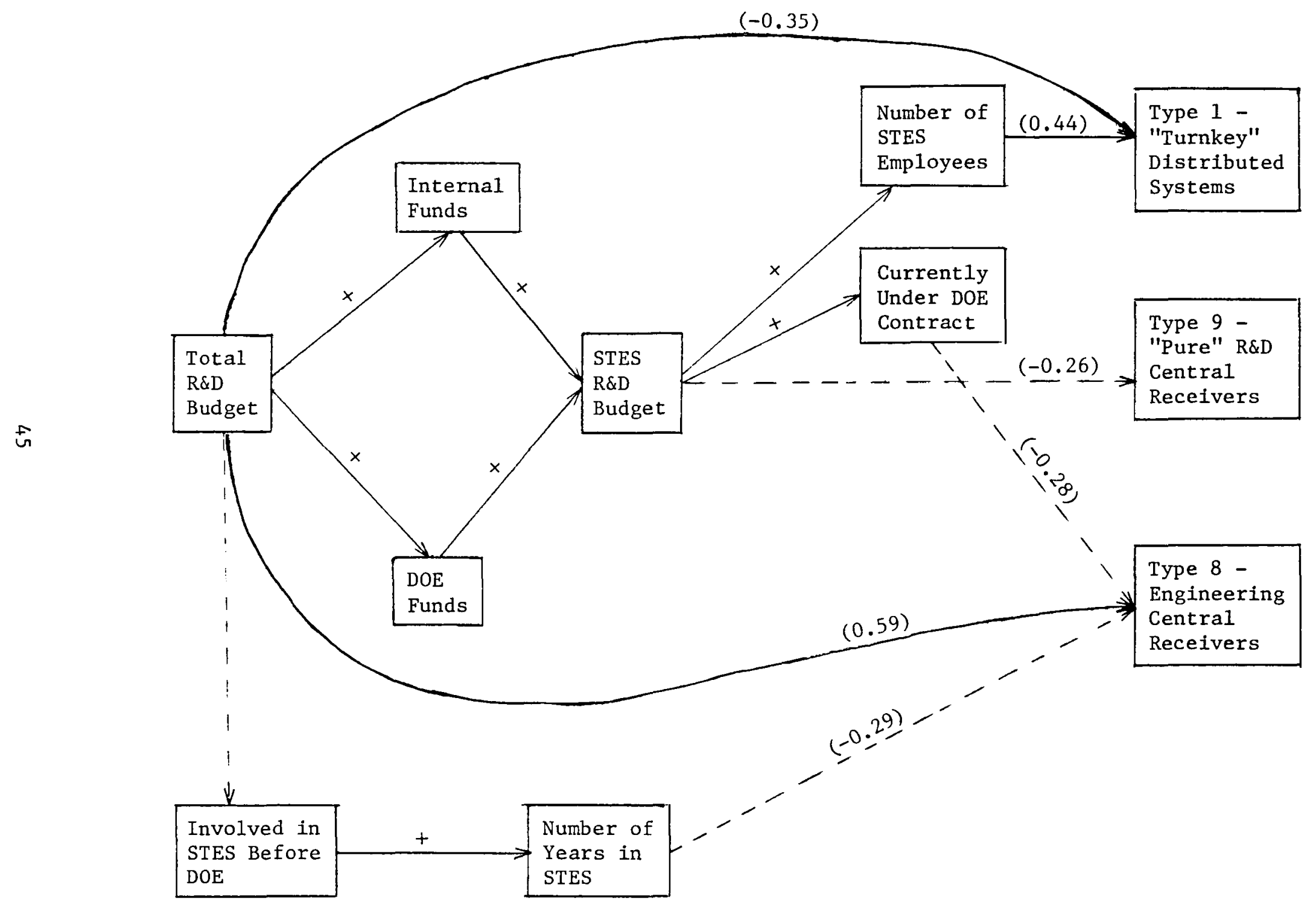


types that are differentiated by the size of the firms: Type 8 firms tend to be large, Type 9 firms tend to be small, and Type 1 firms tend to be mediumsize. Since the Type 1 firms were nearest to marketing, while the Type 9 firms were nearly the farthest from marketing, the medium-size, Type $1 \mathrm{firms}$ probably have more at risk than either large Type 8 firms or small Type 9 firms. It is with these firms that the near-term viability of the technology appear to 1 ie.

Current Marketing

A key variable in the analysis was found to be whether the firm was currently marketing or not. As seen in Table 17, $52 \%$ of the firms were currently marketing to commercial users, other than for DOE-sponsored projects. This number was surprising because it was not expected that many firms would be marketing STES production services; it is possible that marketing to other firms that are being funded by DOE projects was included in this response. Nevertheless, the roughly 50-50 split suggests an interesting difference between the firms.

Table 17. Distribution of Firms that are Currently Marketing.

\begin{tabular}{ccc}
\hline Currently Marketing & Number of Firms & Percent \\
\hline Yes & 28 & 52 \\
No & 26 & 48 \\
\hline
\end{tabular}

The types of products that were currently being marketed included architectural and engineering services, troughs, central receivers, and collectors. There were also a handful of specialized products and components such as Rankine engines, Brayton power systems, and power conversion equipment. The actual sales revenue of the marketed goods was small, but not insignificant. For the 28 firms that were currently marketing, the average sales in 1980 was $\$ 1,763,000$, with the median being $\$ 60,000$. Twelve of the 28 firms expected to make a profit on STES in 1981, and the average number of years until the 28 firms expect to make a profit is approximately two. 
When asked to rate the marketing channels for distributing their products, only eight of the 28 rated them as "Very or Quite Adequate". The major perceived distribution problems were lack of consumer awareness of the products, lack of consumer demand, lack of marketing personnel in STES, and lack of intormation about customers.

The majority believed that funding from the Department of Energy reduced the cost of developing STES products or services and, when asked to estimate how much in additional funds it would have cost their firm to develop the technology themselves, the average estimate was $\$ 13,488,000$, though the median was $\$ 1,037,500$. Although these figures are speculations, they give some feeling for the savings induced through DOE support of STES development.

When the current marketing patterns were examined according to production type, large differences were found (Table 18). For distributed systems and central receivers, a higher proportion of the "turnkey" manufacturers were currently marketing than those producing engineering, subsystems, or components, while none of the "pure" K\&D firms were currently marketing products. Firms were in different stages of product development for all three

Table 18. Percent of Firms Currently Marketing by Typology.

\begin{tabular}{|c|c|c|c|}
\hline & $\begin{array}{l}\text { DISTRIBUTED } \\
\text { SYSTEMS }\end{array}$ & BOWLS & $\begin{array}{l}\text { CENTRAL } \\
\text { RECEIVERS }\end{array}$ \\
\hline $\begin{array}{l}\text { "TURNKEY" } \\
\text { SYSTEMS }\end{array}$ & TYPE 1 & TYPE 4 & TYPE 7 \\
\hline $\begin{array}{l}\text { ENGINEERING, } \\
\text { SUBSYSTEMS, } \\
\& \text { COMPONENTS }\end{array}$ & TYPE 2 & TYPE 5 & TYPE 8 \\
\hline $\begin{array}{l}\text { "PURE" } \\
\text { R\&D }\end{array}$ & TYPE 3 & TYPE 6 & TYPE 9 \\
\hline
\end{tabular}


technologies, and those doing pure research were farther from marketing than others. The production typology clearly distinguishes these different stages and indicates that the three different technologies do not differ so much among themselves in terms of being near or far from marketing, but rather, each can be interpreted to represent different products in different stages of development. The critical difference is in functions, rather than technologies. There were near-term distributed systems, such as the trough and low-temperature dish, and there were also far-term distributed systems, such as the high-temperature dish. Similarly, there were near-term central receiver projects, such as Solar One at Barstow, and far-term, such as "second-generation" heliostat development. To characterize any of these technologies as being either near- or far-term is to make a gross oversimplification.

When the production types and organizational characteristics of firms are used to predict whether or not they were currently marketing, two variables were found to have significant relationships and one variable showed a weak relationship (Figure 8). Type 3 firms - "pure" R\&D on distributed systems -

Figure 8. Predictors of Current Marketing.

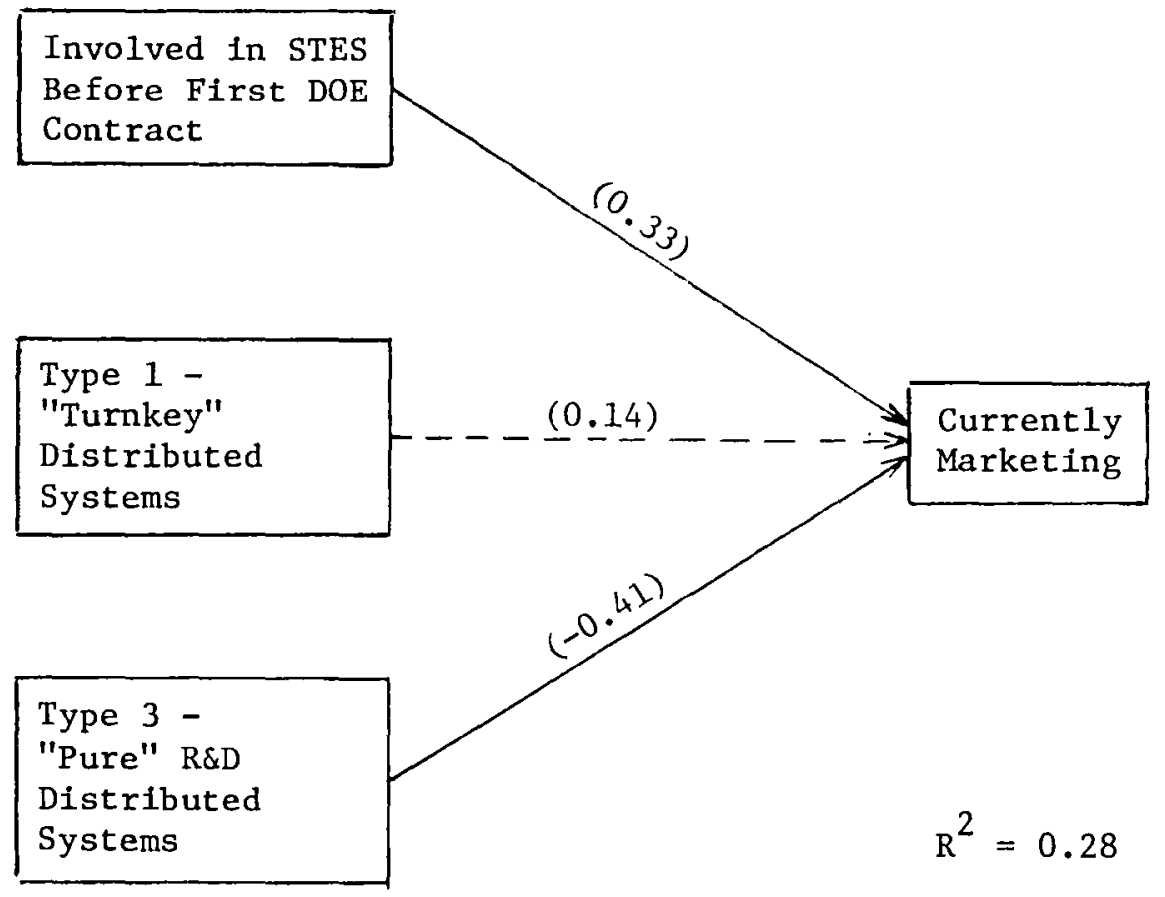


had the lowest percentage that were currently marketing while Type 1 firms "turnkey" distributed systems - had the highest percentage that were currently marketing. In addition, firms that were involved in STES before their first Department of Energy contract ( $56 \%$ of all firms) were more likely to be currently marketing. Thus, early activity appears to have been a critical variable in affecting which firms were currently marketing.

Early activity also seems to be a critical factor for predicting future marketing plans. When the consequences of currently marketing were examined, it was apparent that firms which were currently marketing were more likely to market in the future. Table 19 presents the correlations between the variable currently marketing and a number of variables assessing future marketing concerns. As can be seen, firms that were currently marketing had a stronger future marketing orientation. They were more concerned with the cost of competing energy sources, rather than with the solutions to R\&D problems. They had shorter time estimates for the number of years it will take until their product is competitive without DOE support (an almost significant relationship). They were more likely to market in the future and were more likely to market every type of function. They were more likely to continue their technology development efforts if the DOE STES program were discontinued and were more likely to maintain their level of funding. They were also more likely to enter the market first rather than wait for competitors or for a developed market.

These firms were involved in STES before their first DOE contract, suggesting a strong commitment that is, to some extent, independent of government support. It does not follow, however, that they do not want any federal support. Rather, it points out that firms which were involved in STES prior to the government program are more likely to be committed to the technology over the long run. Because these are the firms more likely to market in the future, current government policy might be directed toward them to help develop a strong and competitive technology base.

\section{Uncertainties in Making STES Competitive}

The respondents were asked to rate three uncertainties in making commercially viable solar thermal products: 1) solutions to research and development problems; 2) the cost of competing energy sources; and 3 ) the 
Table 19. Consequences of "Current Marketing".

Pearson " $r$ " Correlations

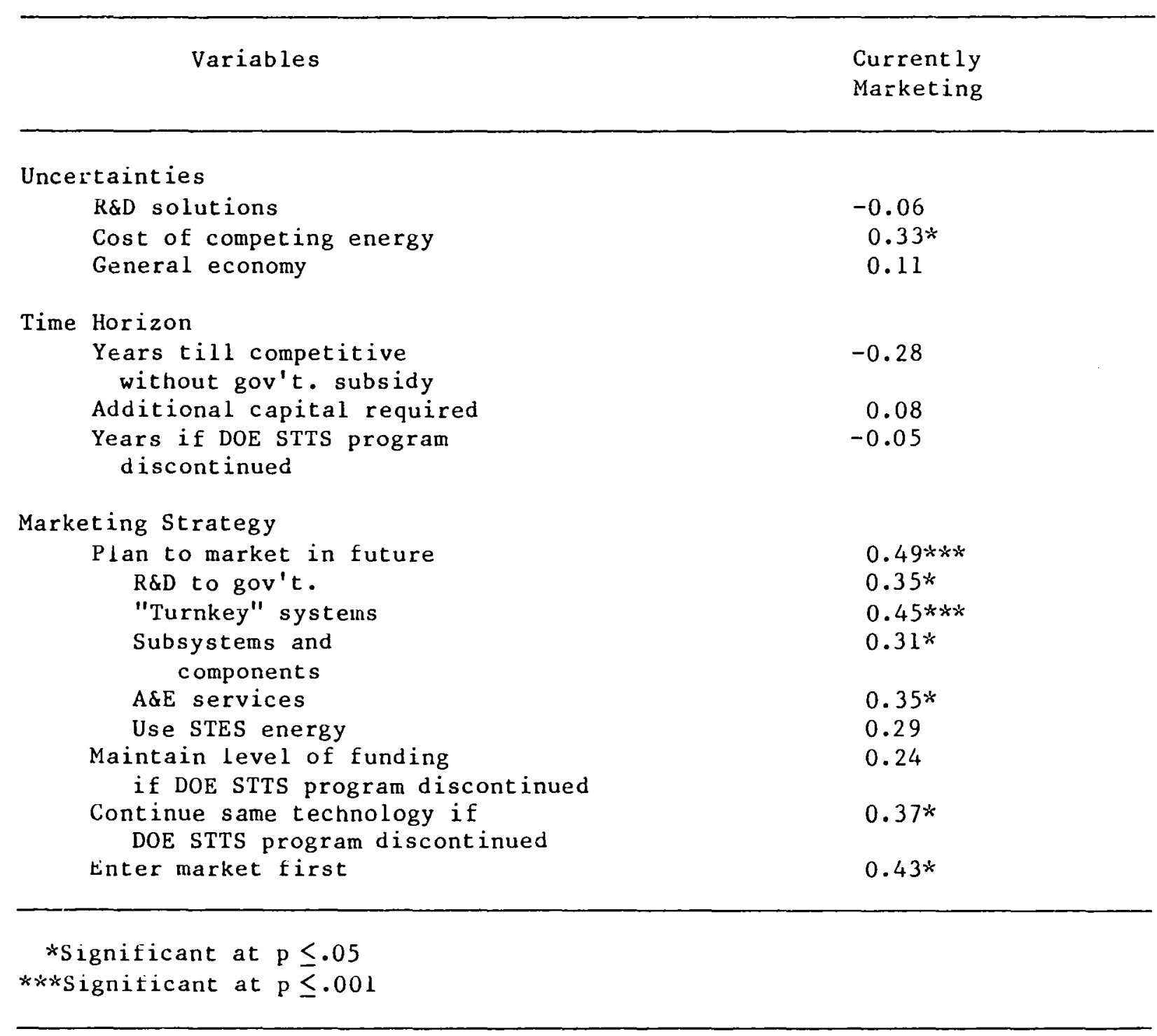


general economic climate. Table 20 presents the results and the intercorrelations among the three. The majority of firms believed that the

Table 20. Perceived STES Uncertainties and their Correlations.

\begin{tabular}{|c|c|c|c|c|c|}
\hline \multirow{2}{*}{ Uncertainty } & \multicolumn{2}{|c|}{ Perception } & \multicolumn{3}{|c|}{ Pearson " $r$ " Correlations } \\
\hline & Yes & No & $\begin{array}{l}\text { Solutions } \\
\text { to R\&D }\end{array}$ & $\begin{array}{l}\text { Cost of } \\
\text { Competing } \\
\text { Energy }\end{array}$ & $\begin{array}{l}\text { General } \\
\text { Economy }\end{array}$ \\
\hline Solutions to $R \& D$ & 23 & 30 & 1.00 & -0.08 & -0.04 \\
\hline $\begin{array}{l}\text { Cost of Competing } \\
\text { Energy }\end{array}$ & 40 & 13 & & 1.00 & $0.40 * x$ \\
\hline General Economy & 42 & 11 & & & 1.00 \\
\hline
\end{tabular}

$* *$ Significant at $\mathrm{p} \leq .01$

general economic climate and the cost of competing energy sources were the greatest uncertainties while less than half believed that solutions to $R \& D$ problems were uncertainties. There is clearly a relationship between the perceived cost of competing energy sources and the general economic climate, but there is no relationship between these two indices and perceived R\&D uncertainties. The cost of competing energy sources affects the economic viability of solar thermal technologies, but the cost of competing energy sources is interrelated with the state of the general economy.

Underlying these responses was a general concern regarding the economic viability of STES. One manager stated, "When looking at other alternative technologies, solar thermal does not come out on top of the list in terms of economic viability. We would rank wind energy systems as being closer to economic viability." Another stated, "Solar thermal is both conversion equipment and a fuel. Fossil fuel is only classified as a fuel and can be 'expensed'. Solar thermal has big capitalization; it is a disincentive to use anything but fossil fuels for a big user." And yet another, "The problem is not solutions to R\&D but that you can't get investment (risk) capital to do development work. Even the best solar mousetrap in the world wouldn't get 
risk capital." In short, there was concern regarding the economic viability of STES. When asked whether there was any other major uncertainty, economic uneasiness emerged on top. There were eight mentions that STES was not economical, six mentions about the capital cost of the technology, and five mentions of lack of public information and awareness. Other concerns were political: four mentions of the consistency of DOE policy and four comments about whether or not the program would continue. One quote: "The problem is the need for a national energy plan which is consistent; that is, one that doesn't blow with the winds of political change."

The ratings of the two major categories of uncertainties - R\&D solutions and the cost of competing energy sources - were examined by the different production types. Regarding R\&D solutions, there was not much of a pattern (Table 21). Fewer "pure" R\&D types rated solutions to R\&D problems as an uncertainty than the other two functions. But aside from this there was very little relationship. The bowl producers, Type 4 - "turnkey" bowls - and Type 5 - engineering, subsystems, and components on bowls - rated R\&D solutions more highly than other types. On the other hand, there were large differences among the different types in rating the cost of competing energy sources as an uncertainty (Table 22). The manufacturing types rated the cost of competing energy sources as more a major uncertainty than the "pure" R\&D types (with the exception of bowls).

When each of these uncertainties is tested against the production types, the organizational characteristics, and the current marketing factor, a model of the concern for each of the uncertainties (Figure 9) can be developed. For those firms more concerned with the solutions to R\&D problems, one finds Type 8 firms - engineering, subsystems, and components on central receivers, firms with larger STES R\&D budgets, firms that were not involved in STES before their first DOE contract, and firms that were currently under DOE contract. In short, large firms that were working on central receivers and entered the technology because of DOE support were more concerned with the solutions to R\&D problems. In terms of the determinants of concern for the cost of competing energy sources, one finds Type 2 firms - engineering, subsystems, and components on distributed systems - and Type 9 firms - "pure" R\&D on central receivers, firms with large total research budgets, firms that were currently marketing, and firms that were not involved in STES before DOE. The strongest relationships in this regression are for the total R\&D budget and 
Table 21. Percent of Firms that Perceived R\&D Solutions as Uncertainty.

\begin{tabular}{|c|c|c|c|}
\hline & $\begin{array}{c}\text { DISTRIBUTED } \\
\text { SYSTEMS }\end{array}$ & BOWLS & $\begin{array}{c}\text { CENTRAL } \\
\text { RECEIVERS }\end{array}$ \\
\hline $\begin{array}{l}\text { "TURNKEY" } \\
\text { SYSTEMS }\end{array}$ & TYPE 1 & TYPE 4 & TYPE 7 \\
\hline $\begin{array}{l}\text { ENGINEERING, } \\
\text { SUBSYSTEMS, } \\
\& \text { COMPONENTS }\end{array}$ & $\begin{array}{l}\text { TYPE } 2 \\
32 \%\end{array}$ & $\begin{array}{l}\text { TYPE } 5 \\
75 \%\end{array}$ & TYPE 8 \\
\hline $\begin{array}{l}\text { "PURE" } \\
\text { R\&D }\end{array}$ & TYPE 3 & TYPE 6 & TYPE 9 \\
\hline
\end{tabular}

Table 22. Percent of Firms that Perceived Competing Energy as Uncertainty.

\begin{tabular}{|c|c|c|c|}
\hline & $\begin{array}{c}\text { DISTRIBUTED } \\
\text { SYSTEMS }\end{array}$ & BOWLS & $\begin{array}{l}\text { CENTRAL } \\
\text { RECEIVERS }\end{array}$ \\
\hline $\begin{array}{l}\text { "TURNKEY" } \\
\text { SYSTEMS }\end{array}$ & TYPE 1 & TYPE 4 & TYPE 7 \\
\hline $\begin{array}{l}\text { ENGINEERING, } \\
\text { SUBSYSTEMS, } \\
\& \text { COMPONENTS }\end{array}$ & TYPE 2 & TYPE 5 & TYPE 8 \\
\hline $\begin{array}{l}\text { "PURE" } \\
\text { R\&D }\end{array}$ & TYPE 3 & TYPE 6 & TYPE 9 \\
\hline
\end{tabular}


Figure 9. Multiple Regression Predictors of Two Uncertainties.
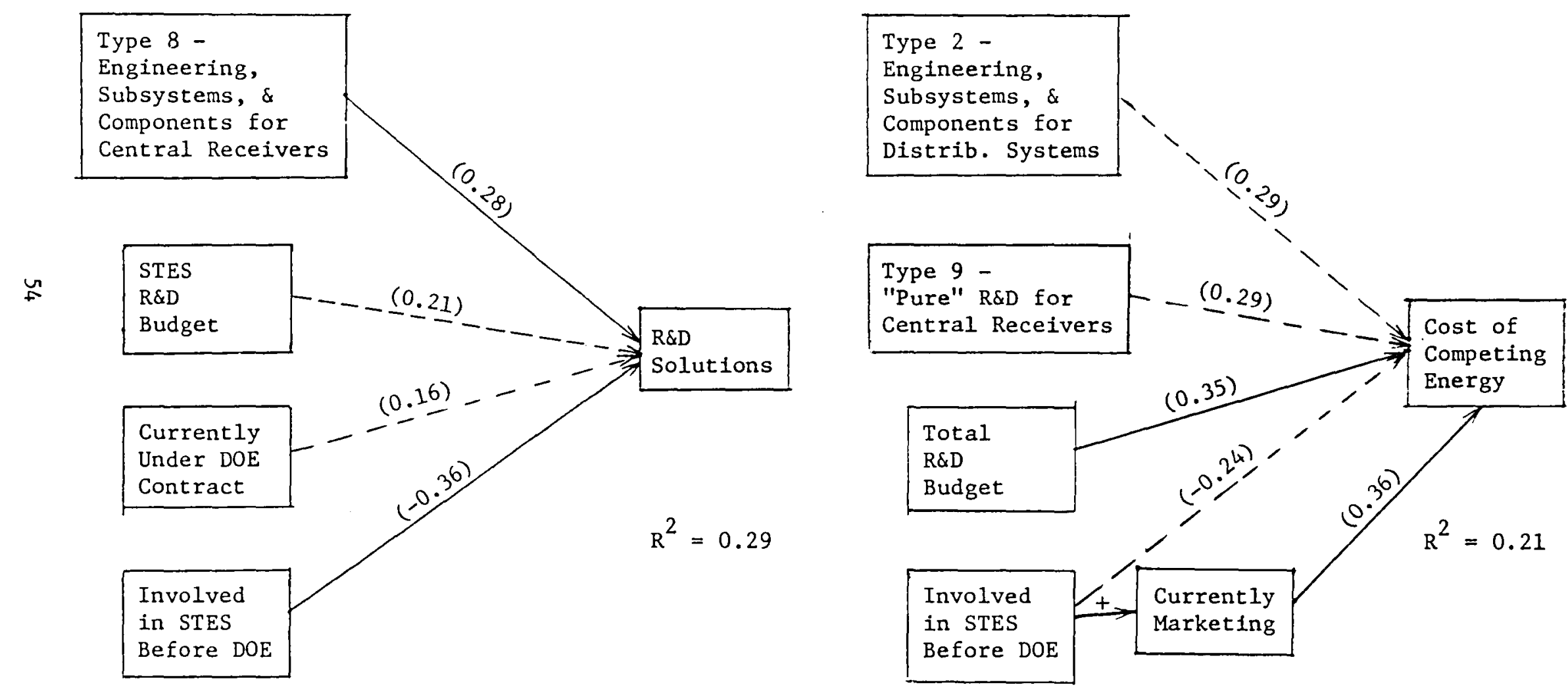

Significant, $\mathrm{p} \leq .05$

Weak, $p \leq .10$ 
for current marketing. Thus, there appears to be a greater concern by firms that were more likely to market in the near future or that were large and had large energy costs.

Future Marketing Plans

The majority of firms planned to market STES products or services in the future (Table 23); all those currently marketing were planning future marketing, and a majority of those not currently marketing also planned to do so. There was a strong sense of comitment to market in the future, suggesting a great deal of optimism. Respondents predicted that their firms

Table 23. Distribution of Firms that are Planning to Market in the Future (Question 16).

\begin{tabular}{crc}
\hline Plan to Market & Number of Firms & Percent \\
\hline Yes & 45 & 83 \\
No & 9 & 17 \\
\hline
\end{tabular}

will market a wide range of products and services. Seventy-four percent expected to supply R\&D to the government; $72 \%$ expected to supply architectural and engineering services; and $60 \%$ expected to produce both "turnkey" systems and engineering, subsystems, and components. The only activity that a majority of firms did not plan to do was to use energy produced from STES $(38 \%)$. Further, there are strong positive relationships among all these functions as indicated by the intercorrelation matrix (Table 24).

At this early stage in the development of the technology, many producers may not have clear perceptions of the scope of the market and the limits to their production. It is possible that the high intercorrelations are indications that firms will commit themselves to everything unless it is later shown to be uneconomic. In five years, these producers will undoubtedly have a much clearer view of the limits of the market than they do now.

The suppliers were asked what products or services they will market in the future. The most commonly mentioned items were distributed system products: troughs, dishes, industrial process heat systems, and collectors; 
Table 24. Correlations Among Future Marketing Functions Firms Will Provide.

\begin{tabular}{|c|c|c|c|c|c|}
\hline & \multicolumn{5}{|c|}{ Pearson " $r$ " Correlations } \\
\hline & $\begin{array}{l}\text { R\&D to } \\
\text { Gov't. }\end{array}$ & $\begin{array}{l}\text { "Turnkey" } \\
\text { Systems }\end{array}$ & $\begin{array}{l}\text { Subsystems } \\
\text { or } \\
\text { Components }\end{array}$ & $\begin{array}{l}\text { AdE } \\
\text { Services }\end{array}$ & $\begin{array}{l}\text { Using } \\
\text { STES } \\
\text { Energy }\end{array}$ \\
\hline R\&D to Gov't. & 1.00 & $0.51 * x * x$ & $0.54 * * * *$ & $0.79 * * * x$ & 0.21 \\
\hline $\begin{array}{l}\text { "Turnkey" } \\
\text { Systems }\end{array}$ & & 1.00 & $0.56 * * * x$ & $0.51 * * * x$ & $0.29 *$ \\
\hline $\begin{array}{l}\text { Subsystems } \\
\text { Components }\end{array}$ & & & 1.00 & $0.40 * *$ & $0.44 * x$ \\
\hline A\&E Services & & & & 1.00 & 0.21 \\
\hline $\begin{array}{l}\text { Using STES } \\
\text { Energy }\end{array}$ & & & & & 1.00 \\
\hline $\begin{array}{l}* \quad \text { Significant at } \\
* * \quad \text { Significant at } \\
* * * \text { Significant at }\end{array}$ & $\begin{array}{l}\mathrm{p} \leq .05 \\
\mathrm{p} \leq .01 \\
\mathrm{p} \leq .001\end{array}$ & & & & \\
\hline
\end{tabular}

central receivers were also mentioned. There was also a range of components and subsystems that could be used for several technologies: control systems, gas turbines, Rankine engines, positioning systems, power conditioners, and thermal storage. Respondents were also asked what they perceived to be their nearest term market and their best far-term market. The two lists are fairly similar. For the near-term markets, industrial process heat, products to electric utilities, products to government, and products to remote site users were all mentioned. For the best far-term market, industrial process heat, electric utilities, third-world remote-site applications, and government products were mentioned. Both the near- and best far-term markets most frequently mentioned were heat applications for industry and electricity applications for utility companies. In terms of the technologies these markets reflect, both distributed systems and central receivers were indicated almost equally. 
A regression equation was constructed to predict the general intent to market in the future (Figure 10); three variables showed significant or almost

Figure 10. Determinants of Future Marketing Plans.

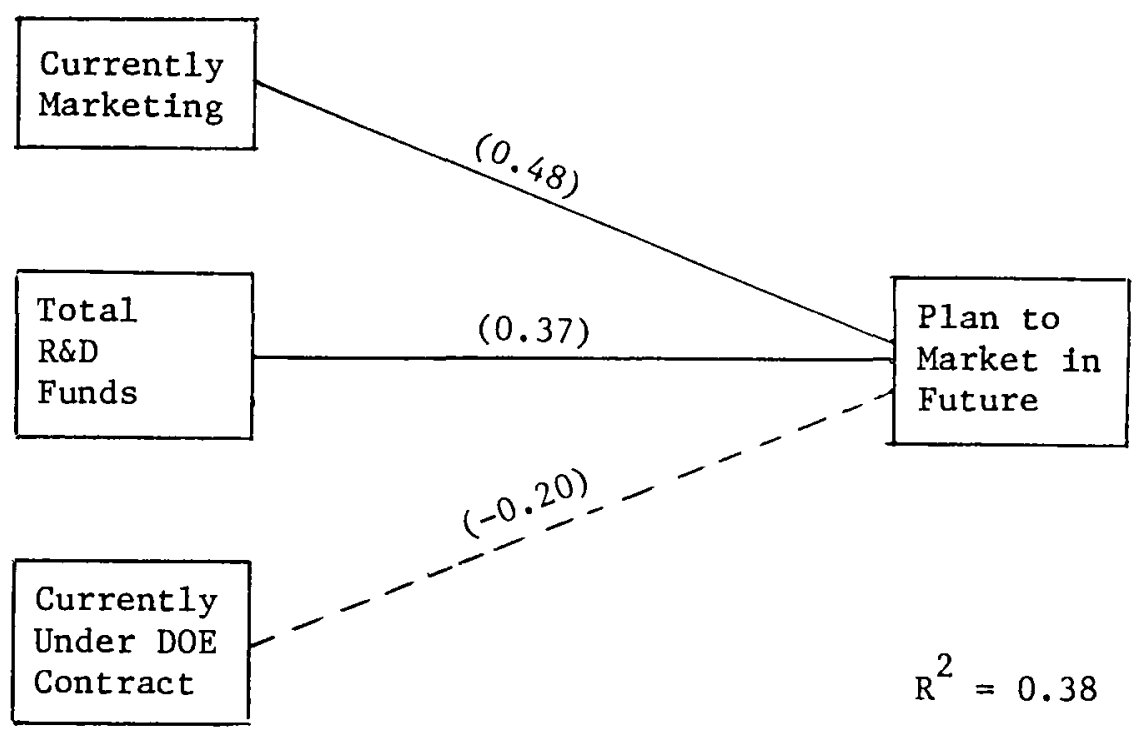

significant coefficients: 1) firms that were currently marketing; 2) firms that had larger total research budgets; and 3) firms that were not currently under DOE contract. In short, large and medium firms that were currently marketing are more likely to market in the future.

\section{Commitment to STES if STTS Program Discontinued}

An important question concerned the commitment to STES independent of support from DOE. Firms were asked if they would continue STES development if the Department of Energy STTS program were discontinued next year (Table 25).

Table 25. Distribution of Firms That Would Continue Same Technology if STTS Program Discontinued.

\begin{tabular}{ccc}
\hline Continue & $\begin{array}{c}\text { Number } \\
\text { of Firms }\end{array}$ & Percent \\
\hline Yes & 26 & 53 \\
No & 23 & 47 \\
\hline
\end{tabular}


Fifty-three percent would continue, while $47 \%$ would not; one firm said it would change to a different solar thermal technology. There are slight differences among the different production types (Table 26): Type 1 firms "turnkey" distributed systems, were more likely to continue if the STES program is discontinued; Type 3 firms - "pure" R\&D on distributed systems, Type 9 firms - "pure" R\&D on central receivers, Type 4 firms - "turnkey" bowls, and Type 7 firms - "turnkey" central receivers, were least likely to continue. Although Type 1 firms were more near-term in marketing, and more likely to continue development if the federal program were discontinued, a sizeable proportion would still drop out if the program is discontinued.

Table 26. Percent of Firms that will Continue STES Development if DOE STTS Program Discontinued.

\begin{tabular}{|c|c|c|c|}
\hline & $\begin{array}{l}\text { DISTRIBUTED } \\
\text { SYSTEMS }\end{array}$ & BOWLS & $\begin{array}{l}\text { CENTRAL } \\
\text { RECEIVERS }\end{array}$ \\
\hline $\begin{array}{l}\text { "TURNKEY" } \\
\text { SYSTEMS }\end{array}$ & TYPE 1 & TYPE 4 & TYPE 7 \\
\hline $\begin{array}{l}\text { ENGINEERING, } \\
\text { SUBSYSTEMS, } \\
\text { \& COMPONENTS }\end{array}$ & TYPE 2 & TYPE 5 & TYPE 8 \\
\hline $\begin{array}{l}\text { "PURE" } \\
\text { R\&D }\end{array}$ & TYPE 3 & TYPE 6 & TYPE 9 \\
\hline
\end{tabular}


More worrisome would be the consequences to the distribution of firm size participating in STES development. Figure 11 presents the rank-size distribution of firms by their total STES budget, comparing the total distribution with the distribution of firms that would remain if the DOE STTS program were discontinued. The rank-order of firms is indicated along the $\mathrm{X}$-axis and the amount of funds along the Y-axis. The most obvious loss is one large firm (rank 2) and a number of medium firms (ranks 7-12). The effect of this would be to produce a more "skewed" distribution of firms, with one very large firm, three large firms, a few medium firms, and the remainder being small firms.

\section{Figure 11. Rank-Size Distribution of Al1 Firms by STES R\&D Budget for Those That Will Continue if STTS Program is Discontinued.}

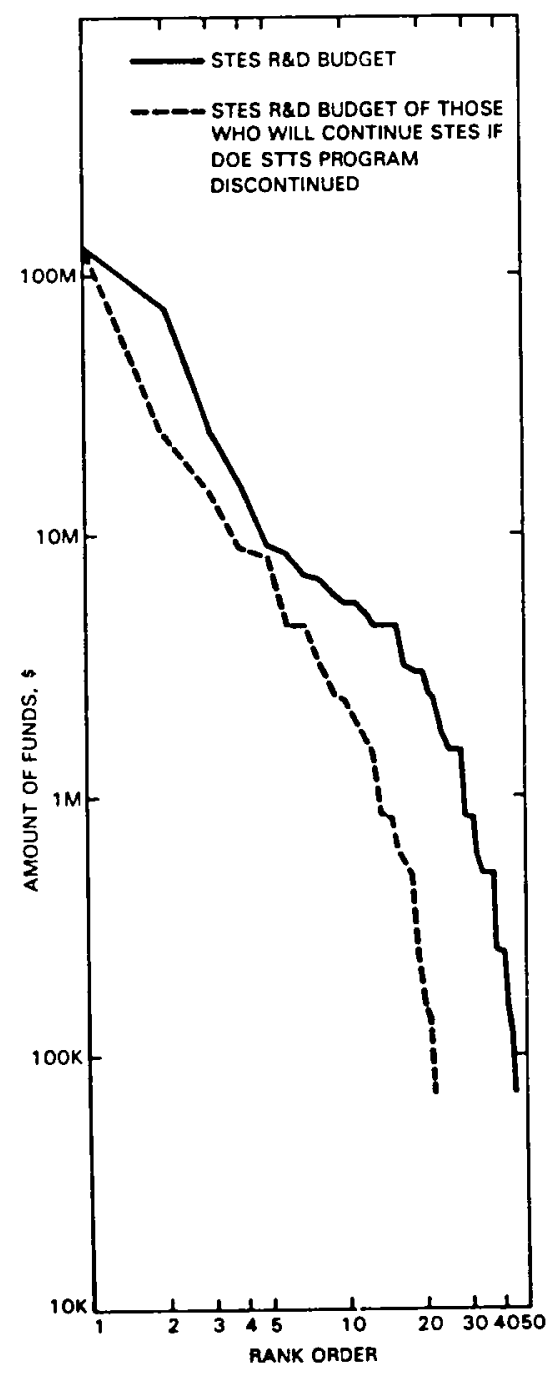


Whether the effects of this change in distribution would be beneficial or harmtul for the development of STES cannot be gauged from this data, but it is a consequence that must be considered. The same effect tends to be consistent for each of the major technologies as well. Figure 12 presents the rank-size distributions for firms developing central receivers. As can be seen, firms ranked $2,4,6,7,8,9,10$, and 15 would drop out, as well as some of the smaller firms.

Figure 12. Rank-Size Distribution of Central Receiver Firms by Total STES R\&D Budget for Those That Will Continue if STTS Program is Discontinued.

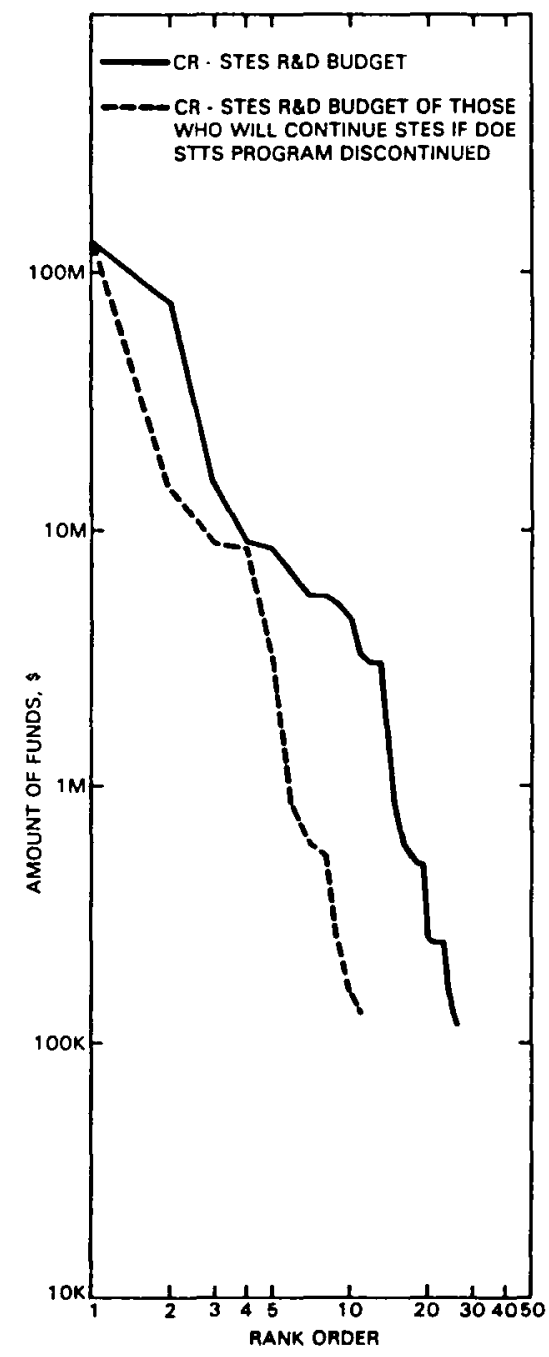


Figure 13 presents the rank-size distributions for firms developing troughs. Firms ranked $3,4,5,6,7$, and 10 would drop out, as well as some smaller

Figure 13. Rank-Size Distribution of Trough Firms by Total STES R\&D Budget for Those That Will Continue if STTS Program is Discontinued.

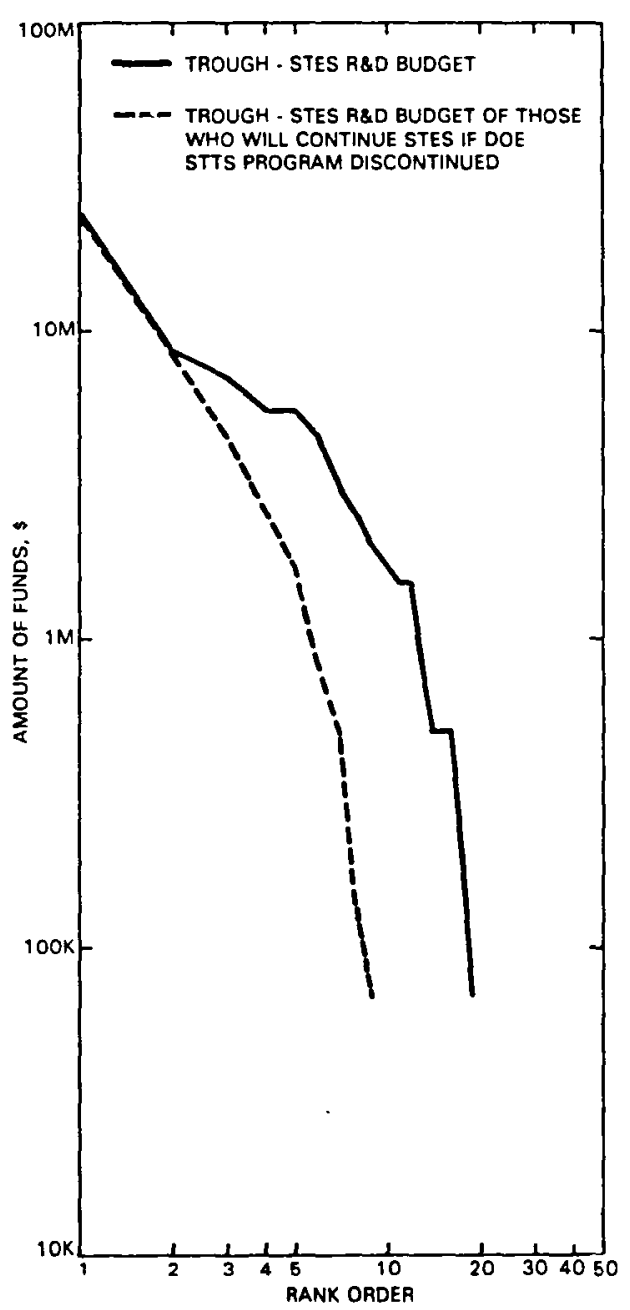


firms. Figure 14 presents the comparable rank-size distributions for firms developing dishes. Here, firms ranked $3,4,5,6,8,9,10,11$, and 12 would drop out, as well as some smaller firms. In short, many of the

Figure 14. Rank-Size Distribution of Dish Firms by Total STES R\&D Budget for Those That Will Continue if STTS Program is Discontinued.

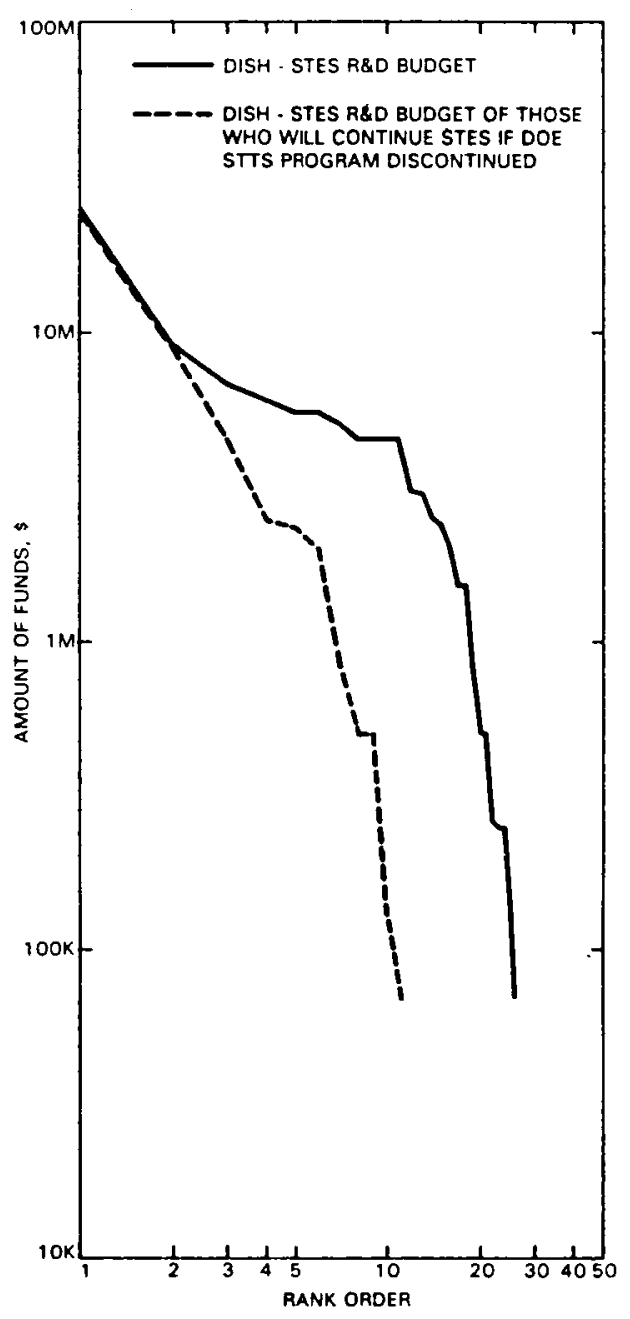


medium-to-large firms developing each of these technologies would drop out, leaving the development to several large firms, only a few medium firms, and many small firms. As one manager tactfully put it, "There is a fragile industrial infrastructure presently existing in the solar thermal market and any public policy (budgetary or other) that indicates a reduction of support would be tantamount to the unraveling of this fragile infrastructure. The only alternative would be to seek foreign sources of these vital raw materials and finished products."

Perceived Time Horizon

The commitment to continue developing STES if the government program is discontinued is primarily related to the viability and vulnerability of the product the firm is developing. It is not that firms choose to develop the technology because DOE encourages them to do so, but rather because they perceive DOE cushioning the risks involved in developing the technology to the point where it will one day be economic. Figure 15 presents a schematic diagram of a number of interrelated regression equations. The decision to continue developing STES is primarily related to the nearness of the product to market; the shorter the perceived time horizon until it is competitive, the more likely the firm is to continue if the STTS program ends. Large firms are more likely to continue than medium or small firms. The commitment to continue is related to a marketing strategy whereby firms were more likely to enter the market first rather than wait for competitors or a developed market. Overall, 53\% intended to enter the market first, while $25 \%$ will wait for competitors and $22 \%$ will wait for a developed market. But a strategy of entering the market first is also related to the perceived time horizon for making the product economically viable without government subsidy. Firms were asked to estimate how many additional years it would take to develop their product if the program ended and the average estimate was 6 years (with the median being 5). There was not much difference for the different production types in these estimates.

Thus, the perceived time horizon is an important intermediate variable affecting the firm's future marketing strategy. The time horizon is a function of the technology that is being developed (Type 1 firms perceive shorter time horizons) but it also appears to be affected by federal support, which provides development capital and reduces the risks involved in developing the technology. Without this support, STES technology could be set back 
Figure 15. Perceived Time Horizon.

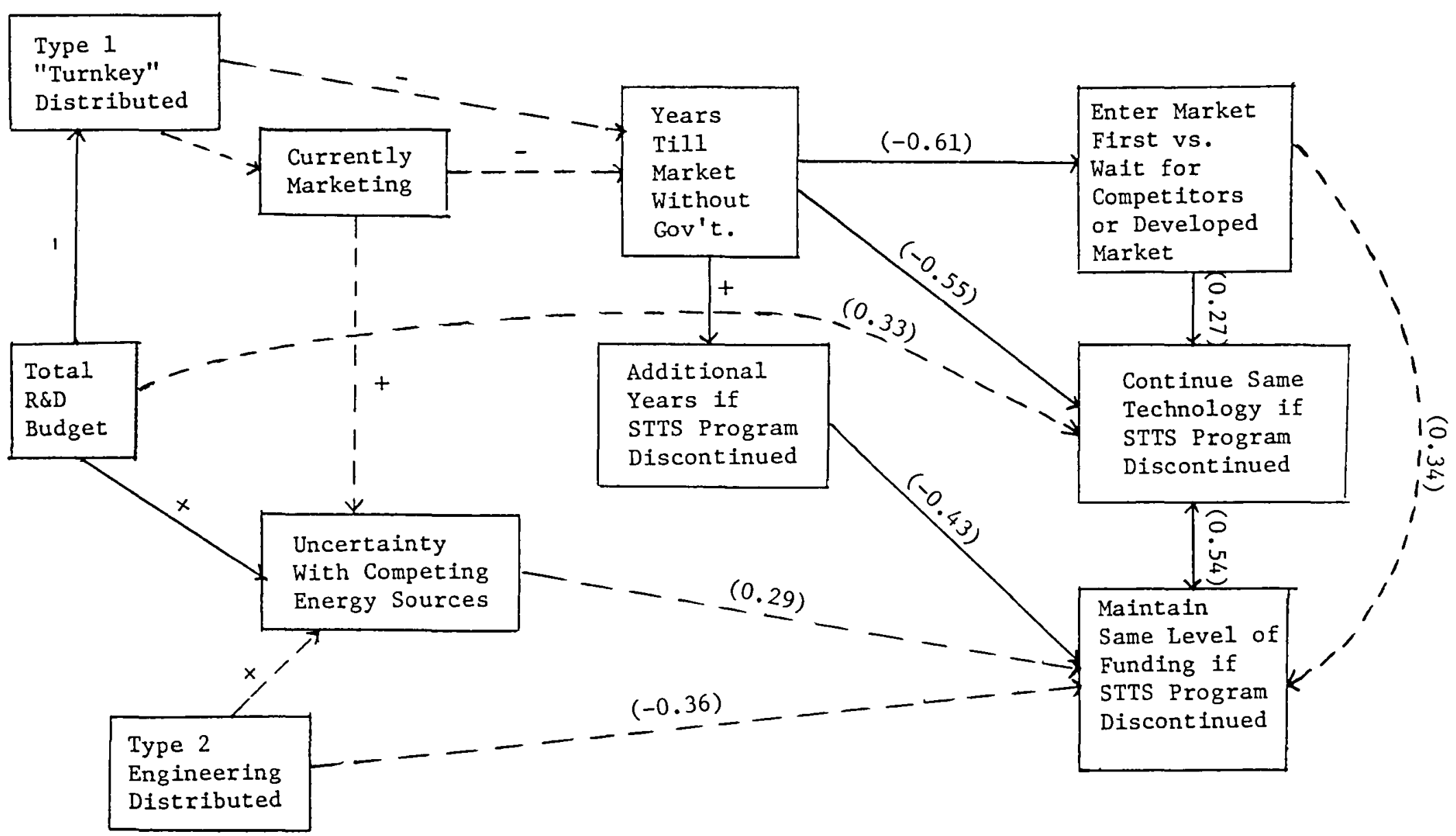


considerably in terms of the number of additional years it will take to develop the technology, the number of firms that will drop out, and the unequal size distributions of the firms that will remain in the industry. Government support of STES has benefited the development of the technology and has allowed a market to develop; if that support is taken away prematurely, the market structure may be harmed considerably.

\section{Needed Federal Support of STES}

However, firms are not relying on the federal government for an open, unending commitment to develop STES. They seem to make some fine, but important, distinctions in the types of support they perceived as needed. As shown in Table 27, most respondents agreed there was a need for federal support for testing prototypes at the system level. Almost as important was support for the development of components and subsystems, followed by

Table 27. Types of Federal R\&D Support Needed.

\begin{tabular}{lc}
\hline Type of Support & $\%$ Yes \\
\hline $\begin{array}{c}\text { Testing prototypes } \\
\text { Develop subsystems } \\
\quad \text { and components }\end{array}$ & 92 \\
$\begin{array}{c}\text { Conduct full-scale } \\
\text { system tests }\end{array}$ & 89 \\
$\begin{array}{c}\text { Develop conceptual } \\
\text { designs }\end{array}$ & 83 \\
Perform basic research & 62 \\
\hline
\end{tabular}

full-scale system tests and user applications. Thus, developing components and subsystems and establishing reliable models was felt to need federal support the most; underlying this was the need to demonstrate that the systems work. Manufacturers were concerned that the public is not aware of solar thermal systems and believed that working prototypes would establish the technology as a legitimate alternative for the marketplace. 
In terms of other types of federal support needed, the vast majority mentioned investment tax credits (Table 28). There was also a perceived need for demonstration projects, a restatement of the above conclusions. Only about half the manufacturers favored deregulatory actions, the most frequently mentioned form being the deregulation of natural gas. In short, there is a strong need to establish the economic viability of the technology. Tax credits can reduce the costs of investment, but the technology will remain very vulnerable until it is fully working and is demonstrated to an unaware public.

Table 28. Types of "Other" Federal Support Needed.

\begin{tabular}{lc}
\hline Type of Support & $\%$ Yes \\
\hline Investment tax credit & 88 \\
Demonstration projects & 75 \\
Deregulation & 52 \\
\hline
\end{tabular}

On these points, there is little difference among the different production types (Table 29). Almost all agreed that prototypes, system tests, and component developments were needed. All these items were combined into a general scale for the need for federal support, and the scale was tested against all the other variables. Two variables resulted in almost significant relationships (Figure 16). Type 1 producers - "turnkey" distributed systems, expressed a slightly stronger concern for federal support, while firms with large STES research budgets also expressed a strong concern. 
Table 29. Policy Priorities for Different Production Typologies.

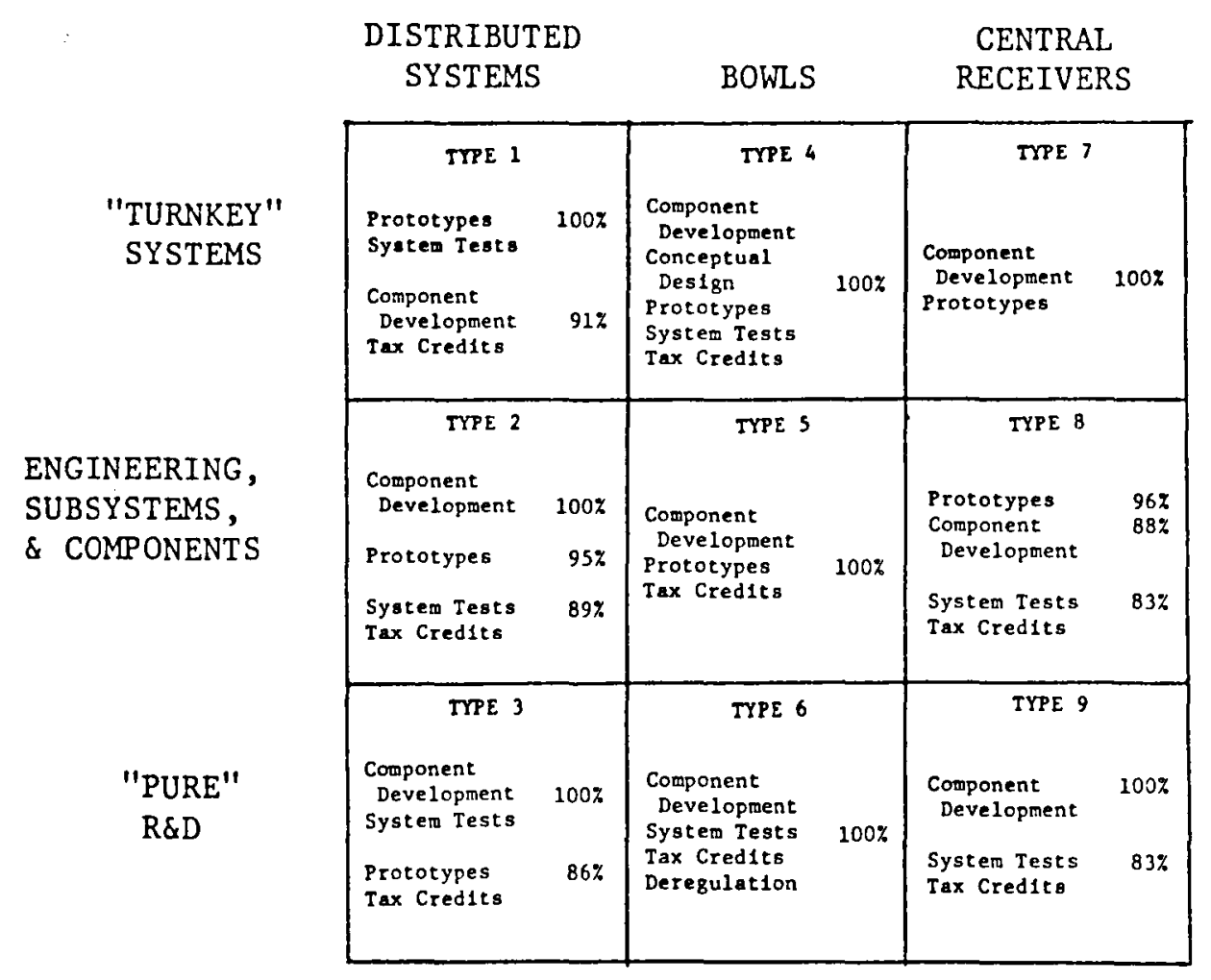

Note: Only the top priorities are listed for each type.

Figure 16. Predictors of Overall Federal Support Need.

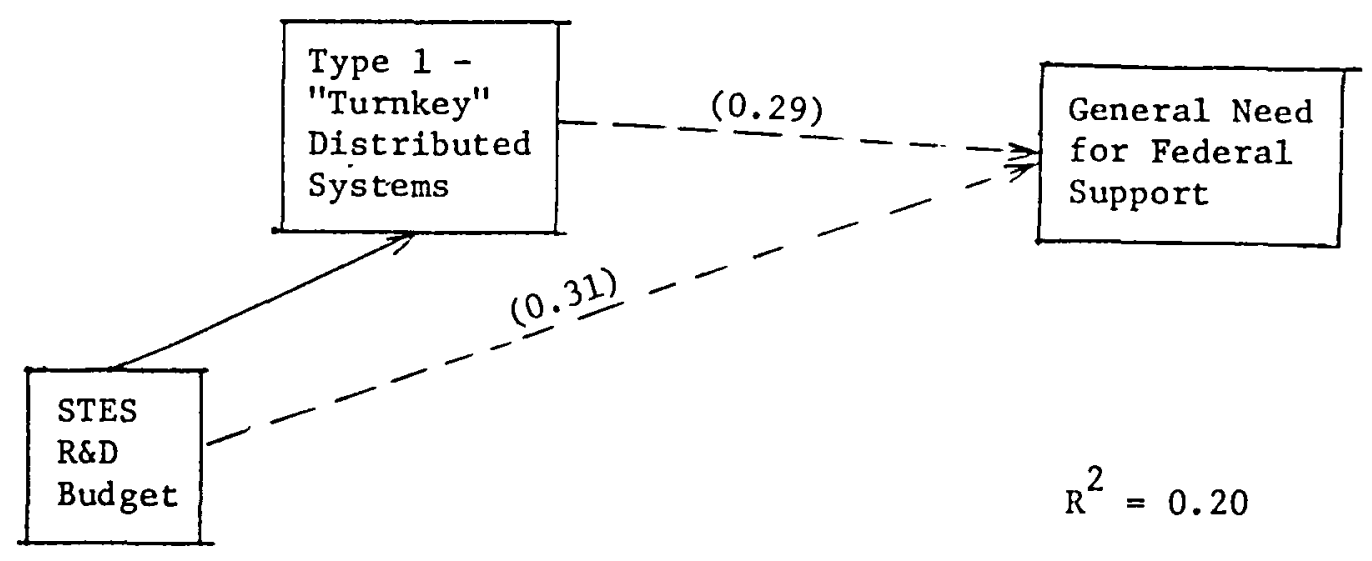




\section{Perceptions of the Department of Energy}

In spite of a strong perceived need for federal support, manufacturers were somewhat critical of the federal role in the development of STES. Table 30 presents a number of evaluations of the Department of Energy's Solar Thermal Technology Systems program. As can be seen, general evaluations of

Table 30. Perceptions of DOE STTS Program.

\begin{tabular}{lc}
\hline Evaluation: & \\
Good or Very Good & $33 \%$ \\
Fair & $40 \%$ \\
Poor or Very Poor & $27 \%$ \\
Number of Years Program Should Continue: & \\
Mean & 10.8 \\
Median & 9.5 \\
Mode & $20+$ \\
Appropriate Level for Annual Budget: & \\
Mean & $\$ 171.3 \mathrm{M}$ \\
Median & $\$ 140 \mathrm{M}$ \\
Mode & $\$ 200 \mathrm{M}$ \\
\hline
\end{tabular}

the program are "lukewarm". Thirty-three percent think that the program has been good or very good, $40 \%$ think that it has been fair, while $27 \%$ think that it has been poor or very poor. When asked for specific accomplishments of the program, there were 16 mentions of the development of various components, 10 mentions of the development of central receiver technology, eight mentions of bringing STES technology to maturity, and seven mentions each of the Solar One project at Barstow and providing public information. Thus, DOE was perceived as having accomplished component development, provided public information and encouraged the development of the technology to the point where it is marketable, especially central receiver systems. In terms of program deficiencies, there were 12 mentions of lack of commitment or sufficient funding to develop the technology further, seven each of lack of consistency in the program and lack of long-term goals, and four mentions of poor administration. Thus, the major criticisms appear to be administrative. DOE 
was perceived as being inconsistent and lacking long-term perspective -- "a lack of vision" is how one respondent characterized it.

When asked how many years longer the STES program should continue, the responses ranged from a minimum of 3 years (one response) up to an indeterminate amount ( 13 responses); this latter estimate was coded as $20+$ years. Thus, the mean number of years is 10.8 while the median is very close, 9.5 years. In short, most of the producers perceived the need for the program lasting throughout the 1980s, at least until the next decade. In terms of the amount of annual funding the program should have, the responses varied from a low of $\$ 35$ million (in current dollars) up to a high of $\$ 600$ million. The mean was $\$ 171.3$ million, while the median was very similar to the 1980 budget, $\$ 140$ million. In summation, the producers perceived a need for the STES program, in spite of being very critical of its administration, and believed it should be funded adequately until it accomplishes its goals. 
Intentionally Left Blank 
Two general conclusions have been reached as a result of the analysis. First, a differentiated policy approach may be more effective for the development of the STES technologies; and second, there is an important role for the federal government in developing solar thermal energy.

\section{Differentiated Policy Approach}

A more differentiated view of the technology is strongly suggested for policy and planning purposes. The size of the firm appears to be important in production decisions; the STTS program should be aware of size differences in developing plans. Previously, distinctions between large and small firms have been made, but this study suggests that distinctions between large, medium and small firms need to be made, because medium-size firms appear to be taking greater investment risks. The largest firms are working on both central receiver development and distributed systems. The small firms are involved primarily with central receivers but, to a lesser extent, with distributed systems as well; their role appears to be as sub-contractors to the large firms. Medium-size firms, on the other hand, tend to concentrate on distributed systems. If the dish and trough programs are cut back, many of these mediumsize firms may drop out of the technology, leaving a more skewed distribution (i.e., several very large firms, a few medium-size firms, and many small and very small firms). Particular concern should be directed toward ascertaining the effect of a more skewed distribution if the STTS program is discontinued. Whether such a distribution will be harmful, beneficial or neutral needs to be examined in detail. Intuitively, it would appear to be less than a desirable outcome. A very skewed industry might be stifling in terms of technology development. A large firm, just like a small one, will concentrate on a limited number of products. Several medium-size firms, as was shown, tend to spend a high proportion of their own funds compared to federal tunds. If these firms drop out of the marketplace, the technology will probably suffer. Although this is speculative, the effects of increased industrial concentration should be carefully considered.

Further, each technology, as defined by the Department of Energy, may actually be represented as several different technologies, each at different stages of development. While the STTS program has recognized these 
differences for funding purposes, it has tended to treat each technology as a single entity for planning and discussion. The production typology developed distinguishes the types on a number of variables that are a good starting point for presenting a differentiated policy approach. For example, Type 1 producers-- "turnkey" distributed systems--are the nearest to marketing; the types of support needed are demonstrations and tax credits. The time horizon for Type 1 can be shorter than other technologies, though if there is no support, almost half the firms indicated that they will drop out. On the other hand, both Type 3--"pure" R\&D on distributed systems--and Type 9--"pure" R\&D on central receivers--are farthest from marketing and will require support over a longer period. The advanced prototypes being developed (e.g., the high-temperature dish, second-generation heliostats) may, in the long run, produce higher performance at more optimal cost, but will take longer to develop. By utilizing these distinctions, trade-offs can be facilitated for policy and planning that were implicitly applied previously.

\section{Federal Support Need}

There is still a strong need for federal support with STES technology. Virtually all the firms perceived a need for continuing federal support, primarily because the technology is still in a vulnerable state. Even those firms closest to marketing (Type 1--"turnkey" distributed systems) expressed a very strong concern for continued federal support. STES technology is in the early stages of development, so that unit costs are expensive. Also, other energy sources are more competitive, at least in the short run (in particular, natural gas). Many producers may be gambling that the cost of these "cheap" alternatives will increase at a much faster rate than STES. It is a commitment for the future. In the short run, very. few producers can afford to maintain production of STES without some kind of federal support. At the very minimum, producers believe there should be tax credits available to help users purchase solar thermal equipment. But there also was a perceived need for the federal government to sponsor a number of demonstrations and system tests. The federal involvement does not only cushion producers from the economic realities of the market, but also, it allows them to take risks that they would not be able to take otherwise. Thus, those firms that take the greatest risks also need a strong federal involvement to fund research and 
develop the technology further, at least until such time that the marketplace can adapt itself to the new technology.

\section{Federal Government Role}

The federal role in STES development is very important. With a long-term perspective that is realistic both in terms of the role of solar in relationship to other energy sources and in terms of what STES options can be developed, the federal government can provide the necessary support to help the technology mature. Additionally, the federal government could provide an essential role in developing the long-term aspects of energy technology. Previously, a sharp distinction has been made between the role of the federal government in assisting energy technology development and the "marketplace". In the past, the goal of the program was to accelerate "commercialization"; this has more recently been adjusted to involvement only in "high-risk", long-term R\&D. In both, however, the distinction between the government and the marketplace was maintained, although few of the firms interviewed in this survey made such sharp distinctions. There was widespread agreement among the producers that the federal government should be involved in funding component development, demonstration projects and system tests. The program was criticized for inconsistent administration and lack of a long-term perspective, but few producers wanted to minimize the federal role. The technology is still in its infancy, and without federal support, it probably could not survive the marketplace. 
APPENDIX

A-1 


\section{FINAL FREQUERCIES}

IDI: :

FIRM

I.D. $\$$

STES MANUFACTURERS SURVEY

FIRM NAME:

CITY/STATE:

CONTACT PERSON:

TELEPHONE \#:

$$
\overline{\text { AREA CODE }}
$$

TIME BEGINNING:

AM TIME ENDING:

AM TOTAL \#

PM OF MINUTES:

MINLTES:

* OF MINUTES INTERRUPTION:

RECORD OF' CONTACT ATTEMPTS

\begin{tabular}{lllll}
\hline DATE DAY OF WK & TIME & RESULT INIEFVIEWER COMENTS
\end{tabular}

I.D.\#.

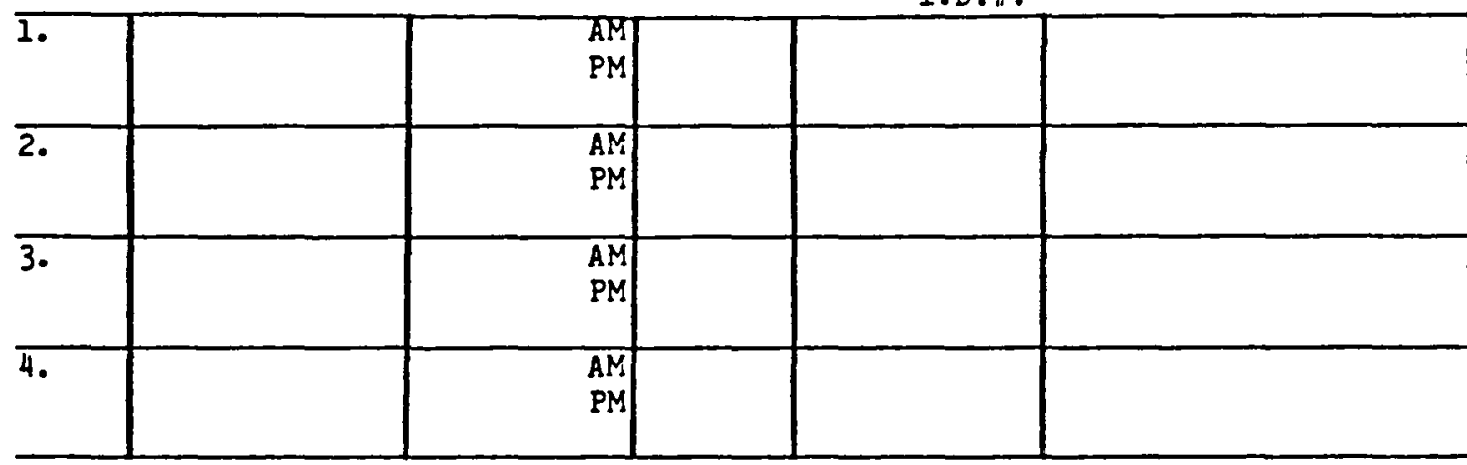

IF CONTACT CANNOT BE REACHED ON THIRD ATTEMPT, USE A PROXY CONTACT - A PERSON WHO IS KNOW"LEDGEABLE ABOUT THE STES PROGRAM IN FIRM.

RESULT

R NOT AVAIIABLE ....SPECIF Y ABOVE...01 CALL BACK ARRANGED.. SPECIFY ABOVE. ..02 R REFUSED.......... SPECIFY ABOVE...03 TERMINATED.......... SPECIFY ABOVE...04 INCAPABLE.......... SPECIFY ABOVE. ..05 COMPLETED WITH R............... COMPLETED WITH PROXY............07 INCOMPLETE. ..................08 OTHER.............. SPECIFY AROVE...O9

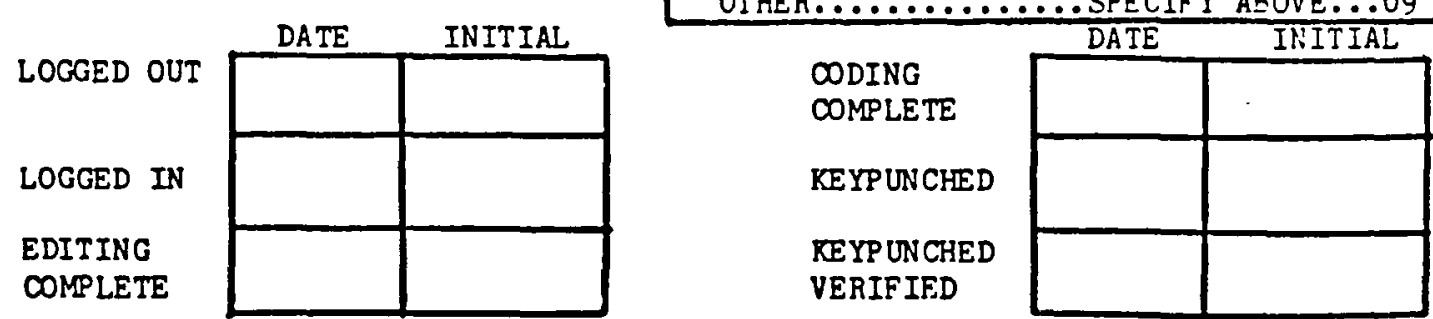




\section{ASR TO INITIAL CONTACT PERSON}

(Good morning/afternoon/evening). I'm from the Jet Propulsion Laboratory in Pasadena, California. We are conducting a survey for the U.S. Department of Energy of firms who have or have had contracts with the Department of Energy for the development of solar-tnerwal energy systems (STES). These are the technologies wnicn concentrate sunilgnt.

Yoar name has been provided as a person who is knowledgeable about solarthermal energy development within your firm (division). We need to Interview the hignest-ranking technical or marketing person responsible for solar-thermal energy systems witnin your firm (division).

Who would that person be?

IF MDRE THAN ONE PERSON MENTIONED, ASK: Which one of these persons would know the most about solar-thermal energy systers within your firm and would be able to present your firm's position with respect to solar-thermal energy systems?

NAME :

TITLE :

TELEPHONE : $\overline{A R E A ~ C O D E}$

IF CONTACT PERSON IS R, CONTINUE WITH INTERVIEW AND READ INFORMED CONSENT. 
I.D. $:$

I would like to read an informed consent statement to you.

We would like to obtain information about your current program with solar-thermal energy systems and about your development plans for the future. The information we obtain fran this study will be used for a general evaluation of the Department of Energy solar-tnermal program. The interview will take approximately 30 minutes. All information tnat is obtained $w^{2}+1$ be neld in the strictest confidence.

1. No information about individual firms will be released. Only - group results for the entire sample will be released.

2. Even thougn the Department of Energy will receive a report from the survey, they will not receive any data on individual firms.

3. None of the information you provide will be shown to any person at the Jet Propulsion Laboratory who is now or will be, in the foreseeable future, involved in the selection of contractors for future solar-tnermal energy systems procurements.

4. After the information has been recorded numerically in the computer, the individual identity of questionnalres will be destroyed.

We nave to make this guarantee of strict confidentiality in order to protect the rignts of individual firms.

Your participation in this survey is entirely voluntary and you may refuse to answer any question or terminate the interview at any time. However, your cooperation is very important because your firm is one of a select number who are central to the development of solar-tnermal energy systems. The information you provide will help in understanding the Impact of the solar-thermal energy systems program.

Again, you may be assured that your answers are strictly confidentlal. They will not be used for other than statistical purposes.

INTERVIEWER ACKNOWLEDGES READING INFORMED CONSENT STATEMENT. 
To start witn, I'd like to ask you some questions about your firm's involvement with solar-tnermal energy systems. Tnese are the tecnnologies which concentrate sunlignt.

1. - Is your firm currently working with any solar-thermal concentrating tecnnology? (developing or marketing a solar-tnermal concentrating product or service)

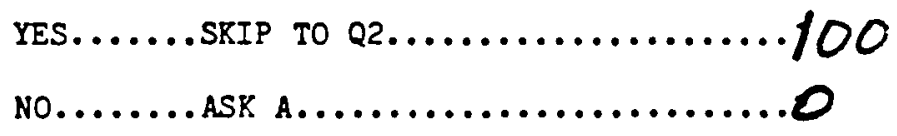

A. Does this wean that your firm is no longer working witn a solar-tnersal concentrating tecnnology?

YES...........................1

IA: (9)

- No................................

CLARIFY DISCREPANCY:

DS :

B. In what year did your firm stop working with solar-thermal

$1 B$ : tecnnologies? RECORD YEAR.

YEAR

STOPPED

STES

DEVELOPMENT :

$(11-14)$

SRIP TO S2 On

SPECIAL FORM, P. 20 
(1)

2. What types of solar-tnerwal concentrating technologies is your firm working on? Are they working on: READ a-e. CIRCLE ALL THAT APPLY.

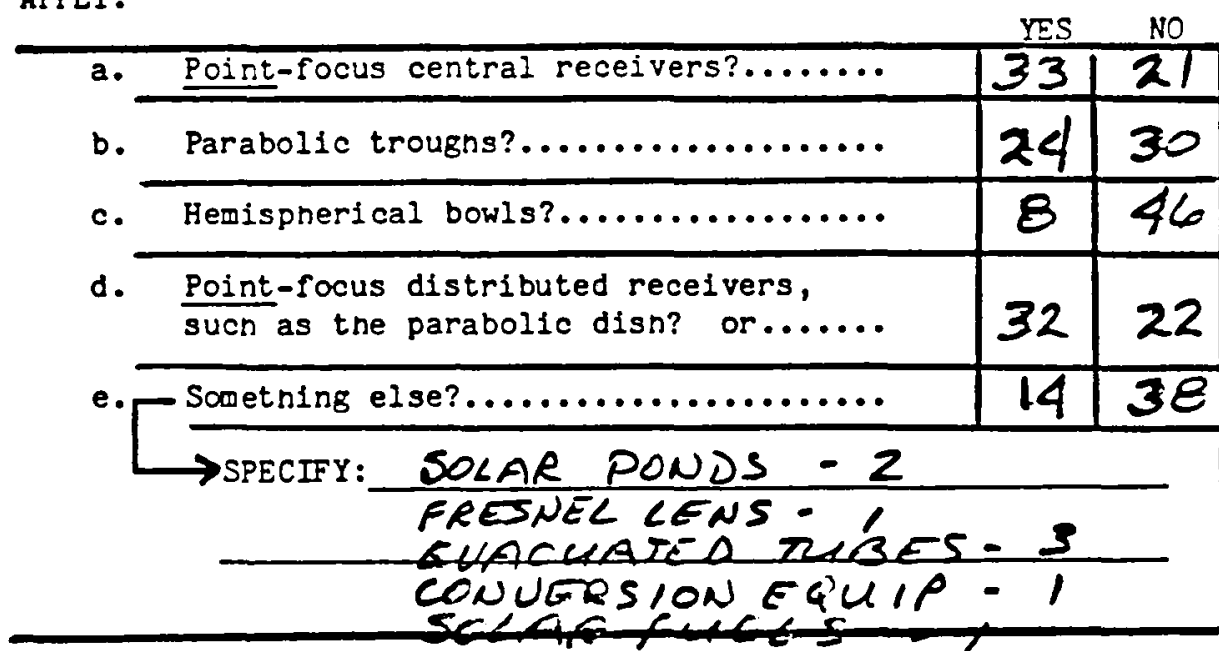

2a: (15)

$2 \mathrm{~b}: \quad(16)$

$2 c: \quad(17)$

$2 d: \quad(18)$

2e: (19)

I : $\overline{(20)}$

II:

$3 a: \quad(22)$

$3 b: \quad(23)$

3c: (24)

3d: (25)

3e: (26)

3f: (27)

I :

$(\overline{28}-\overline{29})$

II: $(\overline{3} \overline{0}-\overline{31})$ 
4. How many years has your I1m or 1ts predecessor been involved with solar-thermal energy systems development? RECORD YEARS.

$$
\begin{aligned}
& \text { NUMBER OF } \quad \bar{X}=6.3 \\
& \text { YEARS WITH } \\
& \text { STES: MED }=5.5
\end{aligned}
$$

5. Last year what was the average number of persons in your firm working on solar-tnermal systems? (full-t1me equivalent) RECORD NUMBER.

IN UNSURE, ASK: Approximately, how many people on average worked on solar-thermal systems?

4:

$\overline{(32}-\overline{33})$

5 : $(\overline{34}-\overline{37})^{-}$

6. Do you currentiy market any solar-tnemal product or service to commercial users? (otner than for Department of Energy-sponsored projects)

No,

R AND D ONLY.......SKIP TO $Q 12$, p. $9 . \ldots .26$

YES, ALSO

6: (38)

MARKET PRODUCT

OR SERVICE.........ASK Q7............ 8 
7. What type of solar-therwal energy product or service does your firm currently market? (or intend to market in the very near future)? LIST IN ORDER OF MENTION UP TO 3 PRODUCTS OR SERVICES. EXCLUDE SOLAR WATER HEATERS AND FLAT PLATE COLLECTORS.

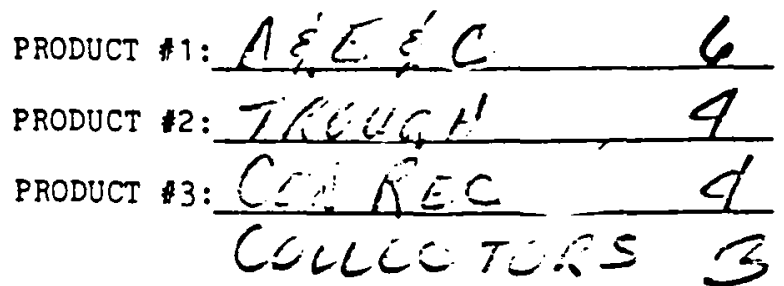

8. Last year, 1980, what was the total volume of sales, in dollars, of your firm's solar-thermal energy products or services? (Otner tnan for Department of Energy-sponsored projects.)? RECORD AMOUNT.

IF UNSURE, ASK: What would be your best guess?

$$
\begin{array}{ll}
\text { TOTAL } & \\
\text { DOLLARS } & X=1763 \\
\text { OF SIES } & \\
\text { PRODUCTS } & M E D=60 \\
\text { IN 1980: } & \text { THOUSAND }
\end{array}
$$

7:

I:

$(\overline{39}-\overline{40})$

II:

$(\overline{41-42)}$

III:

$\overline{(43-\overline{44})}$

8:

$\overline{(45-49)}-$

9: (50)

9. Are the solar-thermal products or services expected to make a profit this year? ASK

A. By which year are they expected to make a profit? RECORD YEAR YEAR IN

WHICH

SOLAR - THERMAL

PRODUCTS

$$
\bar{x}=1983
$$

EXPECTED TO

MAKE PROFIT:

MED $=1981$
9A:

(51-54) 
10. Would you say that the marketing channels for distributing your firm's solar-thermal products are:

Very adequate,.....................

Quite adequate,...................5

10: (55)

Moderately adequate,................

Not very adequate, or.............. 8

Not at all adequate?..............

A. What are the major distribution problems for your solar-tnermal products or services? LIST IN ORDER OF MENTION UP TO 3.

11. Has support from the Department of Energy led to a reduction of

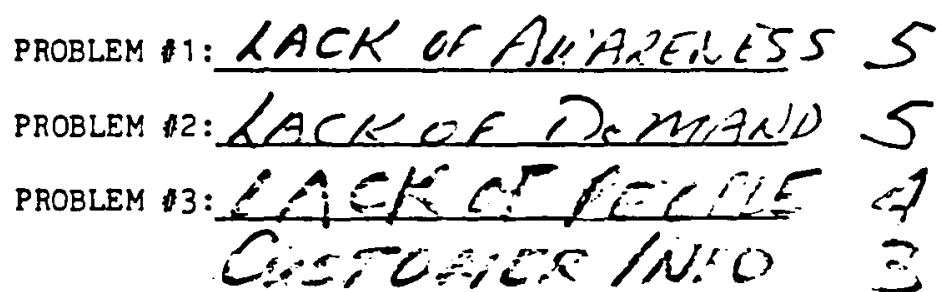
10A: your costs in developing solar-thermal products or services? (the start-up costs of developing the product or service)

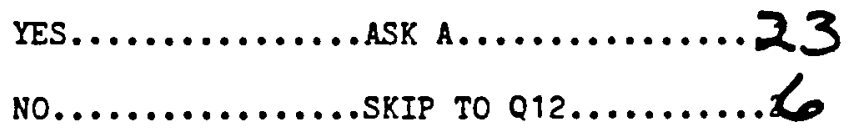

A. Would you nave introduced solar-tnermal products or services on the market witnout Department of Energy support for their development?

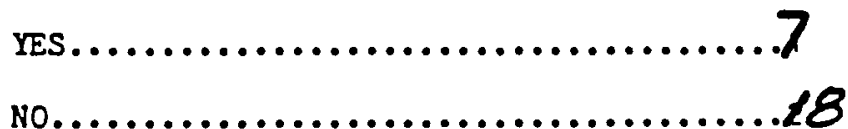

B. Witnout Department of Energy support, now muen in additional funds would it have cost your firm to develop the tecnnology? RECORD AMDUNT.

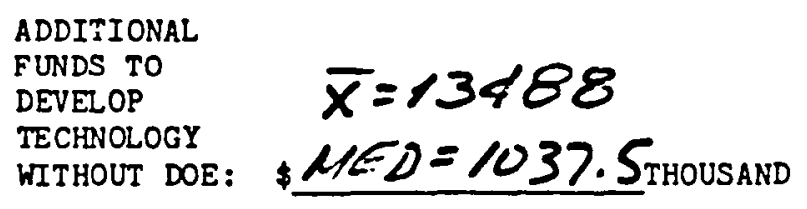

$11 B$ :

I : $\overline{(56-\overline{57})}$

II :

$(\overline{58}-\overline{59})$

III : $(\overline{60}-\overline{61})$ $(62)$ 
Now I'd like to ask you some questions about your researen and development program for solar-themal energy systems.

12. Are you currently under contract with the Department of Energy for the development of solar-tnermal energy tecnnology?

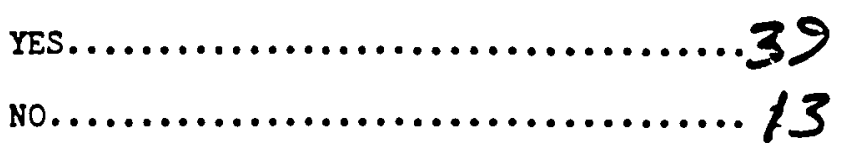

A. Approximately now muen is the total cumulat1ve dollar amount of your Department of Energy contracts for the development of solar-thermal products or services? (the total value for all years you've had contracts). RECORD AMOUNT.

IF UNSURE, ASK: What would be your best guess? An approximate amount is all that we need.

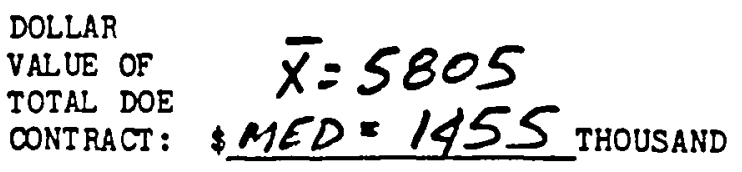

12A:

13. To date, has your firw been able to invest anv of its own private funds for the development of solar-tnermal tecnnology? (including borrowed funds).

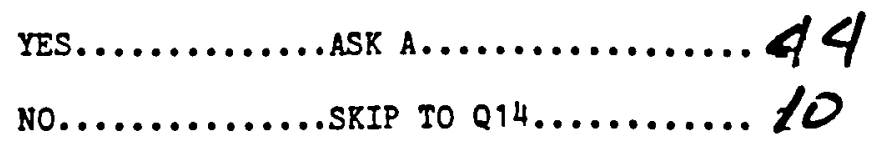

13: (11)

A. Approximately what is the total dollar amount of your own private funding in solar-thermal technologv; for example, investment in equipment and facilities, labor and materials? (with your own firm's funds) RECORD AMOUNT.

IF UNSURE, ASK: What would be your best guess?

DOLLAR VALUE OF FIRM'S OWN FUNDS IN $\bar{x}=1408$ STES R AND D: $\$ M E . D=200$ THOUSAND 
B. Of your research and developrent budget, approximately what percentage goes to solar-tnermal energy development? (that is, of the total amount of your firm's own funds which are invested in $R$ and $D$ ). Would you say:

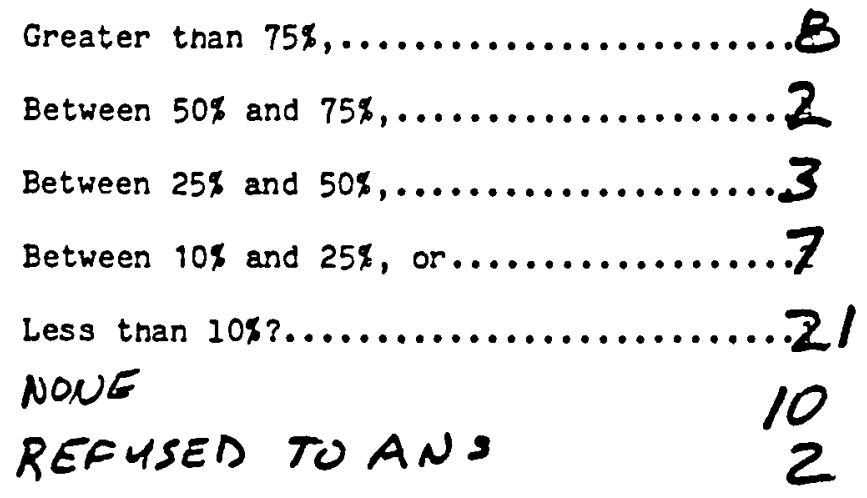

14. Before your first Federal contract for the development of solar-thermal technology, was your firm involved in its development? YES.............................. 
15. Where do the greatest uncertainties lie in making comerclallyviable solar-thermal products? Hould you say tnat (...) is an uncertainty? READ a-c. CIRCLE APPROPRIATE ANSWER IN COLUMN A.

FOR EACH "YES", ASR: How uncertain is (...)? Would you say it was Very uncertain, Quite uncertain, Moderately uncertain or Sligntly uncertain? CIRCLE APPROPRIATE ANSWER IN OOLUMI B.

\begin{tabular}{|c|c|c|c|c|c|c|}
\hline $\begin{array}{l}\text { Would you say } \\
\text { that (...) is } \\
\text { an uncertaintr? }\end{array}$ & YES & NO & $\begin{array}{l}\text { B. } \\
\text { VERY } \\
\text { UNCERTAIN }\end{array}$ & $\begin{array}{l}\text { QUITE } \\
\text { UNCERTAIN }\end{array}$ & $\begin{array}{l}\text { MODERATELY } \\
\text { UNCER.TAIN }\end{array}$ & $\begin{array}{l}\text { SLIGHTLY } \\
\text { URICEPTAIN }\end{array}$ \\
\hline $\begin{array}{l}\text { Solutions to } \\
\text { research and } \\
\text { development } \\
\text { problems }\end{array}$ & 23 & 30 & & 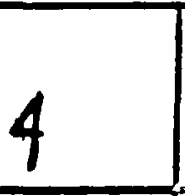 & 13 & 2 \\
\hline $\begin{array}{l}\text { The cost of } \\
\text { competing } \\
\text { energy sources }\end{array}$ & & A3 & & 9 & 9 & 5 \\
\hline $\begin{array}{l}\text { The general } \\
\text { economic } \\
\text { climate }\end{array}$ & 92 & 11 & 16 & 11 & 13 & 2 \\
\hline
\end{tabular}

15a:

$15 \mathrm{~b}:$

(20)

15c: (21)

A. Is there anytning else which is a major uncertainty in making solar-thermal products commercially-viable?

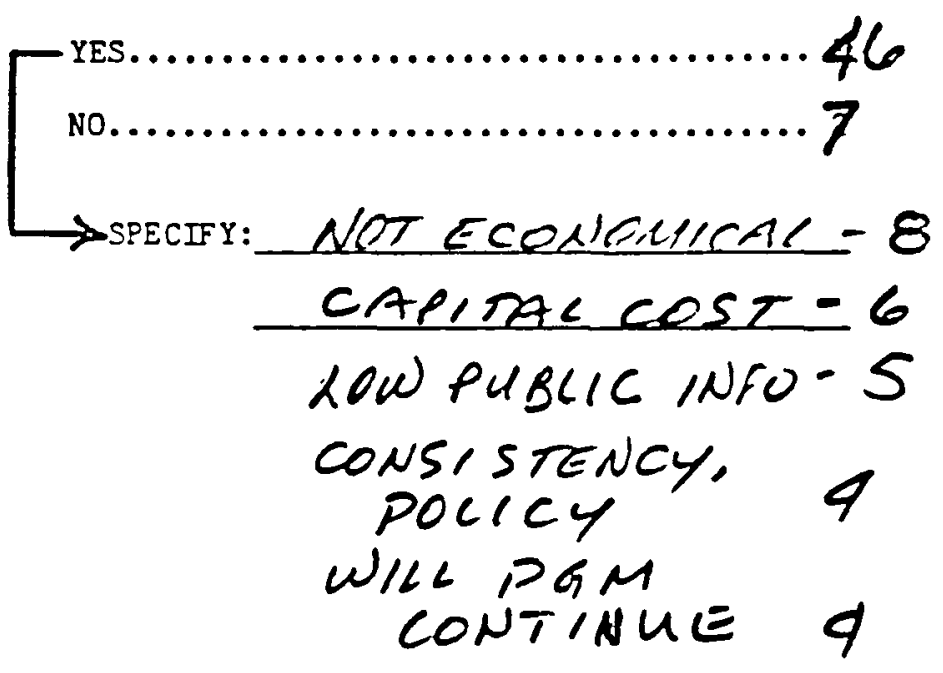

15A:

(22)

I:

$(\overline{23}-\overline{24})$

II :

$(\overline{25}-\overline{26})$

III:

$(\overline{27}-\overline{28})$ 
Now I'd like to ask you about your firms' future plans for the production and warketing of solar-tnermal products or services.

16. Is your firm planning to market solar-tnermal products or services in the ruture?

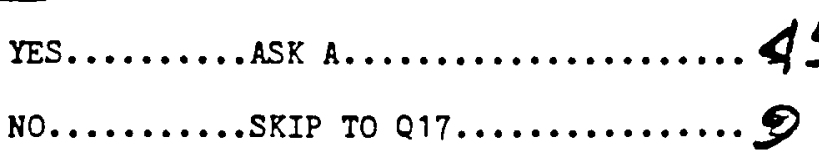

A. In the future, is your firm planning to: READ a-f. CIRCLE ALL THAT APPLY.

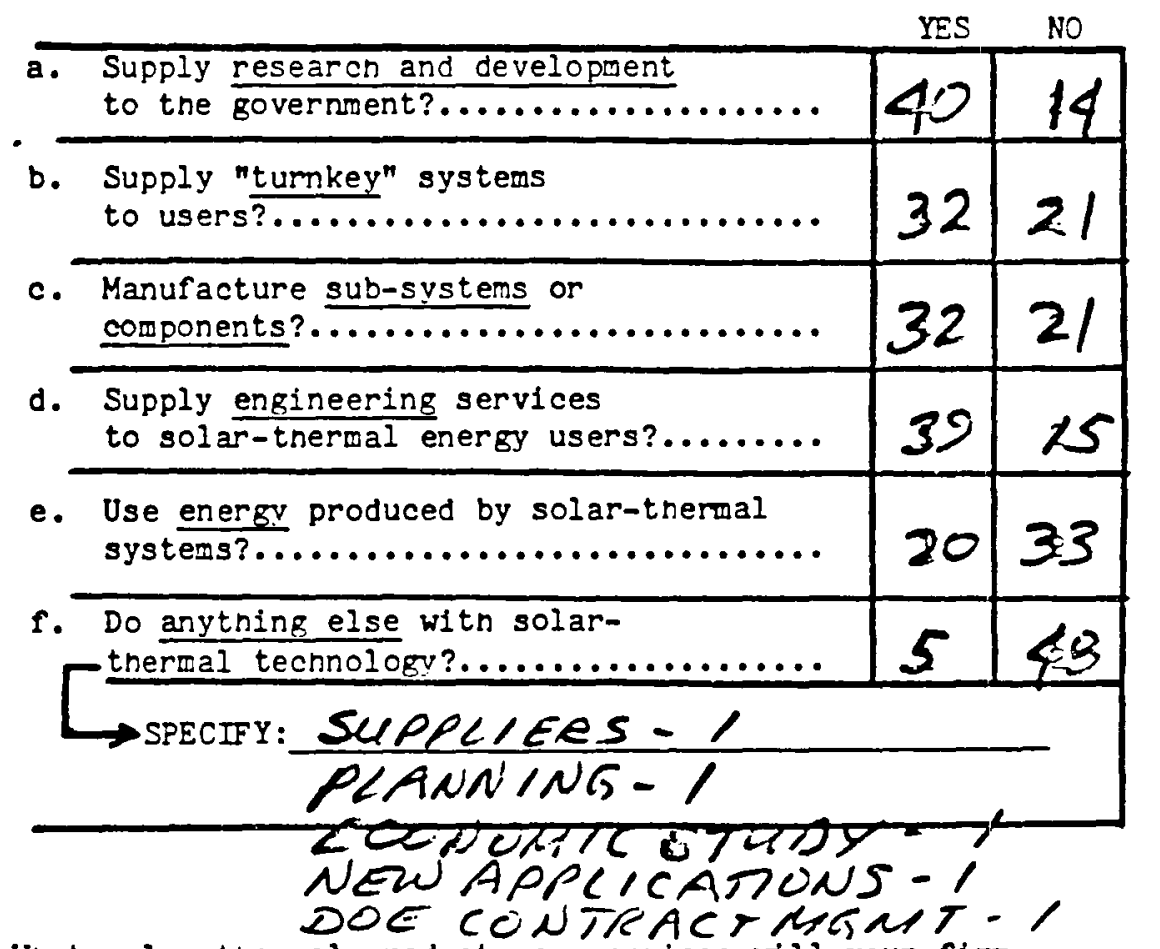

B. What solar-thermal products or services will your firm

eventualiy market? LIST IN ORDER OE MENTION UP TO 3 PRODUCTS.

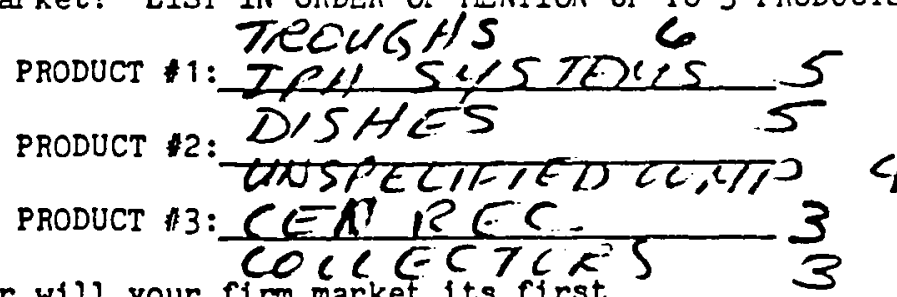

c. In which year will your firm market its first

I I :

solar-thermal product or service witnout government subsidy? RECORD YEAR.

IF UNSURE, ASK: Approximately in which year?

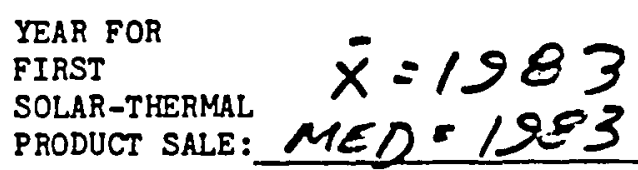


D. Approximately now much capital, in dollars, is needed to bring your solar-thermal products or services to the point where they will be comercially-viable without government subsidy? REORD AMDUNT.

IF UNSURE, ASK: What would be your best guess? An approximate amount is all that is needed?

CAPITAL REQUIRED TO MAKE STES COMPETTIVE:

$$
\bar{x}=133,090
$$

$\$ M E P=2025$ THOUSAND

E. What do you see as the nearest-term market for your $11 \mathrm{rm}$ 's solar-thermal products or services; that is, whicn customer would first be most interested in your tecnnologv and for what purpose? LIST IN ORDER OF MENTION UP TO 3.

$$
\begin{aligned}
& \text { MARKET \#1: } \mid P H L \\
& \text { MARKET 2:LZEC WTIL I9 } \\
& \text { MARKET 3: GOUT RERPRITS } 5 \\
& \text { PENCTE } 5 / T E S \text { O }
\end{aligned}
$$

16D:

I :

II:

III:

$(\overline{59}-\overline{60})$

$16 \mathrm{~F}:$ solar-thermal products or services; that is, the customer and purpose you would most like to make a product for? LIST IN ORDER OF MENTION UP TO 3.

$$
\text { BEST MARKET }: \frac{1 P A}{\text { BEST MARKET } 2: \frac{E L C L T / L}{3 K D} 21}
$$

I:

II:

III :

17. If Department of Energy funding of solar-themal technology development were discontinued in your technology area next year (1982), would your firm increase your own level of funding to make up the slack, maintain your own level of funding at approximately what it has been, or decrease your own level of funding?

INCREASE LEVEL OF FUNDING.............

MAINTAIN SAME LEVEL OF FUNDING..........19 
A. If Department of Energy funding were discontinued in your tecnnology next year, would your firm continue to develop the current solar-thermal technology that you are working on, change to anotner solar-tnermal technology, or discontinue work in solar-tnermal tecnnology altogetner?

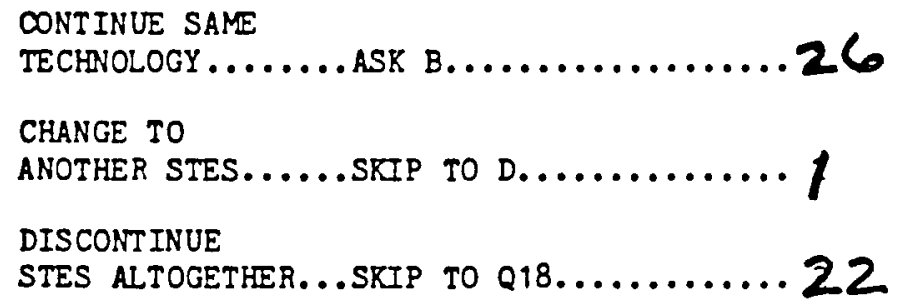

B. How many additional years would it take before your firm could -complete development of the technology without Department of Energy support? (so that it would be comercially-viable) REORD YEARS.

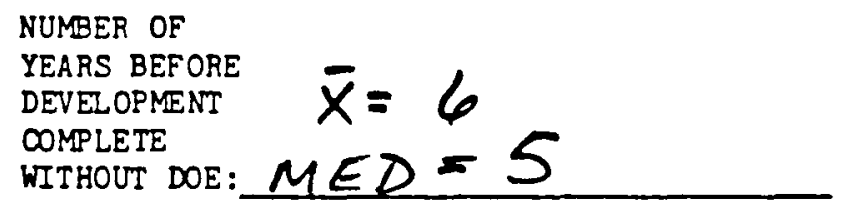

C. Witnout Departwent of Energy support, would you try to be rirst to enter the solar-thermal market, would you wait for competitors to open up the market initially, or would you wait until the market was fully developed before entering?

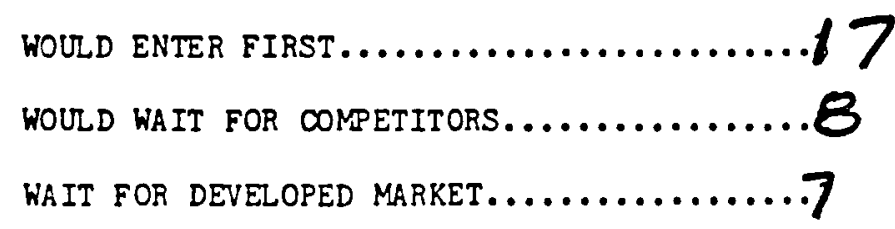

$17 \mathrm{C}:(71)$

D. Would this change be dependent on the existence of Department of Energy funding in tnis new area?

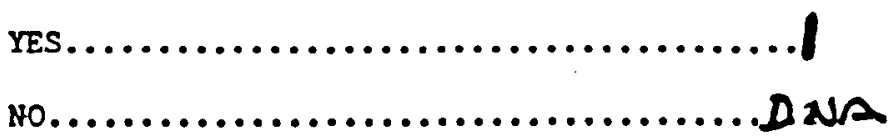


Now I'd like to ask you some final questions about the role of government in general in the development of solar-tnermal tecnnology.

18. From your firm's point of view, how would you evaluate the Department of Energy solar-tnermal program to date? Would you say it nas been:

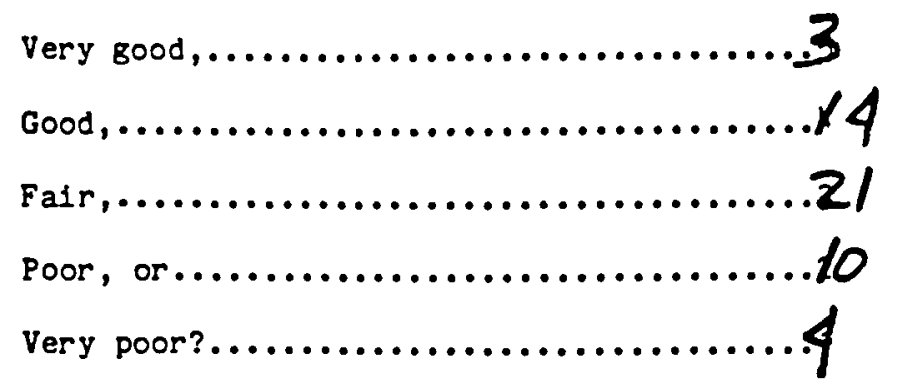

19. What have been the most significant accomplishments of the Federal solar-tnermal program to date? LIST IN ORDER OF MENTION UP TO 3.

$$
\begin{aligned}
& \text { COMPDNENT DEV (AISECTECH) } \\
& \text { ACCOMPLISHMENT } 1 \text { :SPING TEEH TO MARIRITY } 8 \\
& \text { BATESTOW } \\
& \text { ACCOMPLISHENT } 2: \frac{\text { PUbL/C,NFO }}{\text { CEN REC TECHDEV }} \\
& \text { ACCOMPLISHMENT } 3: \text { CRTF }
\end{aligned}
$$

20. What have been the most significant deficiencies of the Federal solar-thermal program to date? LIST IN ORDEF OF MENTION UP JO 3.

$$
\begin{aligned}
& \text { DEFICIENCY \#: } 1 A C M \text { CK CON SISTENTY } 7 \\
& \text { LACK OF LONG TEANA ANG } 7
\end{aligned}
$$
DEFICIENCY \#2: $\angle A C K$ if CCNTINUITY $\angle I$ 
21. In considering the types of Federal research and development that are needed, from your own firm's viewpoint, is there the need for: READ a-e. CIRCLE APPROPRIATE ANSWER IN COLUMN A.

FOR EACH "YES", ASK: How important is Federal support for (...)? Would you say Very Important, Quite Important, Moderately Important, or Not Very Important? CIRCLE APPROPRIATE ANSWER IN COLUMI: B.

\begin{tabular}{|c|c|c|c|c|c|c|}
\hline $\begin{array}{l}\text { Is there the } \\
\text { need for }(\ldots) \text { : }\end{array}$ & $\begin{array}{l}\text { A. } \\
\text { YES }\end{array}$ & NO & $\begin{array}{l}\text { B. } \\
\text { VERY } \\
\text { IMPORTANT }\end{array}$ & $\begin{array}{l}\text { QUITE } \\
\text { IMPORTANT }\end{array}$ & $\begin{array}{l}\text { MODERA TELY } \\
\text { IMPORTANT }\end{array}$ & $\begin{array}{l}\text { NOT VERY } \\
\text { IMPORTALT }\end{array}$ \\
\hline $\begin{array}{l}\text { Basic research } \\
\text { on fundamental } \\
\text { phenomena? }\end{array}$ & & & & & & \\
\hline $\begin{array}{l}\text { Development of } \\
\text { components } \\
\text { and sub- } \\
\text { systems? }\end{array}$ & & & & & & \\
\hline $\begin{array}{l}\text { C. } \\
\text { Developwent of } \\
\text { conceptual } \\
\text { designs? }\end{array}$ & & & & & & \\
\hline $\begin{array}{l}\text { d. } \\
\text { Testing of } \\
\text { prototypes at } \\
\text { the system } \\
\text { level? }\end{array}$ & & & & & & \\
\hline $\begin{array}{l}\text { Full-scale } \\
\text { system tests } \\
\text { and user } \\
\text { applications? }\end{array}$ & & & & & & \\
\hline
\end{tabular}

FOR ANY "YES", OBTAIN SPECIFICS AND RECORD BELOW.

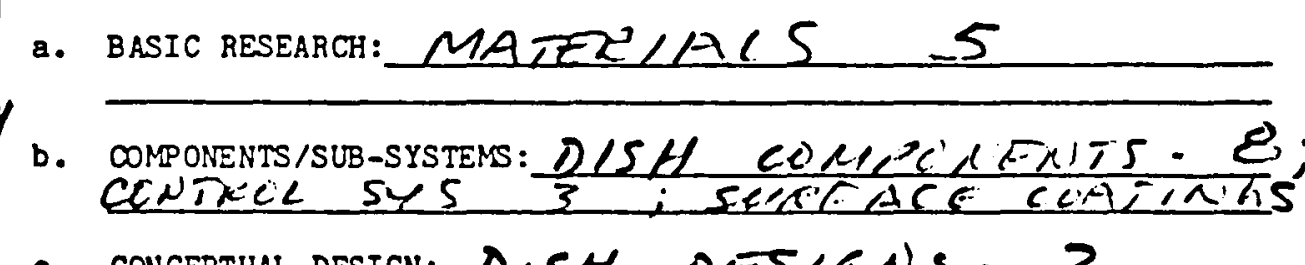

c. CONCEPTUAL DESTGN:DLSA DES/GNS

2la:

21b:

21c:

21d:

2le:

SPECIFICS

I II

$\frac{1}{23} \frac{11}{24}$

b :

3

$\overline{25} \overline{26} \overline{35} \overline{36}$

$\frac{}{27} \overline{26} \overline{37} \overline{38}$

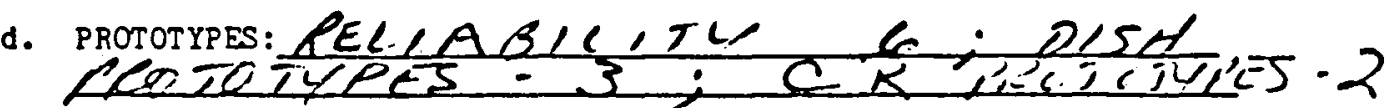

d: $\overline{29}$ 30 $\overline{39} \overline{40}$

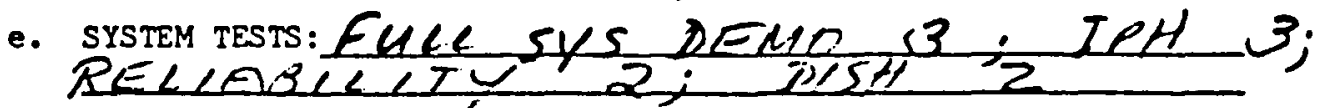
A- 17 
22. Other than research and development, is there the need for any Federal support for the development of solar-thermal technology?

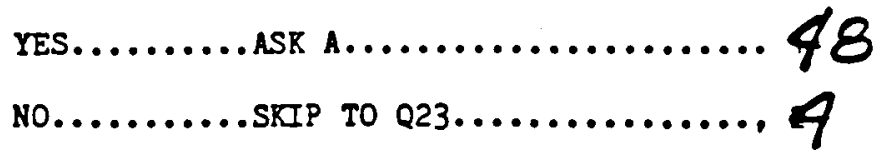

- A. Is there the need for Federal support througn: READ a-e.

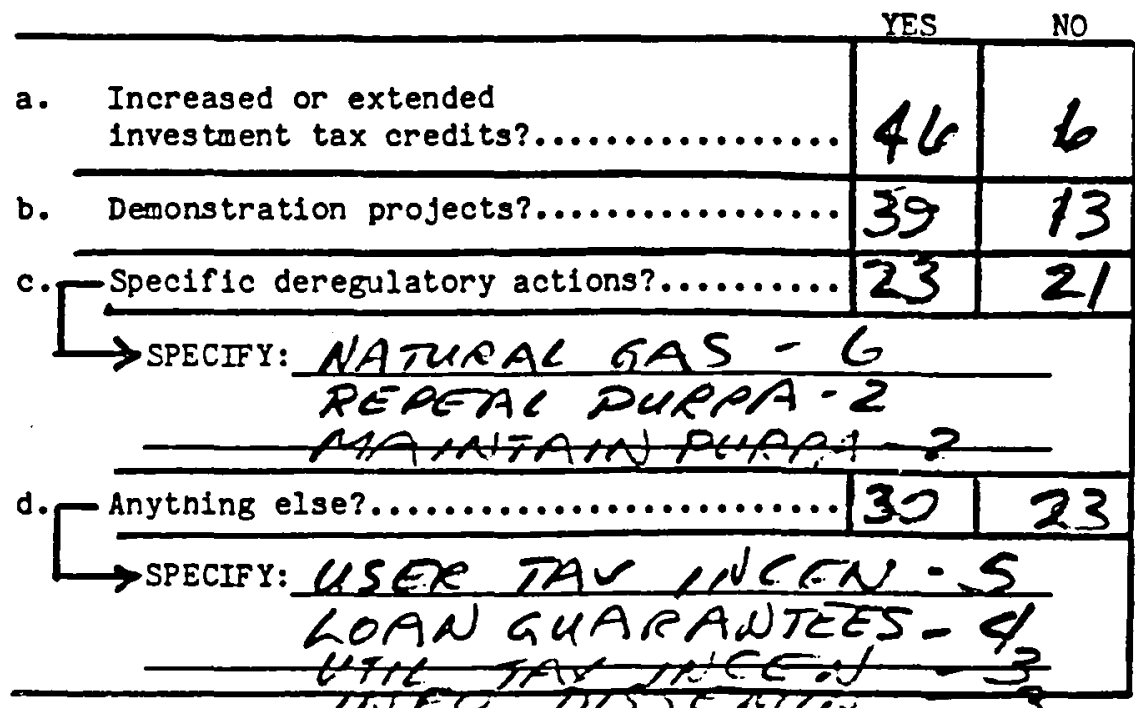

23. How many years longer should Féderal research and development

funding of solar-tnermal continue? RECORD YEARS.

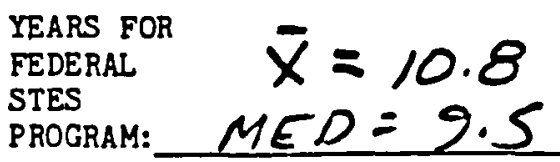

INDETERMINATE/

INDEFINITE

PERIOD.

24. Last year, the Federal budget for solar-thermal energy systems was $\$ 140$ milion. Tnis year, the requested Reagan-budget was $\$ 44$ million. What do you feel is the appropriate yearly level of Federal spending for the development of solar-tnermal technology? RECORD AMOUNT.

APPROPRIATE

LEVEL OF

FEDERAL STES

BUDGET :

$$
\begin{aligned}
& \bar{x}=171.3 \\
& \mu \in D=190
\end{aligned}
$$

MILLION A YEAR
$24:$

$(5 \overline{8-6 \overline{0})}$ 
25. That ends the questions. If I need to ask any more questions, is it alright to telephone you back?

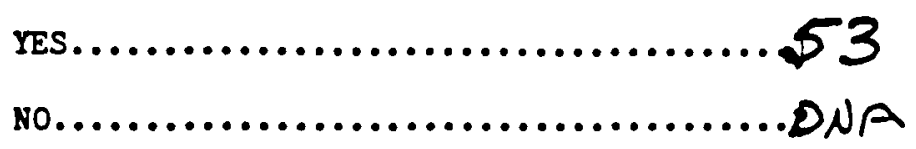

25: (61)

On benalf of the Jet Propulsion Laboratory and the Department of Energy, I would like to thank you for giving us some very valuable information. I would like to repeat our guarantee of complete confidentiality for your information and that only group results will be publisned. 
End of Document 